Portland State University

PDXScholar

$1-1-2011$

\title{
"Outing" Queer Issues in Teacher Preparation Programs: How Pre-Service Teachers Experience Sexual and Gender Diversity in Their Field Placements
}

Olivia Jo Murray

Portland State University

Follow this and additional works at: https://pdxscholar.library.pdx.edu/open_access_etds Let us know how access to this document benefits you.

\section{Recommended Citation}

Murray, Olivia Jo, "'Outing" Queer Issues in Teacher Preparation Programs: How Pre-Service Teachers Experience Sexual and Gender Diversity in Their Field Placements" (2011). Dissertations and Theses. Paper 635.

https://doi.org/10.15760/etd.635

This Dissertation is brought to you for free and open access. It has been accepted for inclusion in Dissertations and Theses by an authorized administrator of PDXScholar. Please contact us if we can make this document more accessible: pdxscholar@pdx.edu. 
“Outing” Queer Issues in Teacher Preparation Programs: How Pre-Service Teachers Experience Sexual and Gender Diversity in Their Field Placements

by

Olivia Jo Murray

A dissertation submitted in partial fulfillment of the requirements for the degree of

Doctor of Education

in

Educational Leadership: Curriculum and Instruction

Dissertation Committee:

Emily de la Cruz, Chair

Martha Balshem

Christine Chaille

Karen Noordhoff

Will Parnell

Portland State University

(C)2011 


\begin{abstract}
Currently in the United States there are more than 4 million lesbian, gay, bisexual, and transgender (LGBT) students in K-12 public schools (Bochenek, Brown, \& Human Rights Watch, 2001). Despite the prevalence of LGBT youth and the diversification of family populations, teacher preparation programs rarely acknowledge "queer" aspects of multiculturalism (Letts, 2002). As a result, a majority of K-12 educators enter the field of teaching unwilling and/or unprepared to engage with queer issues as they relate to students and families, curriculum, and instruction. The culture of silence around homosexuality can put queer youth at risk and deter school stakeholders from addressing queer issues, the discussion of which can lead to deepened understanding, increased empathy, and social action.

Employing critical social theory as a theoretical framework, this paper examines the promise of increased awareness about and use of queer-inclusive pedagogy and curriculum in pre-service teacher education. It is argued that such inclusion is necessary to counteract heterosexism in schools that reinforce gender norms and impart heteronormative values. Guided by interpretivist inquiry, the current multiple-case study describes how eight pre-service teachers encountered, made sense of, and responded to sexual and gender diversity in their K-8 field placements. Findings are presented in individual case descriptions followed by a cross-case synthesis and suggest that preservice teachers came into direct and constant contact with queer issues. Participants' overwhelming desire to process and make sense of their encounters as a means of supporting students as well as negotiating their own personal sense of identity also
\end{abstract}


emerged from the data. The implications of these findings for pre-service teacher education are discussed as is a proposed framework for queer inclusion and next steps for future research. 


\section{Acknowledgements}

Over the past thirty years, equal rights and anti-discrimination legislation extended the umbrella of protection to many disenfranchised groups, but Sears (2005) observes that the new legislation and policy, "can be judged as weak to moderate in their coverage and impact [upon the health and safety of queer youth]" (p. xxvii). This is, in part, because such policies are debated within a complex social and cultural history in this country. Philosophically, the U.S. Declaration of Independence and Constitution emphasize the supremacy of individuality and equality. But when the philosophy is shaped into educational policy, the heterosexual biases of religious fundamentalists and family values conservatives leave no room for queer students or their issues. Thus the heterosexist policies which countenance homophobia send painful and tragic messages to our youth which can have fatal consequences.

Take for instance, Carl Walker-Hoover, an 11 year-old boy from Springfield, Illinois. Carl went home after school on April 6, 2009. The sixth grader grabbed an extension cord, walked up the stairs to his bedroom, and weaved the cord through his closet rafters before slipping the plastic noose around his neck. Carl committed suicide because students at his school called him "faggot" and verbally threatened him. Classmates shouted homophobic remarks in the hallways and taunted him daily about being gay (GLSEN, 2009). The New Leadership Charter School that Carl attended offered grief counseling to students and staff and collected donations for Carl's family in response to the community's loss of a child. What the school failed to do, however, was to address the problem before it was too late. According to Carl's mother, Sirdeaner 
Walker, she had phoned the school every week since September, 2008 to complain about children bullying her son. More than twenty phone calls from a concerned parent failed to persuade school officials to intercede on Carl's behalf because they perceived him to be gay and equated this identity as inferior.

Stories similar to Carl's are far too common in contemporary society. The Federal Bureau of Investigations (FBI) reports that hate crimes - violent, intentional attacks on people because of their actual or perceived race, ethnicity, religion, or national origin occur nearly 10,000 times per year (FBI, 2007). The National Coalition of Anti-Violence Programs (NCAVP) (2005) reports that between 1990 and 1999, hate crimes in the United States increased each year, with crimes perpetrated against queer individuals increasing $328 \%$. A more recent study conducted by the NCAVP (2009) reveals that from 2007-2008 the number of 15-18 year-olds identifying as victims of hate crime violence rose by $118 \%$. Perhaps these trends are responsible for returning federal hate crime legislation (18 U.S.C. $§ 245$ ) back to the Senate floor for revision in July 2007, 9 years after the brutal torture and murder of 21 year-old Matthew Shepard near Laramie, Wyoming. This marked the first time a gay rights bill had been brought to the floor of the House. Ultimately, the amendment was dropped by the Democratic leadership because of opposition, including a threatened veto from then-President George W. Bush.

Resurfacing in April 2009, the Act, designated H.R. 1913, passed the House Judiciary Committee and the Senate. President Barack Obama signed it into law on October 22, 2009, which extends the 1969 federal hate-crime law to include crimes motivated by a victim's actual or perceived gender, sexual orientation, and/or gender identity. Many 
social conservatives remain opposed to the law, arguing that it will effectively prevent people of faith from expressing their moral and biblical concerns about homosexuality. As this political saga dragged on many more youth were targeted. On May 16, 2007, Sean Kennedy was pulled from his car by an 18 year-old who called him "faggot" as he administered a blow to the face. Sean immediately collapsed to the asphalt, which cracked his head open and caused his death. His murderer only served twelve months in prison. Equally tragic is the killing of 15 year-old Lawrence King on February 12, 2008. Lawrence, who like Sean was openly gay, was shot in the back of the head by fellow student, 14 year-old Brandon McInerney. The district attorney's filings state that Brandon sat behind Lawrence in class on that tragic day for 20 minutes before he fired one shot into the back of Lawrence's head. After Lawrence collapsed, Brandon stood up and fired a second shot before storming out of the classroom. Brandon had publicly stated that he was going to shoot Lawrence the day before the murder. He told one of Lawrence's friends, "Say goodbye to your friend Larry because you're never going to see him again" (Saillant, 2009, p.3). After eight weeks of testimony and more than fifteen hours of deliberation, it was announced days ago that the jury was unable to reach a verdict. Meanwhile those who could have prevented the destruction of these two boys lives (administrators and teachers who were directly involved), have since been transferred and replaced (Sammon, 2011).

A week after the mistrial, perhaps where these teachers relocated, 14 year-old Jamey Rodemeyer committed suicide. Jamey had uploaded an It Gets Better video a few 
months prior to taking his own life. In the video he talked about being bullied for publicly questioning his sexuality.

While the brutal murders and tragic suicides of Matthew Sheppard, Carl WalkerHover, Lawrence King, Jamey Rodemeyer, and other queer youth sometimes receive minimal media attention, there are several untold stories that are equally tragic and far more recurrent. The present study acknowledges the lives that have been lost and is dedicated to all the resilient queer youth that currently exist. Dan Savage (2010) created the It Gets Better Project to show young queer people the levels of happiness, potential, and positivity their lives will reach - if they can just get through their adolescent years. This paper is intended to offer an alternative reality, one where children are not asked to wish away their early experiences in life; a reality that requires teachers to make it better. 
Table of Contents

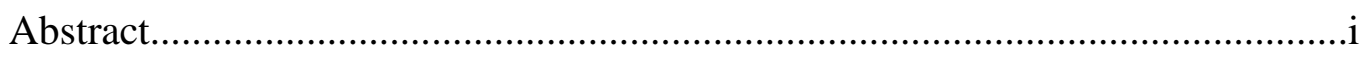

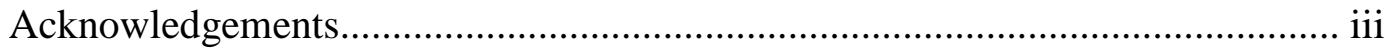

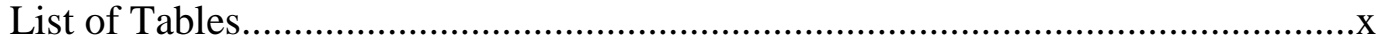

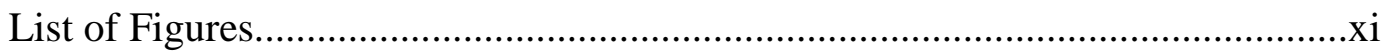

Chapter One: Introduction..............................................1

Key Terms and Concepts

Theoretical Framework

Purpose of the Study and Research Question

Significance of the Study

Chapter Two: Review of Literature........................................ 15

K-12 School Climate

Risk Factors for Queer Youth

Teacher Influence

Curricula and Pedagogy

Queering Elementary Education

Middle and High School Curriculum and Practice

Pre-Service Teacher Preparation

Multicultural Education

Queer Exclusion

Envisioning Queer-Inclusive Teacher Education

Teacher Reflection

Teacher Dispositions

Assessing Dispositions toward Queerness

Discussion

Chapter Three: Research Design and Methodology.

Paradigm

Research Question

Context of the Study

Participants

Methodological Approach

Data Collection

Individual Interviews

Group Conversations

Direct Observation

Research Log

Participant Journals

Electronic Prompt/Response Submissions

Artifacts

Data Analysis 
Chapter Four: Findings...................................................65

Section One: Case Descriptions

Jack

Mrs. H

Quercus

Moses

Christine

Beatrice

Townes

Ramona

Section Two: Cross-Case Synthesis

Encounters with Gender and Sexual Diversity

Gender Dichotomy

Classroom Students Perceived To Be Queer

Participant Identity Construction

Sense-Making of Encounters with Gender and Sexual Diversity

Identity and Visibility

Language in Discourse and Media

Fear

The Impact of the Study on Participant Experience

Participant Sense-Making Related To Components ff Teacher Preparation

Responses to Encounters with Gender and Sexual Diversity

Chapter Five: Discussion.

Summary of Findings

Subsequent Conclusions

Assertions

Proposed Framework

Implications for Stakeholders

Reflections on My Positionality

Limitations of the Study

Restricted Sample

Self-Report Measures

Suggestions for Future Research

Conclusion

References.

Appendices.

A. Gender and Sexual Orientation Classifications

B. Multicultural Education Course Topics and Objectives

C. Letter of Informed Consent. 
D. Data Collection Timeline and Procedures

E. Organization of data

F. Protocol for Individual Interviews

G. Protocol for Group Conversations

H. Observation Protocol

I. Journal Guidelines

J. Artifact Summary Form

K. Data Analysis Procedures

L. Willow Enrollment Newspaper Article Artifact Summary Form

M. Spectrum of Visibility 
List of Tables

Table 1: Participant Observations of Gender Dichotomy as Perceived in the Field....102 


\section{List of Figures}

Figure 1: Quercus' Understanding of Teachers' Responsibility................................78

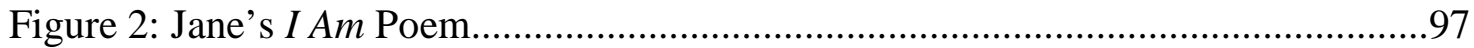

Figure 3: Cross-Case Synthesis Themes and Sub-Themes.....................................99

Figure 4: Transcript from Second (and Final) Group Conversation...........................125

Figure 5: Framework for Queer Inclusion in Pre-Service Teacher Education..............140 


\section{Chapter One: Introduction}

There are more than 4 million lesbian, gay, bisexual, and transgender (LGBT) school-age youth living in the United States (Bochenek, Brown, \& Human Rights Watch, 2001). Furthermore, LGBT youth are becoming aware of, identifying, and disclosing their sexual and gender identities at younger ages (Grossman, Haney, Edwards, Alessi, Ardon, \& Howell, 2009; Savin-Williams \& Berndt, 1990). When you include LGBT parents and siblings, as many as nine out of 30 students - nearly one-third of a classroom - are significantly affected by sexual orientation (Fontaine, 1998). Despite this shift in youth culture and the diversification of student and family populations, teacher preparation programs rarely acknowledge "queer" aspects of multiculturalism (Letts, 2002). As a result, a majority of K-12 educators enter the field of teaching unwilling and/or unprepared to discuss queer issues as they relate to students and families, curriculum, and instruction.

In fact, several studies reveal that teachers have little knowledge about homosexuality, accepting the myths and avoiding the topic as much as possible (Sears, $1989,1992)$. This culture of silence around queer issues is important for everyone to acknowledge and grapple with, regardless of conflicting social and ideological perspectives. As a matter of social justice, which is based on the concepts of human rights and equality, it is important to consider how homophobia benefits some people in society while causing others to suffer. Beyond striving for justice on a social scale, the significance lies in the fact that queer people exist. Queer figures and events help shape history and compose current reality. Education does not occur in a vacuum and 
prospective teachers should be prepared to encounter and deal with the complex ways gender and sexuality influence the social and academic schooling experience. Another reason people should care about this topic is because compared to their straight and gender conforming peers, queer youth experience increased physical, emotional, and psychological risks as a result of real or perceived orientation (Bochenek et al., 2001; Unks, 1995). Finally, all educational stakeholders, regardless of sexual orientation, can benefit from learning about and discussing issues around sexual and gender diversity because doing so can lead to deepened understanding, increased empathy, and social action that reaches beyond one minority group and touches us all.

Although there are many avenues within education for increasing awareness of queer issues (e.g., professional development for educators, policy, curricula and instruction, materials and resources), this paper focuses on pre-service teacher education. I believe that if prospective teachers are given the opportunity to develop the knowledge, skills, and dispositions to better support queer youth and to challenge all students to think more critically, then K-12 schools can be transformed into more open, accepting institutions. In an essay on queer developments in teacher education, Bedford (2002) writes:

Since prejudice against lesbians, bisexuals, and gays, along with the belief in the superiority of heterosexuality, are learned attitudes and cultural constructions, teacher education lies at the heart of combating homophobia and 
heterosexism and faces the challenge of breaking the culture of silence. (p. 134)

Like Bedford (2002), I think increased awareness about queer issues is imperative in teacher education. I also maintain that conversations on supporting queer youth and expanding student knowledge about queerness is particularly important at the pre-service level because it is at this stage that many aspiring educators formally begin to develop their role as a teacher, a role that is often characterized as a construction of a person's professional identity (Hammerness, Darling-Hammond, Bransford, Berliner, CochranSmith, McDonald, \& Zeichner, 2005; Danielewicz, 2001). Part of developing this role, this identity, is to consider who students are and how to best support their learning. Given previously cited statistics that suggest $30 \%$ of the student population is significantly affected by sexual orientation, it is logical to conclude that pre-service teacher education should penetrate the heteronormative culture of silence that exists in order to better prepare prospective teachers for meeting the needs of all learners.

This paper describes and justifies a research study to increase understanding of how pre-service teachers encounter, make sense of, and respond to sexual and gender diversity, indeed queer issues, during their field experience. I believe that interpreting how prospective teachers experience the phenomenon of sexual diversity and nonconforming gender identification and expression in the field is an important step toward improving teacher preparation programs to better meet the needs of queer youth and to dismantle heteronormativity within education. 
The paper is presented in five chapters. This introduction explains the key terms queer, cisgender, transgender, gender non-conforming, queerness, heterosexism, heteronormativity, homophobia, youth, teacher education, and field experience. It describes the complex process of sexual identity development among lesbian, gay and bisexual youth in order to support the reader's understanding of the "coming out" process. Critical social theory is introduced as a theoretical framework and is later elaborated upon in Chapter Three. The first chapter concludes by discussing the purpose and significance of the current research study. Chapter Two offers a critical review of existing literature drawing from three fields of study: K-12 school climate, pre-service teacher preparation, and teacher dispositions. These bodies of knowledge contribute to the conceptual model that guided my research. Research methodology is described in Chapter Three. Utilizing interpretivism as a research paradigm, elements of the study and details of its design are described. Chapter Four presents findings of the seven-month study in two sections: An analysis of individual cases and a synthesis of data across multiple cases. Finally, in concordance with previous research, Chapter Five presents my interpretation and explanation of findings. An answer to the research question is summarized and the study is critically evaluated. The chapter concludes with reflections on positionality and suggestions for future research.

\section{Key Terms and Concepts}

To be queer is to have a sexual orientation, gender identity, and/or gender expression which is different from that acceptable in mainstream society. Throughout this paper, queer will refer to lesbian, gay, and bisexual (LGB) orientations. By orientation I 
mean a same-sex/gender pattern of emotional, romantic, and/or sexual attraction. Queer also refers to a myriad of gender identities and ways of expressing one's gender. Someone whose assigned sex and gender identity match are considered cisgender whereas people who are transgender identify in a way that falls outside the cultural norms for people of their assigned sex (Transactive, 2010). The term queer will be inclusive of individuals who are transgender, as well as significantly gender nonconforming, which refers to a person who is or is perceived to have gender characteristics and/or behaviors that do not conform to traditional or societal expectations.

I use the term queer because it is inclusive of various sexual and gender identities and holds cultural and political significance (Pinar, 1998). Once used by straight society against homosexuals, the word was reappropriated by the LGBT community in the 1990s to revitalize the spirit of gay activism (Haggerty, 2000). When possible, I intentionally avoid the terms homosexual and sexual minority because they are clinical terms that reference behaviors (often reducing queer individuals to purely sexual beings) rather than multi-dimensional aspects of one's identity. There are, however, some places I use the word homosexual(ity) to refer to scholarly literature that espouses this term. In these cases, homosexuality describes the sexual orientation, behavior, and/or identity of persons inclined to be physically and emotionally attracted, committed to, or interested in persons of the same gender (Campos, 2005). Throughout this paper I use queerness as a synonym for both homosexuality (i.e. non-dominant sexual orientation) and trans (i.e. non-dominant) identities. 
The term heterosexism refers to a form of oppression that assumes everyone is or should be heterosexual (Friend, 1993). It refers to acts, beliefs, or values that are maintained by power arrangements that ignore the experiences of queer individuals. Heteronormativity describes the concept of an entire culture or community that institutionalizes heterosexuality as the only accepted and reproduced lifestyle. Thus, individual acts of heterosexism reinforce heteronormative values within a culture or community and, likewise, heteronormative values enable heterosexist practices. For example, teacher educators often exclude queer topics because the issues are beyond their consciousness, they are unsure of whether and how to approach such subject matter, and/or because of personal homophobic beliefs (Lipkin, 2002; Sears, 1992). Intentional or not, omission of queer issues in education is a heterosexist behavior that reinforces heteronormative values and practices within a teacher preparation program. Homophobia is the fear and hatred of queerness in one's self or others (Weinberg, 1972) and often emerges as a result of heterosexism and heteronormativity. Homophobia is often considered institutionalized because of social and cultural arrangements in society. Laws, cultural rules, social expectations, and religious beliefs reward people who are (or appear to be) heterosexual. They also often punish (or withdraw privileges from) those who appear to be queer (Campos, 2005).

For the purposes of this paper, the term youth will correspond to school students in grades kindergarten through twelfth (K-12). I eschew child or adolescent because sexual identity development can occur before and extend beyond the period of adolescence (Fish \& Harvey, 2005). 
Teacher education will refer to the formal higher education that pre-service teachers, or teacher candidates, receive within a graduate university program. Teacher education generally consists of two central components: University coursework and field experience. Sometimes referred to as student teaching, field experience offers teacher candidates opportunities to observe and work in actual K-12 classrooms. In the context of this paper, field experience, which I sometimes choose to call field placement, begins in late August with the pairing of a cooperating teacher (i.e. practicing K-12 classroom mentor teacher) with one or two pre-service teacher(s). This placement is maintained throughout the academic year with a gradual release of classroom responsibility to the teacher candidate.

In order to explore the experience of queer youth and discuss heterosexism and homophobia in schools, it is important to first frame the notion of sexual identity. SavinWilliams and Berndt (1990) describe sexual identity as a constant, enduring sense of one's own sexuality and of recurring sexual feelings, thoughts, and/or behaviors. In other words, sexual identity is made up of a person's sexual characteristics (based on biology) as well as sexual orientation (which is socially and culturally constructed). At various ages, youth begin to conceptualize themselves (and be conceptualized by others) as sexual beings with particular desires and orientations (Mission, 2005). This stage in life can be difficult for all youth, but poses specific challenges for queer youth who must make constant decisions regarding whether, how, and to whom to "come out." This figure of speech refers to queer people disclosing their sexual orientation and gender identity. 


\section{Theoretical Framework}

A personal interest that informs my research is the investigation into the extent to which education is inclusive of queer issues. This means discussing the degree to which educational institutions develop, implement, and respond to curricula, instruction, discourse, and policies to reflect an intentional recognition and inclusion of queer identity and culture. Within the available literature addressing queer topics in education, three major categories surface to describe educational approaches to queer issues. They include: safety (e.g., verbal and physical harassment against queer students), equity (e.g., gay-straight alliance clubs), and critical social theory.

While all are mentioned in this paper, I rely heavily on the last approach as a theoretical framework. Critical social theory offers a way to analyze "the social" as a construction molded and influenced by context, beliefs, and the power maintained within dominant groups (Grace, 2005). As it relates to education, critical social theory provides a lens for discussing democratic forms of schooling, social justice, and ethical educational practices. Allman (1999) argues that critical social theory helps us examine how education can play a pivotal role in transforming a society through political and cultural action. By building students' knowledge and understanding of why and how queer individuals have been marginalized, schools can begin to question, and perhaps transform their practices to reflect a more critical pedagogy.

\section{Purpose of the Study and Research Question}

Employing critical social theory as a framework for this proposed research study facilitates an understanding of a classroom-based discourse capable of cultivating pre- 
service teachers' ability to critique institutional and conceptual dilemmas, particularly those that lead to domination or oppression (Allman, 1999). Extending beyond discourse, this theory also promotes a language of transcendence and social action which can lead to transforming the ways in which society categorizes (and teaches) sex, gender, gender expression, and sexual orientation. With this in mind, the purpose of this proposed study is to explore, through observation and discourse, how pre-service teachers experience, think about, and respond to sexual and gender diversity within their field placements.

Maxwell (2005) identifies three separate goals for doing research: Intellectual goals, practical goals, and personal goals. An intellectual goal that drives this study is to understand the context and meaning of events, situations, and experiences of participants with regard to sexuality and gender in education. Maxwell writes, "In a qualitative study you are interested not only in the physical events and behavior that are taking place, but also in how the participants in your study make sense of these, and how their understanding influences their behavior" (p. 22). The goal of focusing on the context and process by which events and actions take place and how participants make meaning of such phenomena informed the overall design of the current study.

According to Maxwell (2005), a practical goal can include "generating results and theories that are understandable and experientially credible, both to the people you are studying and to others" (p. 24). Achieving the intellectual goal noted above can inform the practical goal of identifying ways to better prepare pre-service teachers to work with queer students and families. Understanding the different ways pre-service teachers encounter and makes sense of sexual and gender diversity, and common responses to 
such phenomena, can influence curriculum and instruction within teacher preparation. Promoting a level of awareness and discussion of queer issues in teacher preparation programs is a practical goal that influences the research design.

The current study was also driven by my personal motivation to interrupt heteronormativity in K-12 education. Rooted in my own identity as a lesbian student and educator, I am interested in transforming schools to mirror socially just and equitable institutions when it comes to all forms of diversity. My sexual orientation offers a distinct frame of reference that informs my role as researcher. I recognize that my queer identity helps shape the way I reflect on my own K-12 education as well as how I experience post secondary schooling. I admit that I hold unique perspectives as a queer woman living on the margins in a heterosexist society. I acknowledge that my past and present exposure to homophobia places both a critical and personal lens on my approach to research. What brings me hope, however, and also influences how I come to this work, is the overwhelming support and understanding that often comes about when people are exposed to, and learn more about, diverse ways of being.

To achieve the practical, intellectual, and personal goals outlined above, I need to first understand the context and meaning of pre-service teachers' experiences with queer issues as they perceive them within their field placements. Thus, under an interpretivistic research paradigm I strived to answer the following research question: How do preservice teachers encounter, make sense of, and respond to sexual and gender diversity within their field experience? In order to fully understand this multifaceted question it is 
important to make clear what I mean by the terms encounter, make sense of, respond to, and sexual and gender diversity.

I conceptualize encounter as a meeting of sorts for which a pre-service teacher might describe how he or she came to know or recognize an event, situation, and/or experience involving gender or sexual diversity. In addition to interpreting how preservice teachers encounter phenomena, I sought to understand their processing of such meetings. In other words I wanted to consider how they make sense of what they encountered, or as Weick, Sutcliffe, and Obstfeld (2005) describe, the process of sensemaking. According to the authors, sensemaking involves "the ongoing retrospective development of plausible images that rationalize what people are doing” (p. 409). Upon encounters, I probed pre-service teachers to articulate events or situations for which sexual and gender diversity could be talked into existence and more clearly understood. Finally, I collected data on how pre-service teachers respond to queer issues that surfaced within their field experiences. By respond to I mean the commonly referenced definition, which is to say or do something in return. For the purpose of data analysis I qualified a lack of response as the response itself.

The current research question is concerned with how pre-service teachers experience sexual and gender diversity within their field placements. For the purpose of this study I use commonly referenced descriptions of sexual and gender classifications (Bridge 13 program, 2006; Sears, 2005) that recognize their complex yet fluid nature (see Appendix A for a complete list of definitions). Sexual diversity encompasses a range of emotional, erotic, and/or physical attractions toward others. Labels to describe these 
orientations include heterosexual (i.e. emotional, erotic, and/or physical attractions toward people of the "opposite" gender) and homosexual (i.e. attractions toward people of the "same" gender). Sexual diversity also includes people who identify as bisexual (i.e. a person who is attracted, but not necessarily equally attracted, to other males and females), asexual (i.e. a person who is not interested in or does not desire sexual activity), and pansexual (i.e. a person who is attracted to some individuals of any gender identity).

Contrary to popular belief, millions of Americans (including children) currently reside outside the gender binary. By opening up the dichotomy of male/female one is able to see the rich gender diversity in the world. Embedded within gender diversity is one's gender identity, gender expression, and perceived gender expression. The former refers to how one experiences and conceptualizes one's own gender (i.e. how they feel inside as man, woman, somewhere in between, and/or, neither, regardless of biological sex). Gender expression is the way a person manipulates their appearance and/or behavior to express their gender whether it's feminine, masculine, or androgynous. In addition to how one self-identifies and expresses their gender, they also carry with them a perceived gender expression. This includes the way others (society) perceive one's gender identity based on one's gender expression (appearance/mannerisms).

The decision to examine both sexuality and gender is based on a theoretical understanding of the two and the relationship they share. In her seminal text, Gender Trouble, Butler (1990) argues that gender and the accepted institution of heterosexuality are socially constructed to serve particular individuals and organizations. 
Heterosexuality, in other words, both requires and produces limited gender possibilities within an oppositional, binary gender system. She writes:

The institution of a compulsory and naturalized

heterosexuality requires and regulates gender as a binary

relation in which the masculine term is differentiated from

a feminine term, and the differentiation is accomplished

through the practices of heterosexual desire. The act of

differentiating the two oppositional moments of the binary

results in a consolidation of each term, the respective

internal coherence of sex, gender, and desire. (p. 31)

The relationship between gender and sexuality will be further illustrated throughout this paper.

\section{Significance of the Study}

Although there has been a steady increase of research on queer issues in K-12 schools, studies of gender and sexuality in teacher education are limited. Based on my review of the literature, there is a substantial gap in research on the impact of acknowledging and implementing queer-inclusive curricula in teacher preparation programs. Studies have examined how teacher education programs prepare students to counteract some sociological issues like racism and poverty, but queer concerns have been noticeably omitted. Of the literature reviewed for this paper, even less focuses on how pre-service teachers confront and deal with issues pertaining to non-heteronormative phenomena in K-12 education. 
Increased awareness of how pre-service teachers encounter and make sense of queer issues in their field placements, as well as the implementation of queer-inclusive pedagogy and curricula in teacher education, will benefit multiple groups. Understanding pre-service teacher's experiences and efforts to implement a queer-inclusive pedagogy can pair with teacher education to deepen perspective teachers' understanding of the historical roots of contemporary heterosexism and develop educators who model honesty, authenticity, integrity, fairness, and respect. Pre-service teachers that mirror these qualities and demonstrate competency as teachers of diverse learners also satisfy accreditation requirements and reflect favorably on the teacher education program. In addition, a rise in consciousness among future educators can, in turn, help K-12 students develop better critical thinking skills. Also, recognizing queer identity and culture in higher education is likely to validate and legitimize queer college students, instructors, department faculty, alumni, and community members. Ultimately, dissecting the student teacher experience and exploring queer pedagogy and inclusive curricula is likely to benefit society as a whole as people engage in historically closeted discussions. Within all levels of schooling, such awareness and dialogue has potential to improve student support, promote social justice, and enhance the education of all learners as we move toward a more just and equitable society. 


\section{Chapter Two: Review of Literature}

To understand how pre-service teachers experience queer issues in K-12 education I conducted a review of the published theoretical, historical, and empirical literature. I was particularly interested in exploring the potential of pre-service teacher education as a tool to increase knowledge and skill among teachers working with queer students and families. This search identified three fields of study: K-12 school climate, pre-service teacher preparation, and teacher dispositions. I explore each area separately to gain a deeper understanding of how it relates to queer issues in education. In the final section I offer a synthesis of the literature arguing for reform of teacher education to intentionally provide opportunities for pre-service teachers to consider personal dispositions toward, and obtain accurate knowledge and skills about, queer identity and culture. I simultaneously justify the need for in-depth research to characterize the experiences of pre-service teachers as they came in contact with, make sense of, and react to, sexual and gender diversity during student teaching. Interpreting these data, I believe, will inform pre-service teacher education practice in ways that increase support for a growing number of at-risk queer youth, aid in dismantling heteronormativity in K-12 schools, and provide all stakeholders with a means of advancing social justice.

\section{K-12 School Climate}

School is not only a site for students to acquire academic knowledge and ability, but also to develop personal and social skills that persist throughout life (Hansley \& Pratt, 2005; Merrell \& Gimple, 1998). The product of social interactions among students and with teachers, which is influenced by educational and social values, is often referred to as 
school climate (Emmons, Comer, \& Haynes, 1996; Moos, 1979). How students perceive their school climate can greatly impact their academic achievement (Battistich, Solomon, Kim, Watson, \& Schaps, 1995; Griffith, 1999), behavior (Battistich et al.; Wilson, 2004), and attitude (Battistich et al.).

Although the topic of queer youth in the context of education has emerged only in the last three decades, recent research investigates school climate for this population. Studies of queer students show them to be at high risk for experiencing a negative school climate (Bochenek et al., 2001; Kosciw, Diaz, \& Greytak, 2008; Kosciw, Greytak, Diaz, \& Bartkiewicz, 2010; Payne \& Smith, 2010).

Risk factors for queer youth. The Gay Lesbian Straight Education Network (GLSEN) has commissioned a National School Climate Survey every two years for the past decade. The most recent publication, the 2009 School Climate Survey (Kosciw et al., 2010), examines the experiences of queer students in connection with indicators of negative school climate (e.g., pejorative and homophobic language, harassment and violence as a result of actual or perceived sexual orientation). The sample consisted of a total of 7,261 LGBT students between the ages of 13 and 21. Survey responses indicate that nearly $85 \%$ of students reported being verbally harassed and almost half (41\%) of students had been physically harassed. The data are congruent with Massachusetts 2005 Youth Risk Behavior Survey (Massachusetts Department of Education, 2006), which identified that queer high school students are more likely than their heterosexual peers to experience bullying, (44\% vs. $23 \%)$, threats or injuries with a weapon (14\% vs. $5 \%)$, and sexual contact against their will (34\% vs. 9\%). 
Additional research produces similar findings. For example, in a study of 528 lesbian, gay, and bisexual youth, D’Augelli, Grossman, and Starks (2008) found that 78\% reported experiencing verbal abuse and $11 \%$ said they suffered physical abuse because of their sexual orientation. A study by Kimmel and Mahler (2003) situates homophobic brutality within the broader epidemic of school violence. They performed an extensive analysis of 28 random school shootings in American middle and high schools from 1982 to 2001. Based on the authors' coding of adolescent masculinity, homophobia, and violence in schools, they contend that all of the 28 incidences involved some type of gaybaiting or bullying resulting from gender expression.

Grossman et al. (2009) conducted a qualitative study aimed at "understanding what LGBT youth found as oppressive and destructive social conditions in their schools" (p. 27). Divided among five separate focus groups, the research team provided queer youth opportunities to talk about their past and current experiences of school violence. Data was recorded, transcribed, and then analyzed using grounded theory techniques (Strauss \& Corbin, 1990). Core themes focused on lack of community and empowerment leading to youth lacking a sense of human agency in school. Negative attention themes were indicative of the vulnerability that the youth felt at school.

The harassment and violence experienced by queer youth can contribute to increased truancy and drop-out, as well as lowered academic achievement and educational aspirations (Grossman et al., 2009; Kosciw et al., 2008, 2010). Tharinger and Wells (2000) researched the developmental challenges for gay and lesbian youth using attachment theory as a theoretical base to understand the impact that rejection of 
relationship connections can have on the development of queer youth. They argue that as queer youth become aware of their sexuality and attempt to integrate this knowledge into their identity, there is the potential for parental and societal rejection. Indeed research documents this rejection. One study found that $61 \%$ of the violence reported by queer youth happened in the home (Hunter, 1990). In another study, more than one-third of the youth surveyed had been verbally abused in the home, and $10 \%$ were physically assaulted by a family member because of their sexual orientation (Pilkington \& D'Augelli, 1995). In addition to alienation from friends, family, and religious institutions, studies indicate that when compared to heterosexual peers, queer youth are also at a greater risk of suffering with social identity issues, depression, suicidal tendencies, drug and alcohol abuse, homelessness, and sexual harassment (Bochenek et al., 2001; Jennings, 1994; Kosciw et al., 2008, 2010; Unks, 1995; Walling, 1996). Several researchers have compared the patterns of alcohol and drug use among queer and straight youth. Congruent with other studies, Orenstein (2001) found substance abuse to be consistently higher for gay and lesbian youth with the gap widening as the substance became more dangerous. The exact number of queer youth who are homeless is difficult to quantify, but based on his review of the literature, Campos (2005) estimates that about 1.2 million gay and lesbian youth run away from home each year. His work also cites studies of street youth in Seattle, Los Angeles, and Philadelphia that suggest that as many as $40 \%$ are queer. A large amount of the literature that investigates and reports on these tragic realities for queer youth turn toward teacher influence as a possible means for improving school climate and student experience. 
Teacher influence. Given the topic of this paper, the most disheartening finding in the 2009 National School Climate Survey is the report's indictment of administrators and teachers. According to the study, the majority of students who experienced harassment or assault in school chose not to report it, believing little to no action would be taken. In fact, a third of the students who did report an occurrence said that school staff did nothing in response. Similar data is evidenced by studies performed Holmes and Cahill (2005), Grossman et al. (2009), and Bochenek et al. (2001), which find queer youth to be aware that teachers and school staff are often silent and do nothing in response to reports of homophobic harassment. A study of 289 teachers and 52 principals from nine urban, suburban, and rural Connecticut high schools indicated that teachers are a most unwilling group to discuss homosexuality with students (Woog, 1995). Of those polled, $65 \%$ of the teachers, $70 \%$ of the principals, and $100 \%$ of the teachers who selfidentified as gay or lesbian believed that teachers were not open to the discussion of homosexuality with gay or non-gay students (Woog, 1995). Reis (1999) verified this nonreporting of the victimization of queer students by the discovery that only one in four cases of queer youth victimization witnessed by adults were reported to the Washington State Safe Schools Coalition.

Russell, Seif, and Truong (2001) utilized data from over 11,000 participants to examine the role of four different domains related to negative attitudes about school held by queer youth: Family, teacher, social, and peer. As a means of increasing participant privacy to maximize high levels of self-disclosure, queer youth and parents of queer youth listened to questions through earphones and their responses were recorded on a 
laptop computer. Results indicate that teachers play the largest role in predicting school success or failure for queer youth. Among the sample population, youth with positive feelings about their teachers were significantly less likely than their peers to experience the broad range of school troubles. According to the study, teachers largely determine if queer students pay attention, complete homework, and get along with other students. At the conclusion of their article, the authors claim:

Perhaps the most important implication for schools in the U.S. is the finding that relationships with teachers play a leading role in explaining the school troubles experienced by sexual minority adolescents. Supportive teachers can help prevent school troubles of sexual minority youth; teachers need the awareness and training to help them be supportive of their sexuality minority students. (p. 124)

Although a body of research exists to document educators' failure to intervene with homophobic bullying and harassment, several studies indicate that queer youth who are able to identify at least one supportive school staff member are more likely to attend school, experience academic success, develop educational aspirations, and maintain a sense of belonging (Kosciw et al., 2008; Owens, 1998). The Human Rights Watch, a national organization which also reports on the experiences of queer youth, published a report in 2001 stating that teachers play a vital role in the schooling experience of queer youth (Bochenek et al., 2001). As the report puts it, "In virtually every case where lesbian, gay, bisexual, and transgender youth reported that their school experience has 
been positive, they attributed that fact to the presence of supportive teachers" (p. 79). The report goes on to say, however, that most students do not receive such support from teachers and administrators. A lack of training, fear of controversy, and homophobia are some reasons why educational professionals frequently neglect queer issues and fail to adequately support queer youth (Bochenek et al., 2001; Letts \& Sears, 1999; Woog, 1995). Dave Buckel, a staff attorney with the Lambda Legal Defense and Education Fund, summarized in the report a typical response he hears from administrators: "If you're going to be gay, you have to expect this kind of abuse, because you'll face it for the rest of your life" (p. 79). This widespread attitude among school leadership and educators' tendency to avoid queer issues combines with curricula and pedagogy to condone homophobic harassment to persist in schools.

Curricula and pedagogy. For queer youth, the language and symbols at school serve as daily reminders of their marginalization. Heterosexist and gender-specific ideologies surface in kindergarten when students learn the standardized equation for what constitutes a family and when they survey social and gender norms from daily curricula and pedagogy (DePalma \& Atkinson, 2009; Sears, 1999). Delamont (1990) suggests that the gender role beliefs of early childhood educators are predictive of their instructional strategies and curricula choices, which, in turn, are likely to shape children's gender role perceptions and behaviors. Cahill and Adams's (1997) findings suggest that when teachers have limiting gender role beliefs (i.e. separate and traditional notions of the ways in which boys and girls should think, act, feel, and behave), homophobia ensues. These discoveries are significant because it has been repeatedly shown that early childhood 
educators play a vital role in the early socialization - the process by which children learn the values and behaviors accepted in society—of young children (e.g., Ashiabi, 2000; Kemple \& Hartle, 1997; Mussen \& Eisenberg, 1977; Piker \& Rex, 2008). Thus, teachers may discourage cross-gender play and reinforce heteronormativity at a critical time when learners are forming identity and negotiating their place in the world.

Often individual educators don't intend to teach or model homophobia to students. Cognizant of this, a number of researchers have investigated how schools as a whole function as homophobic and heteronormative institutions. Silin (1995) joins a long list of scholars (e.g., hooks, 1994; McLaren, 2003; Sears \& Williams, 1997; Sedgwick, 1990) who have examined the ways in which heteronormativity manifests in school curricula and classroom instruction. He writes, "We attempt to regulate sexuality and desire, the reproduction of heterosexual norms, through covert communication about appropriate feminine and masculine behaviors and aptitudes and through the overt products of popular culture" (p. 159). Silin links his assertion to a narrative study in which Walkerdine (1990) examines how young girls are taught to conceptualize the ideology of romantic love and are prepared for entering heterosexual practices through children's literature. Regardless of teachers' intent, students such as those described in Walkerdine's study receive messages about what is deemed normal and accepted in society through classroom content and experience.

Literature cites many reasons for excluding queer curricula and discouraging classroom dialogue on sexual and gender diversity. Owens (1998), in a survey of 89 school districts, found that fewer than $25 \%$ use queer adults and organizations as 
classroom resources or consultants. Cited reasons for not using these resources are that such outside aid is unnecessary and that use might raise vocal opposition in the community. In addition to political and ideological motives for withholding queer issues in education, researchers have demonstrated that school personnel and educators lack the awareness, sensitivity, knowledge, and skills appropriate for meeting the needs of queer youth. Fricke (1981) showcased his school's lack of understanding in a book called Reflections of a Rock Lobster: A Story About Growing Up Gay. Fricke's ethnographic research tells the story of his desire to take a male date to his high school prom and details the ignorant and unpleasant reactions by the school.

Queering elementary education. Although most of the research from the 1980s and 1990s focuses on problematizing the issue of queer-inclusive education (e.g., Kochheiser, 1975; Liebert, 1971), there has been an increase in literature over the past decade that offers a way forward. Pioneering investigations into "queering" early childhood education, DePalma and Atkinson (2009), as well as Sears (1999), contribute alternative pedagogies that challenge traditional views of childhood, gender, and sexuality. "Those who teach queerly," Sears attests, "refuse to participate in the great sexual sorting machine called schooling wherein GI Joes and Barbies become star quarterbacks and prom queens, while the Linuses and Tinky Winkys become wallflowers or human doormats" (p. 5).

The research and scholarship contributed by Sears challenges educators to reexamine the way they perceive childhood and schooling. He envisions "queer elementary classrooms" as those that challenge categorical thinking, promote 
interpersonal intelligence, and foster critical consciousness. This pedagogy demands that we explore assumptions about diversity, identities, childhood, and prejudice. Toward this end, Sears offers five propositions for elementary classrooms which, he argues, challenge educators to reconceptualize who, what, and how they teach.

1. Diversity is a human hallmark. When it comes to sexuality and gender, he argues, educators tend to mold children into "curriculum cookie cutter identities" whereas a cornerstone to teaching queerly is to deconstruct sexual and gender binaries.

2. (Homo)sexualities are constructed essences, meaning sexual identity is structured and re-structured within a social and cultural context. When it comes to supporting queer youth, rather than focusing on what causes homosexuality, Sears challenges educators to consider the factors that contribute to homophobia and heterosexism.

3. Homophobia and heterosexism are acquired. In other words, hatred and fear of those who love the same gender are acquired early in life. Sears says queering elementary education requires educators to confront personal prejudices indoctrinated through decades of heterosocialization.

4. Childhood innocence is a fictive absolute. All too often adults seem to mask their fear of discomfort by underestimating children's capacity for critical thinking and deep understanding.

5. Families are first, by which Sears acknowledges the ways in which concepts, such as family and parenthood, have become "unhinged." He 
proposes that educators identify and teach reality (e.g., some families have two mommies or daddies that love each other).

In recent years, DePalma and Atkinson (2009) have adopted their own

conclusions about "putting queer into practice" (p. 1). Borrowing existing theory from the likes of Sears $(1992,1999,2002)$, the team of British scholars created the No Outsiders Project. Designed according to the participatory action research model, which links practice and systematic reflection, DePalma and Atkinson recruited a team of educators to examine gender normalization and heteronormativity inherent in their own practice. In order to explore alternative pedagogies, descriptive data were collected from September 2006 to December 2008 and published in their book, Interrogating Heteronormativity in Primary Schools. Through the vivid use of vignettes and personal narrative, the researchers espouse possibilities of including queer content and conversation in the classroom and reveal the transformative power of disrupting heterosexism in schools. Of particular interest is the authors' salient critique on tolerance training around homophobic bullying and harassment. They argue that a “don't ask, don't tell” approach silences real dialogue and can perpetuate stereotypes and propagate assumptions that all people fit neatly and permanently into existing categories. Rather, they assert, "Primary teachers must go beyond an anti-bullying discourse of tolerance in the form of quiet acceptance...teachers need to reach beyond passive and disingenuous tolerance of 'those LGBT people' to proactively incorporate discussions of sexuality and gender into their curriculum" (pp. 3-4). 
Middle and high school curriculum and practice. A failure to acknowledge queer issues and interrupt heterosexism in early grades can perpetuate the homophobia witnessed in middle and high school. Queer epithets and phrases like "that's so gay" echo throughout classrooms and hallways. In fact, the average queer youth hears anti-gay slurs such as "homo," "faggot," and "sissy" about 26 times a day, or once every 14 minutes of an average school day (Kosciw et al., 2008). Middle and high school are also marked by a "hidden curriculum" that emphasizes the perspective of the dominant group (Nieto, 2000; Sleeter \& Grant, 1999). An example is a lesson that recognizes poet and writer Langston Hughes as an African American, but fails to acknowledge and discuss his queer identity; or a curriculum that honors and teaches Martin Luther King Jr. while exploring the Civil Rights Movement, but ignores the influence of Harvey Milk, Anne Kronenberg, and the Stonewall Riots on the American political landscape during the 1960s and 1970s.

Temple (2005) used content analysis to examine 20 high school textbooks for content related to sexuality and relationships. She found that $95 \%$ of the 610 pages she coded made no reference to queerness. One hundred thirty-three pages explicitly defined sexuality as heterosexuality and only 33 pages made reference to homosexual relationships. Interestingly, where homosexuality was mentioned, it was "in negative contexts almost $80 \%$ of the time" (p. 281).

My review of the literature indicates a substantial need to conduct further research in this area; however current mainstream curricula appear to be practically void of any mention of queer history, people, and events. Although several organizations such as The Safe Schools Coalition and Groundspark have created resources to assist educators (e.g., 
lesson modules, videos, and books), these are not widely publicized. Beyond a lack of awareness, many educators don't even know if they are allowed to discuss queer topics in their schools. This, in addition to the fear of being fired or labeled queer, often deters educators from the topic altogether. The fact that teacher preparation programs rarely address the topic only exacerbates fearful unknowns.

\section{Pre-Service Teacher Preparation}

Darling-Hammond (2006) claims that one of the most harmful myths in American education is the idea that effective teachers are "born and not made" (p. ix). In fact, reviews of research conducted since 1960 affirm that, even with the admitted shortcomings of current teacher education, fully prepared and certified teachers are generally higher performing and more successful with all students (Evertson, Hawley, \& Zlotnik, 1985; Ashton \& Crocker, 1986; Olsen, 1985; Wilson, Floden, \& Ferrini-Mundy, 2001). The following review of literature thus assumes that teacher education is an effective and necessary means for equipping pre-service teachers with the knowledge, skills, and dispositions needed to become successful educators.

This section focuses on two components of teacher preparation programs: Multicultural education and teacher reflection. I choose to look at these two aspects of teacher education because (a) multicultural education is a frequent and logical place to examine personal and cultural values and their relevance to educational practice and policies and (b) the process of examining personal and cultural values can be painful, controversial, and rich with opportunities to raise opposing points of view and is aided by one's ability to self reflect. 
Multicultural education. Multicultural education courses have long been a part of teacher education programs in the United States (King, Hollins, \& Hayman, 1997; Ladson-Billings, 1995). Early approaches to acknowledge "diversity" and comprehend "multiculturalism" in teacher education stem from the "melting pot" theories of the 1950s and 1960s: Diversity was recognized and valued, but the ultimate goal was to create a homogeneous society within classrooms where all students were assumed to be equal. As the Civil Rights movement matured and the nation engaged in postmodern discourse, teacher education began to emphasize the importance of individual identity. Minority students were no longer viewed as interchangeable (Banks, 1997; Grant \& Sleeter, 1989) and thus, prospective teachers need to learn how to meet the needs of an increasingly diverse student population (Banks, 2006; Irvine, 2003).

Current national and state standards, among other diversity and equity values, require teacher preparation programs to prepare candidates who are able to "teach from multicultural and global perspectives that draw on the histories, experiences, and diverse cultural backgrounds of all people" (NCATE, 2008, p. 36). Yet despite recent efforts to implement such standards, research reveals that many pre-service teachers enter classrooms with limited awareness of how marginalized youth experience school. Sleeter's (2001) review of literature, which examines research on the preparation of teachers for diverse and underserved school settings, provides evidence of this phenomenon. Her work cites Barry and Lechner (1995) who found that, although students thought their coursework increased awareness of cultural diversity, a majority felt unprepared to teach a multicultural curriculum and to effectively interact with diverse 
students. Sleeter also refers to a number of in-depth qualitative studies that have elaborated on how White pre-service teachers interpret and try to comprehend race (McIntyre, 1997; Smith, Moallem, \& Sherrill, 1997; Valli, 1995). It is noted in these studies that student teachers brought limited cross-cultural experience, which prompted their acceptance of various forms of racial discrimination.

Schools across the nation are opening their doors to an increasingly diverse student population. As a result, a major challenge of teacher preparation programs is to develop in future teachers the knowledge, skills, and dispositions that will enable them to work more effectively with students from diverse social and cultural backgrounds; how this goal is achieved varies upon academic scholarship. Bennett (2003), Brown (2004), Gay (2000), and Pang (2001) agree that, to be effective, classroom teachers must possess multicultural knowledge, dispositions and behaviors that respond to issues of student diversity and cross-cultural acceptance. Additional multicultural theorists espouse that classroom teachers must be prepared to recognize biases and advocate for equity (Banks, 1995; Pai, 1990). Howard (2002) and Zeichner (1993) emphasize the importance for future educators to view multicultural education from a global perspective and learn how to transfer ideas about social justice and equity to students. Advocating for a broader definition, Nieto (2003) contends that multicultural education should permeate all areas of schooling. She argues that it is for all students, encompassing "not only race, ethnicity, and language, but also gender, social class, sexual orientation, ability, and other differences" (p. 17). 
According to Cochran-Smith (1995), teachers need to examine personal experiences and tacit assumptions surrounding teaching and learning in order to form their understanding of their roles as teachers. She states:

In order to learn to teach in a society that is increasingly culturally and linguistically diverse, prospective teachers...need opportunities to examine much of what is usually unexamined in the tightly braided relationships of language, culture, and power in schools and schooling. This kind of examination inevitably begins with our own histories as human beings and as educators - our own cultural, racial, and linguistic backgrounds and our own experiences as raced, classed, and gendered children, parents, and teachers in the world. It also includes a close look at the tacit assumptions we make about the motivations and behaviors of other children, other parents, and other teachers and about the pedagogies we deem most appropriate for learners who are like us and who are not like us. (p. 500)

The diverse perspectives outlined above directly inform approaches for implementing multicultural education in school practice. Based on my review of the literature, two bodies of thought consistently emerged. The first is offered by Sleeter and Grant (Grant \& Sleeter, 1993; Sleeter \& Grant, 1988) who examined the published 
literature on multicultural education to determine how researchers, teachers, and academic scholars conceptualized the field. Analysis led them to articulate four common approaches: (1) teaching culturally different students to fit into mainstream society; (2) a human relations approach, which emphasizes diverse individuals living together amicably; (3) the single group studies approach that focuses on developing awareness, respect, and acceptance for diversity; (4) reducing prejudice and providing equal opportunities for all groups in society; (5) education that is multicultural and social reconstructionist, which advocates for students to become critical thinkers and social reformers committed to equity.

Banks (1995) also contributed to the ways we approach multicultural education. His five dimensions to multicultural education include: (1) content integration; (2) knowledge construction process; (3) prejudice reduction; (4) equity pedagogy; (5) empowering school culture and social structure. Banks argues that to implement multicultural education effectively, teachers and administrators must attend to all the approaches.

Given the wide range of literature on the purposes and approaches to multicultural education, it is not surprising that colleges and universities around the nation implement different methods. One common approach is to require pre-service teachers to enroll in a stand-alone multicultural or diversity course. Although this forum provides an opportunity for pre-service teachers to talk explicitly about issues of diversity, some teacher educators say that a single course is insufficient to bring about significant changes in future teachers' attitudes, understanding, and practice (Ahlquist, 1992; Brown, 
2004; Grant, 1994; Weisman \& Garza, 2002). Despite the variance in programmatic philosophies and methods, one common element does exist: Queer issues are frequently excluded.

Queer exclusion. Although perspectives focused on inequities related to gender, class, race, ethnicity, and disability have drawn the increased attention of educators and researchers, when it comes to preparing teachers to work effectively with queer youth, there is near silence (Letts, 2002). The scarce research that does exist linking queer issues to teacher education has concentrated on the victimization of queer youth and the creation of safe schools (Epstein, 1994; Kissen, 1993; Letts \& Sears, 1999; \& Woog, 1995). Alternatively put, there has been little focus on influencing the knowledge and beliefs of pre-service principals and teachers about these issues (Butler, 1999; Rofes, 1985).

In a dissertation, Baldwin (2002) describes her examination of pre-service teachers' perceptions of current equity practices (as related to queer issues) in teacher preparation. Baldwin administered a 60 -item survey to 250 pre-service teachers among three northwest universities. All participants were completing their final two years of teacher education programs and were currently enrolled in either diversity or social foundations courses. One objective of Baldwin's research was to give pre-service teachers an opportunity to assess if and how their program approached queer issues as they relate to education. The quantitative data were analyzed by site using descriptive statistics and written comments were analyzed using content analysis. Of the 208 surveys returned, $72 \%$ indicated that their instructors did not use activities that highlighted the importance of educating queer youth. Almost a third of the participants felt there would 
be resistance from the college if an instructor wanted to include queer issues in a teacher preparation course, and half expressed that students would probably be resistant. When asked if they thought instructors seemed comfortable addressing queer issues in classes, only $44 \%$ of the total population said yes. Overall, Baldwin found that current practices used to educate pre-service teachers neglect discussions about the lives of LGBT people and fail to emphasize the importance of educating queer youth.

The limited empirical research available from this field of study supports Baldwin's (2002) findings: Little has been done to integrate sexual and gender diversity into teacher education curriculum. Queer issues are seldom reflected in course syllabi (Lipkin, 2002) and rarely make their way into class discussions (Lipkin; Sears, 2002). Perhaps this is because the climate of higher education-specifically any given department of education - is reported to be rampant with homophobia and heterosexism (Dolan, 1998; Euben, 1999; Hunsicker \& Freedley, 2000). Research suggests that queer people often experience negative attitudes, harassment, and violence on college campuses (Eddy \& Forney, 2000). D’Augelli (1992) conducted a study to determine school climate for queer youth on college campuses. He concluded that harassment is a predictable outcome for college students who openly identify as queer. "The many instances of abuse, mistreatment, and violence [on college campuses] provide ample evidence that gay/lesbian affectional status leads to repeat violations of personal dignity, personal choices, and freedom to pursue personal and professional goals” (p. 392).

Envisioning queer-inclusive teacher education. Arthur Lipkin (2002) has produced a substantial amount of literature surrounding queer politics, content, and 
pedagogy in teacher education. He proposes that colleges and graduate courses teach preservice teachers to (p. 18):

- Understand the significance of LGBT issues in education

- Teach more comprehensively about the human experience through the integration of LGBT subject matter into the core of learning in a variety of disciplines

- Promote the psychological and physical health and intellectual development of all students

- Reduce bigotry, self-hatred, and violence by increasing tolerance for sexual differences

- Aid communication between LGBT youth and their families and schools

- Facilitate the integration of LGBT families into the school community

- Nurture the well-being of faculty, staff, and administrators of all sexual orientations

- Collaborate with the greater community in achieving these ends Although the body of literature exploring queer-inclusion in teacher education is in its infancy, there is growing evidence for its efficacy in preparing pre-service teachers to meet the needs of queer students and families. Swartz (2003) used the film called It's Elementary (Chasoff, 1995) to teach prospective teachers in Appalachia about the ways heterosexuality is normalized. The film, which addresses homophobic prejudice by providing adults with practical lessons on how to talk with kids about queerness, enabled 
the students in Schwarz's course to, "interrogate their prejudices and cultural constructions as well as to think critically about how to introduce such discussions" (p. 53). Her entire experience of using the film to generate discussion on queer issues among "Appalachians living in socio-economically depressed rural areas and small towns" (p. 52) is chronicled in her ethnographic research.

Athanases and Larrabee (2003) conducted a study of nearly 100 pre-service teachers enrolled in one of three Cultural Diversity and Education courses at a large California public state university. The purpose of the study was to examine the process and outcomes of providing prospective teachers with instruction on queer issues as they relate to education. Classroom activities included readings, a video, a guest speaker, discussion, and writings. Written responses of 97 students indicated lack of knowledge of queer youth prior to instruction and strong appreciation for new knowledge. Audiotaped interviews with instructors revealed that students made many links to broader social justice issues.

Elizabeth Payne and Melissa Smith's (2010) article, Reduction of Stigma in Schools (RSIS): An Evaluation of the First Three Years, is an evaluation of a program to bring an increased awareness of queer youth's experience into schools. Timothy Larrabee and Pamela Morehead (2010) wrote Broadening Views of Social Justice and Teacher Leadership: Addressing LGB Issues in Teacher Education, which concerns teacher leaders addressing homophobia in classrooms as part of a social justice component in their teacher education programs. Their findings support those of Payne and Smith, as well as Athanases and Larrabee (2003): Pre-service teachers want to learn more about 
queer issues as well as acknowledge their lack of awareness of the insensitive remarks or actions of their own students in the classroom.

When considering how to achieve these objectives, faculty members of teacher preparation programs may want to think about the essential questions posed in the article, The Invisible Minority: Preparing Teachers to Meet the Needs of Gay and Lesbian Youth. In this article, Mathison (1998) identifies questions related to teacher educators' responsibility in preparing pre-service teachers to work with queer youth: "What teacher behaviors most alienate queer students? What negative messages does the school/classroom communicate? What messages does the curriculum send?" (p. 152). These questions, and the complex issues they raise, can challenge teacher educators not only to look at the underlying principles of their program, but to wrestle with and make sense of the mystifying phenomena encountered in K-12 schools. As described here, the process by which teachers engage in thought and discourse models another common aim of teacher preparation programs, which is to engage pre-service teachers in the development of on-going and meaningful reflection.

Teacher reflection. In addition to entertaining a variety of ideological definitions of multicultural education, teacher education also employs a vast conceptualization of teacher reflection. According to Dewey $(1933,1938)$, reflection is the process of stepping back and analyzing a puzzling situation or experience. He envisioned reflection used by educators in a holistic way that encourages one to think about and respond to everyday problems experienced in schools. Schön (1983) coined the term reflective practice, which involves an individual considering his or her own experiences in applying knowledge to 
practice while at the same time receiving guidance by professionals in the field. Schön also contributed the distinction between reflection-on-action and reflection-in-action. In teaching, reflection-on-action consists of the thought that leads to lesson design and instructional planning (i.e. theory) whereas reflection-in-action occurs as teachers respond to students and adjust instruction (i.e. practice). Both instances engage educators in a cycle of using knowledge and information from their setting to inform practice. Zeichner and Liston (1996) note, however, that two essential components of reflection are omitted from Schön's conception of reflection. In their book, Introduction to Reflective Practice, Zeichner and Liston highlight the important roles that communication and context play in the process of reflection. According to the authors, dialogue with school stakeholders and expanding reflection beyond classroom walls can lead to deeper meaning and a broader understanding of teaching and learning.

A thorough review of literature prompted Grimmett, Erickson, Mackinnon, and Riecken (1990) to describe three distinct perspectives on reflection. The first, reflection as instrumental mediation of action, conceptualizes the use of knowledge to direct practice. Reflection as deliberating among competing views of teaching emerged from a group of studies that highlighted the importance of context, deliberation, and choice among competing views of effective practice. Finally, according to their review of the literature, Grimmett et al. propose reflection as reconstructing experience, which considers reflective action as the reconstruction of experience. Within this third perspective, perplexing experiences and subsequent reflection can lead to new or reconceptualized meaning found in situations or within teachers themselves. The metaphor 
of reflection as reconstruction includes "taken-for-granted assumptions about teaching" (p. 31), which the authors offer as a means by which critical theory can be practiced.

The critical approach to reflective practice views schools as cultural and political organizations that help re-produce a capitalistic society based on unjust social relations (Giroux \& McLaren, 1986; Valli, 1990). Or as Beyer (1984) writes:

Rather than seeing the school as an essentially apolitical and meritocratic institution, which provides for social and economic mobility by giving students a fair chance at enjoying the wealth and advantages of our society, these critical investigations have sought to uncover the ideological dimensions of aspects of school life. (p. 37)

Mezirow $(1998,2000)$ defines critical reflection by making an important distinction. He notes that reflection does not necessarily involve making an assessment of what is being reflected upon. Critical reflection, however, involves a learning process of "becoming critically aware of one's own tacit assumptions and expectations and those of others and assessing their relevance for making an interpretation" (Mezirow, 2000, p. 4). According to Mezirow $(1998,2000)$ this type of reflection can lead to psychological, convictional, and behavioral transformation. He suggests:

When the object of critical reflection is an assumption or presupposition, a different order of abstraction is introduced, with major potential for effecting a change in one's established frame of reference....critical self- 
reflection of an assumption involves critique of a premise upon which the learner has defined a problem. Significant personal and social transformations may result from this kind of reflection. (1998, p. 186)

Offering his contribution to the field of critical reflection, Brookfield (1988) identifies four activities that he believes are essential: Assumption analysis, contextual awareness, imaginative speculation, and reflective skepticism. The first step in the critical reflection process involves thinking in such a manner that challenges personal beliefs, values, cultural practices, and social structures in order to assess their impact on daily life. Second, contextual awareness consists of realizing that assumptions are personally and socially constructed and embedded within historical and cultural context. The third activity, imaginative speculation, includes thinking about phenomena and imagining alternative or challenging ways of knowing. Finally, according to Brookfield, reflective skepticism is the act of suspending universal truths and constantly questioning the status quo.

Whether employing Brookfield's (1988) methodology or through other means, utilizing a critical approach enables teachers to reflect upon and perhaps alter the circumstances of their schools that benefit some student populations while limiting experiences and opportunities for others. This link between reflection and practice is noted by Valli (1990) who writes "The primary goal of teacher preparation is to assist prospective teachers in understanding ways in which schools might be contributing to an unjust society for the purpose of engaging in emancipatory action" (p. 46). 
Moss (2001) conducted a study rooted in critical theory that examined student reflection in a graduate level multicultural education course. The 15 participants were asked to engage in group activities that required them to take on different cultural viewpoints. The mixed methods study used survey, interview, and personal narrative data to determine what kind of critical pedagogical development had occurred in the preservice teachers. Several patterns emerged. The author concludes:

Most of the participants were critically impacted during one or more of the learning activities in a way that resulted in a broader perspective and critical self-reflection with regard to their teaching practices...The changed practices reflect critical pedagogy because the practices are culturally sensitive and empower students and their families to have a greater participation in the educational process. (p. 9)

The findings illustrate that critical reflection can be used to raise cultural awareness and foster transformational learning (Mezirow, 1998) among pre-service teachers.

Representative of other literature in the field, Moss's study describes how one course can provide space and structure for pre-service teachers to move beyond the acquisition of new knowledge into reflection that questions personal and societal assumptions, values, and perspectives. By restructuring existing curricula, the instructor provided opportunities for students to engage in meaningful activities and discourse. Support and guidance were provided to learners as they processed phenomena and this, in part, is documented to have led students toward a more critical disposition. 


\section{Teacher Dispositions}

Reflection and growth surrounding disposition is also apparent within teacher education. In fact, an essential aim of teacher preparation programs is to develop in preservice teachers the knowledge, skills, and dispositions necessary to meet the needs of diverse learners (NCATE, 2008). A large body of research demonstrates that educators' beliefs and tendencies, indeed their dispositions, determine what is and what is not important in their practice (Charlesworth, Hart, Burts, \& Hernandez, 1990; Clark, 1988; Cole, 1989; Dewey, 1933). In this paper, disposition includes a person's beliefs as well as their "attitudes, values, interests, self-concept, and motivation" (Stiggins, 2001, p. 101).

The National Council for Accreditation of Teacher Education (NCATE) (2008) defines dispositions as the "professional attitudes, values, and beliefs demonstrated through both verbal and non-verbal behaviors as educators interact with students, families, colleagues, and communities" (pp. 89-90). Further, NCATE argues that "these positive behaviors support student learning and development" (p. 90) and that teacher preparation programs need to assess professional dispositions in educational settings.

Some educators maintain that personal dispositions and even societal values do not interfere with providing support and education to students. Yet it has been found that students' race, class, gender, and sexual orientation can have an impact on how they are perceived by peers and evaluated by teachers (Bochenek et al., 2001; Harbeck, 1992; Kosciw et al., 2008). Nespor (1987) proposes that dispositions have a stronger affective and evaluative component than knowledge and often operate independent of cognition. Thus, regardless of teacher awareness or intent, personal dispositions can significantly 
influence classroom behavior and practice. Students are acutely aware of teachers' dispositions and stereotyped beliefs. A study by Rosenbloom and Way (2004) found that Latino and African American students perceived their teachers as racist or discriminatory. Interviews and participant observation revealed that students perceived teachers as uncaring and ineffective as a result of perceived low academic expectations and stereotypes about behavior problems relating to race.

Sears (1992) articulates further ways that educators' beliefs and behaviors influence classroom teaching and learning, specifically drawing attention to dispositions toward sexual diversity. He writes:

It is an educator who chooses how to teach the prescribed sexuality curriculum; it is the educator who challenges or winks at homophobic comments or jokes among students; it is the educator who comforts or ignores a student suffering from heterosexist tirades of peers or doubts about their sexual identity; it is the educator who fosters dialogue among fellow professionals about the penalties all pay in a heterosexual mandated society. (p. 61)

Sears reminds us that teaching often comes down to the art of decision-making. In the hearts and minds of queer youth, overt and subtle choices about if, when, and how to respond to homophobia can have a profound impact on how students perceive their teacher, their school, and themselves. 
This paper has argued that teacher dispositions can be transparently communicated to students and influence classroom practice. It has also been demonstrated that NCATE and other professional organizations value the development and evaluation of teacher disposition in order to support students and ensure effective learning. To increase the likelihood that educators have a positive impact on queer youth, scholars examine how to assess educators' dispositions toward queerness.

Assessing dispositions toward queerness. Several of the instruments currently available to assess individuals' disposition toward queer people and culture were developed in the 1980s. Some scales use a very small number of items (e.g., Nyberg \& Alston, 1976) while other instruments are longer (e.g., Leitner \& Cado, 1982; Smith, 1971). Differences also occur in defining what types of questionnaire items measure attitudes toward queerness. Some researchers ask only questions concerning the sexual act itself or the individual's desire to participate in a homosexual act (e.g., Smith, Resick, \& Kilpatrick, 1980; Young \& Whertvine, 1982). Others have focused on whether or not homosexuality is morally wrong (e.g., Glenn \& Weaver, 1979; Nyberg \& Alston). Hudson and Ricketts (1980) measured only the desire to associate with queers.

A review of the literature identifies the Internalized Homophobia (IHP) scale (Meyer, 1995) and the Attitudes Toward Lesbians and Gay Men (ATLG) scale (Herek, 1994) as prominent assessment instruments. Data collected from these instruments over the past few decades suggest that: Heterosexual males consistently hold more negative attitudes toward queers and homosexuality than do heterosexual females (Herek, 1988; Clift, 1988); males' attitudes are more negative toward gay men than they are toward 
lesbians; negative attitudes toward homosexuals correlate with traditional attitudes about gender and family-roles, strong devotion to an orthodox religion, and past negative experiences with queer people (Clift, 1988; Herek, 1984, 1988; Nyberg \& Alston, 1976).

A thorough review of the literature produced limited research specifically examining pre-service teacher dispositions toward queerness. A study by Sears (1992) examined pre-service teachers' knowledge about and disposition toward homosexuality. He found that $80 \%$ of the prospective teachers surveyed held negative feelings toward queer people. Of this sample population, one-third was considered highly homophobic. Interestingly, Sears research reports that the more knowledge pre-service teachers have about homosexuality, the less the likely they are to harbor negative dispositions towards queer people.

Butler (1994) and Petrovic and Rosiek (2003) conducted separate studies to examine prospective teachers' attitudes toward homosexuality and willingness to discuss the topic as future teachers. Both studies yielded similar results: Pre-service teachers demonstrated a lack of knowledge about homosexuality, slightly homophobic attitudes, and an unwillingness to include queer issues in their future classrooms. In response, Butler suggests that pre-service teachers engage in cognitive activities to experience transformational knowledge (e.g., lecture, discussion, audiovisuals, and assigned readings) as well as affective pursuits which focus more on feelings, attitudes, and emotions (e.g., speaker panels, role plays, simulations, small group discussions, and case studies). Petrovic and Rosiek claim that pre-service teachers need opportunities to rework their habits of subjectivity. The authors assert that, through a dialectical process 
involving authentic interaction, adult learners can transform homophobic attitudes. Petrovic and Rosiek argue:

Only by engaging pre-service teachers in dialogue about [lesbian, gay, bisexual] LGB issues that addresses the malignant silences, as well as the explicitly espoused bigotry in their thinking about the issues, will we have teachers who can provide spaces for LGB youth and their families to flourish in schools. (p. 168)

Michael Sadowski's (2010) article, Core Values and the Identity-Supportive Classroom: Setting LGBTQ Issues within Wider Frameworks for Preservice Teachers, focuses on the core values that teacher candidates bring to teaching, and then incorporates research about queer youth and schooling-related issues. His approach places queer issues within larger ideals that reflect generally agreed-upon beliefs about public schooling (e.g., all children have a right to learn, all students have the right to feel safe at school). Thus, he incorporates queer students and issues into the overall curriculum rather than focusing on them as separate from mainstream, heteronormative discourse. His inclusive approach is supported by Payne and Smith's (2010) research (described above) on the professional responsibility of teacher educators to deconstruct the hidden curriculum of heteronormativity.

Although there is a substantial absence in the literature on pre-service teachers' beliefs about queer students and issues, the research that is available concludes that many prospective teachers hold homophobic dispositions. Given the impact disposition can 
have on teaching and learning outcomes, further research is needed to determine how preservice (as well as experienced) teacher's dispositions affect queer youth.

\section{Discussion}

The three bodies of literature explored in this paper are vast. For decades scholars have examined and documented K-12 student experiences and school climate, pre-service teacher preparation, and teacher dispositions. Although literature on queer youth and LGBT issues in education has a shorter history, the burgeoning evidence of risk factors for this population warrants further research. Yet, based on my review of the literature, there has been little effort to combine these multiple fields of study. The discussion below demonstrates my conceptual understanding of how these fields are related and how they can be combined to advance an important and often overlooked social justice initiative in modern education.

An essential aim of teacher preparation programs is to develop in pre-service teachers the knowledge, skills, and dispositions necessary to meet the needs of diverse learners. This review has also acknowledged an historical trend within most teacher preparation programs to address issues around student diversity in a multicultural education course. Thus, it is logical to see how a course that intentionally provides opportunities for pre-service teachers to gain accurate knowledge about queer issues and culture, for example, can help pre-service teachers understand and relate to queer youth. But knowledge alone is not enough. Teacher preparation programs need to equip students with the skills needed to implement a queer-inclusive pedagogy and/or interact with queer faculty, students, and families. 
In addition to knowledge and skills, pre-service teachers need to be taught how to develop professional dispositions toward queerness. A self-awareness of disposition can help pre-service teachers confront queer issues in school even in the presence of selfconflicting ideological beliefs. For instance, a teacher who opposes homosexuality, yet is able to reflect upon this disposition as it relates to his or her professional work, may be more likely to interrupt homophobic name-calling even if he or she holds similar stereotypes.

The reference to reflection in this example prompts my final proposition: Preservice teachers must be taught how to engage in on-going critical reflection. In the model I propose, teacher educators should facilitate the process of learning to analyze, reconsider and question experiences within a broad context of issues. I believe that preservice teachers able to critically reflect on knowledge, skills, and personal dispositions related to queerness will prompt social action to emancipate knowledge and affirm diverse ways of being. Pre-service teachers engaging in this form of praxis (Freire, 1970) will be prepared to disrupt heteronormativity as K-12 educators and provide increased support for queer youth.

Based on my review of the literature a clear path exists for me as a researcher to fill a gap in current scholarship. My goal is to explore, through observation and discourse, how pre-service teachers encounter, make sense of, and respond to sexual and gender diversity within their field placements. An in-depth interpretation of pre-service teachers' experiences can provide rich data to raise awareness of queer issues in preservice teacher education and to encourage individuals to take a stand against oppressive 
forces, especially homophobia, which permeate schools across the nation. By

implementing a sound research design it is also my intention to elicit data that will inform pre-service teacher preparation programs on ways of providing better support and preparation to pre-service teachers who will inevitably work with queer students and families. 


\section{Chapter Three: Research Design and Methodology}

Chapter Three serves as a blueprint for understanding my overall research goals. This section includes a clear link between my chosen theoretical framework (i.e. critical social theory), the research question, the research paradigm (i.e. interpretivism), and case study research design. I begin with a discussion of the research paradigm that, combined with critical social theory, contributes to the conceptual understanding of my research inquiry. Then I link this conceptual framework to my research question and provide context for the study. A discussion of the methodological approach follows as well as a description of the research participants, and data collection and analysis procedures.

\section{Paradigm}

Interpretivism serves as a logical overarching paradigm to research the experience of pre-service teachers as they encounter and make sense of queer issues within their field experience. Guba and Lincoln (2005) state that the basic beliefs that define a particular research paradigm may be summarized by the responses given to three fundamental questions: (1) the ontological question (i.e. what is the form and nature of reality); (2) the epistemological question (i.e. what is the basic belief about knowledge); and (3) the methodological question (i.e. how can the researcher go about finding out whatever s/he believes can be known). Interpretivism challenges the positivistic assumption that the world has an objective reality that can be captured and translated into testable hypotheses (Guba \& Lincoln). Rather than viewing knowledge as an awareness of objects that are independent of any subject (Fieser \& Dowden, 2004; Trochim, 2001), researchers adopting an interpretivist approach view the world subjectively and search for patterns of 
meaning. Interpretivists argue that knowledge and reality do not have an objective or absolute meaning, but rather are created in multiple ways depending on the participants and their social context (Abdal-Haqq, 1998; Applefield, Huber, \& Moallem, 2000). This theory of ontology and epistemology relates to contemporary ways in which individuals (such as pre-service teachers) and institutions (such as schools) handle diverse notions of identity and sexuality. Everyone in society has a unique perspective about gender and sexuality based on prior knowledge, learning opportunities, and experiences. Most individuals have distinct ideas about what it means to be born male or female, display masculinity or femininity, and to desire men or women.

With an overarching aim to discover, understand, and communicate the meaning of an occurrence for the person who experienced it, interpretivism clearly relates to the research question and critical social theory, which I have identified as my broader theoretical framework. As the researcher, I examine how pre-service teachers identify and comprehend queer issues as they surface in the field. By asking how pre-service teachers encounter, makes sense of, and respond to queer issues in education I uncover their experiences and describe reality as constructed in the minds of individual preservice teachers. An interpretivist framework, which views knowledge as a matter of interpretation, offers a window into imagining and realizing such dialogue, which can ultimately evolve into new perspectives and practice for participating pre-service teachers as well as my dissertation audience. Thus, interpretivism serves as a vehicle to transport critical reflection and to perhaps establish within teacher preparation programs a cycle of praxis among social actors capable of disrupting heteronormativity within education. 


\section{Research Question}

In order to understand the context and meaning of pre-service teachers' experiences with queer issues in education, I sought to answer the following research question: How do pre-service teachers encounter, make sense of, and respond to sexual and gender diversity within their student teaching field placements?

\section{Context of the Study}

In summer 2010 I co-led a cohort of students in the Teacher Preparation Program (TPP) at Greensgo University (GU). I guided and instructed 19 newly admitted preservice teachers from their initial entry into the program to graduation and licensure. Upon enrollment (July 20, 2010), pre-service teachers are required to take a multicultural education course. This introductory class constitutes the only required course that specifically tackles issues surrounding student culture and diversity. As course instructor, I included the topic of queer issues in education as a means of determining appropriate support for queer students and families, as well as recognizing the larger heteronormative and transphobic culture that exists in schools (see Appendix B for course topics and objectives). Around the time of completion of the five week course, students were assigned a cooperating teacher and a school to conduct their year-long student teaching. It was within the first seven months of this field experience that I collected data.

\section{Participants}

The TPP admitted 80 students to three full-time elementary cohorts; I worked with one cohort of 19 students. Students are randomly assigned to cohorts, yet faculty members often strive to achieve a balance between groups with respect to gender, age, 
and life experience. It is important to note that as a member of the admissions committee, I advocated for a transgender student to be placed in the cohort with which I was associated. The disclosure of the student's transgender identity was assumed based on letters of recommendation submitted by the applicant. Two letters referred to the candidate as male while the third used female pronouns. I intentionally wanted this student in my cohort because I believed he would likely have a unique experience and enhance the group's depth of knowledge and understanding of queer issues. I also anticipated learning from his experiences in the field.

To obtain my sample I provided a brief overview of the study to the entire cohort during the final multicultural education class (held August 11, 2010). Then, after cohort members received their grades for this course (August 20, 2010), I emailed an invitation to an open information session where cohort members could obtain more facts about the study and also ask questions. At the information session I distributed a letter of informed consent that clearly stated the research purpose, potential risks, and participant expectations (see Appendix C). I communicated participant responsibilities and shared a timetable that indicated scheduled activities (see Appendix D). Students were encouraged to read the documents and reflect on the information presented in the session to decide if they would like to participate. I planned to independently contact those who attended the information session during the following week to finalize the sample population, however all eight attendees confirmed their placements on the spot. Although every initial volunteer ended up completing the study, one participant, Ramona (all names are 
pseudonyms), was removed from her field placement in February 2011 and therefore did not contribute to the final round of individual interviews.

I deemed six to eight cases necessary in order to gather sufficient data and draw upon a range of personal and professional experiences. A minimum of six participants offered a safeguard should participants voluntarily withdraw from the research study or be asked to discontinue TPP. Collecting and examining data from more than eight cases may have increased the risk of scheduling conflicts among participants and posed difficulties with regard to the management of time and resources.

\section{Methodological Approach}

I employed a case study research design. The overarching goal of the case study was to holistically examine, interpret, and describe the ways in which pre-service teachers confronted queer issues in education. Given this aim, I conducted a multiplecase study and defined my units of analysis, or cases, as the individual pre-service teachers who participated in the study. A multi-case, or comparative, research design was more likely to illustrate different perspectives through the various representative cases (Creswell, 2007; Merriam, 2009; Yin, 2009). It was my belief that this design would yield descriptive data that could be used to articulate the experiences of pre-service teachers with regard to how they experience queer phenomena (e.g., non-conforming gender identification and/or expression, homophobic bullying, heteronormative school curricula or policies, same-sex orientation of students, families, or school faculty).

The multiple-case study relied on inductive reasoning which involved moving from a set of specific facts to conceptual conclusions. Generalizations about including 
queer content in multicultural education to pre-service teachers, for example, emerged from data provided by student experience in the program. Although the purpose of qualitative research is not to generalize to the larger population, I believe that my research findings can inform and potentially influence TPP as a whole.

\section{Data Collection}

Drawing a comparison to ethnography, Creswell (2007) notes that case study data collection involves "a wide array of procedures as the researcher builds an in-depth picture of the case" (p. 132). In order to understand how pre-service teachers encounter, make sense of, and respond to sexual and gender diversity, I collected data from the following sources: (a) individual interviews; (b) group conversations; (c) direct observation; (d) research log; (e) participant journals; (f) electronic prompt/response submissions; and (g) artifacts. Data was collected for seven consecutive months from September 2010 to March 2011 (see Appendix D for data collection timeline and procedures). Data was collected (and either recorded/time stamped or transcribed) throughout the duration of the study (see Appendix E for more information about the strategy used to organize data).

Individual interviews. Understanding how pre-service teachers experienced issues around sexual and gender diversity required individual and on-going interviews with each participant over the course of the study. These one-on-one interviews provided structure and space for participants to reflect upon, articulate, and make sense of issues that surfaced in their respective field placements and how these issues related to the research question. Interviews were conducted in late September, mid-January, and mid- 
March. Within these distinct rounds of individual interviews I asked questions and facilitated dialogue that led to a deeper understanding of the phenomena experienced by participants in the field.

Although guiding questions and discussion topics relied heavily on context (e.g., what came up in the previous discussions, experiences that surfaced in the field), interviews were guided by an interview protocol (see Appendix F). The first interview focused on how pre-service teachers encounter sexual and gender diversity. Questions, such as, what do you see going on in your school or classroom and how are sexuality and gender communicated, were addressed. This initial interview provided appropriate scaffolding for second interviews, which focused on the making of meaning. In the third and final interview, participants were asked to elaborate on their encounters, sensemaking, and discuss the ways in which individuals responded to sexual and gender diversity in the field. Talking about the ways in which participants (and cooperating teachers, co-teacher candidates, classroom students, school administration, parents, and community members) reacted to issues surrounding sexual and gender diversity provided telling data that informs implications discussed in later chapters.

Participants were encouraged to bring "artifacts" to individual interviews. Artifacts, which could be collected at field placement sites, included items such as classroom curricula, materials, documents, and photographs. This task provided participants with the opportunity to assess their school and/or classroom climate toward queer issues and also generated conversation around authentic and relevant issues from the field. Artifacts as a data collection strategy is described in detail below. 
The location of interviews was largely determined by the interviewees. Although sites were suggested (e.g., the university, field placement settings, nearby coffee shops), I accommodated participants' schedule and location preference with regard to privacy and comfort.

As mentioned, I aimed to facilitate three separate rounds of individual interviews with each participant. Interviews ranged from 15 to 90 minutes in length. All interviews were audio taped and transcribed. Only the researcher had access to the audiotapes, which were stored under lock and key where they will remain until they are destroyed in October 2014. Interviews were transcribed verbatim. At the top of the first page of transcription I listed identifying information (i.e. the date, time, location, and participant pseudonym). Each interview was saved as an individual electronic document and labeled as "name_interview\#”. Stored as coded files in my computer, this organizational method for transcribed data aided later computer-assisted analysis.

Group conversations. In addition to individual interviews, participants will engaged in whole group conversations focused on the content of the study. In his book, Research Interviewing, Mishler (1986) discusses restricted conceptualizations of the interview process. "This view obscures the essences of interviewing... and undercuts the potential and special contribution of interviewing for the theoretical understanding of human action and experience" (p. vii). Offering an alternative, Mishler proposes interview as a form of discourse. Further, he articulates interviews as speech events jointly constructed by interviewer and respondent(s) in which the meanings of questions and answers are contextually grounded. 
Mishler's (1986) interpretation of the interview process guided the method of group discourse discussed here, which focused on the context and meaning of pre-service teachers' experiences with queer issues. Within these conversations I facilitated dialogue using semi-structured, open-ended questions. As with individual interviews, conversations heavily relied on context (e.g., what came up in the previous meeting, experiences that surface in the field) and were therefore adaptable. Sessions, however, were loosely guided by a conversation protocol (see Appendix G). As indicated by the protocols, group conversations were structured to offer alternatives to a standard question/response strategy that seemed to further engage participants, focus discussion, and support critical thinking. As was the case with individual interviews, participants were encouraged to bring "artifacts" to group conversations.

I facilitated two separate group conversations (October 27, 2010 and January 25, 2011), each spanning 60 to 90 minutes in length. Group conversations were videotaped and immediately transcribed. These meetings were held in private conference rooms at GU to avoid the inclusion of non-participants on the videotapes. As was noted with individual interview data, only I have access to the videotapes, which are locked away, until they are destroyed in October 2014. After each session I transcribed recorded conversations verbatim. Utilizing video to record conversations allowed me to capture nonverbal behavior in addition to what was said. I accounted for nonverbal data in my transcription with bracketed, italic writing to describe physical behaviors, such as facial expressions and gestures. 
Prior to discussing my procedural plans for observational data, it is important to expand on the construct of this group. As collective conversations progressed over time the participant group became somewhat of an intervention. By engaging in continuous dialogue and the process of negotiating meaning, the group formed a learning community within which knowledge, skills, and dispositions were challenged, altered, or otherwise developed. This is discussed later in Chapter Four.

Direct observation. According to Yin (2009), "Because a case study should take place in the natural setting of the 'case,' you are creating the opportunity for direct observations" (p. 109). Direct observation of pre-service teachers in their school and classroom environment will provide authentic context from which to gather data. Guided by an observation protocol (see Appendix H), I used this form to record my perception of how pre-service teachers encountered and responded to sexual and gender diversity in the field. Direct citations of this data source will be denoted as "direct observation," which means that I handwrote field observations directly onto a copy of the protocol and then cataloged the document for later analysis. As illustrated in the data collection timeline and procedures (see Appendix D), I conducted a minimum of two observations of each participant.

Research log. To document the process of the study I managed an electronic research log. Registering phenomena using a research log occurred throughout the study, but it is important to note two distinct ways I used this data collection strategy. First, I recorded personal thoughts, feelings, and assumptions before all group interviews as a means to reduce researcher bias and better comprehend the perspective and experiences 
of others. Likewise, I reserved time after each interview to record my perspectives of group discourse and brainstorm possible next steps.

Second, I made use of the research log to chronicle and narrate direct observations of field visits. This electronic collection of data captured my interpretation of how preservice teachers encountered and responded to sexual and gender diversity in their classroom settings. Such data informed research procedures (e.g., demonstrated the need for more or less direct observation), provided additional context for group interviews, and ultimately offered rich context for reporting the overall case study findings.

Participant journals. Pre-service teachers were asked to maintain a written log of their experience. At the onset of the study I provided each participant with a bound journal. The journal was intended as a tool for pre-service teachers to critically reflect on their field experience and to specifically identify and describe the ways they encountered, made sense of, and responded to sexual and gender diversity. Pre-service teachers were encouraged to produce, on average, 10 minutes of writing each day they were in the field. Inside the front cover of every participant's journal was an insert (see Appendix I) that summarized the purpose of the study and logistical information such as the suggested writing frequency. Additional guidelines included the content of journal entries. Participants were informed that while the focus of this study was centered on their field experience, they may have chosen to include how relevant issues (i.e. sexuality and gender) were experienced throughout the program. They may have, for instance, considered how TPP classes and/or required course texts related to the topic of the study. 
Content-specific journal entry ideas and prompts were located inside the back cover of all journals (see Appendix I) to assist participants in thinking about the ways that sexuality and gender were represented in their immediate school environment. The insert read, for example, "Write down striking words, images, phrases, or details found in your school/ classroom. Speculate about them. Why did you choose them? What do they add to the experience? Why did you notice them?" (Appendix I). Another suggestion outlined in the journal insert encouraged participants to observe their cooperating teacher instruct a lesson looking specifically for intentional or unintentional content pertaining to gender or sexuality.

Participants were asked to bring their journals to individual interviews and group conversations in order to recall experiences and reference recorded information. Persuading participants to bring their journals also provided an opportunity to ensure that such data was being recorded. Journals were collected from participants during final oneon-one interviews (March 14-18). At this stage of analysis and coding, journals were kept in a locked cabinet until they are returned to participants or destroyed in October 2014.

There were many advantages to having participants hand-record data into a physical, bound journal. For one, participants recorded pertinent events and/or emotions as they were experienced. Given that research spanned over fall and winter quarters when pre-service teachers were expected and coached to actively observe classroom climate and teacher/student behavior and interactions, this was a prime time to record phenomena as it occurred. The open-ended nature of the journals also offered freedom and choice with regard to what and how pictures and words were recorded, as well as when data was 
entered. The front and back inserts provided constant reminders about journal guidelines and potential writing ideas, but there was choice and variety within the process.

There were, however, limitations to using physical, bound journals as well. In the age of electronic calendars and virtual correspondence, participants may have forgotten to record data in their journals, or perceived the task to be antiquated and/or laborious. In addition, if participants failed to bring their journals to individual interviews and group conversations then it was difficult to ensure that consistent and accurate data entries were being recorded. Finally, from a researcher's perspective, decoding and transcribing handwritten text was time intensive and arduous. To address these limitations I offered both a physical, bound journal for participants to record data (described above) as well as an email prompt that participants voluntarily responded to once every two weeks.

Electronic prompt/response submissions. Implementing bi-weekly electronic journal prompts satisfied a goal of case study research, which is to gather as much data from as many sources as possible, and also accommodated participants' diverse learning styles and needs. I sent one email every two weeks. This data collection strategy was available to all participants and spanned over the entire course of the study. Emails contained one or two voluntary questions/prompts and participants were informed to spend an average of 10 minutes writing a response. Participants were encouraged to submit responses directly after composition. I read and filed electronic responses into appropriate computer folders for easy access and coding.

Participants were given the option to keep a journal and/or respond to email prompts. Encouraged to do either or both, it was my hope that participants would choose 
a method that they found most effective, which in turn, would produce ample data. As with journals, the electronic prompt/response strategy contained both positive and negative features. On the one hand, authoring bi-weekly prompts granted me greater control over the content and direction of thought. Also, this method had the potential to focus the discussion, which supported participants in articulating their experiences and also aided in the organization and coding of data; data, which because it was collected immediately, was used to inform my work throughout the process.

On the other hand, one reason participants relied more heavily on their physical journals was because emails almost always required participants to recall experiences from their past rather than focus on (and document) events, emotions, and experiences that occurred in the moment. Also, while zooming in and responding to a specific prompt can stimulate some individuals, others can find such focus confining. Thus, through constant negotiation and dialogue, participants found what on-going journaling strategy or combination of strategies worked best for them.

Artifacts. Multiple sources of documentation, or artifacts, served as points of data. My written correspondence with participants was one example for analysis. Artifacts also included written and/or authentic materials that participants shared with me in individual interviews. I photocopied and time-stamped these records and attached an artifact summary form (see Appendix $\mathbf{J}$ ) before filing them accordingly.

\section{Data Analysis}

The study was designed to be heuristic by producing data designed to clarify the reader's understanding of the phenomenon (i.e. how pre-service teachers identify, 
articulate, and respond to queer issues in their field placements). According to Merriam (2009), a heuristic study illuminates understanding and "can bring about the discovery of new meaning, extend the reader's experience, or confirm what is known" (p. 44).

As outlined in my data analysis procedures (see Appendix K), I reviewed and transcribed data as it was collected. I saw this as valuable in order to guide decision making throughout the study, and also to begin constructing categories. I used the margins of transcripts and documents to record notes, comments, and observations. Following the guidelines of Miles and Huberman (1994), I gave myself permission to change codes and categories as I collected and analyzed data using ATLAS.ti. Once all data were coded, I evaluated my classification strategies and made appropriate adjustments such as renaming or collapsing certain categories.

Findings are presented in two distinct and sequential ways. First, I zoom in to expose one or more unique incidents experienced by each participant, or case. These critical encounters relate to sexual and/or gender diversity and were perceived to have impacted participant experiences in the field. Following a holistic analysis of each case, I zoom out to examine themes and sub-themes that emerged across the data. I attribute the language of this zooming method to my university mentors, Christine Chaille and Emily de la Cruz, however the methodology is most commonly associated with Yin (2009). This technique, he writes, "Treats each individual case as a separate study. In this way, the technique does not differ from other research syntheses-aggregating findings across a series of individual studies" (p. 156). 
As I engaged in the various stages of data analysis, I continued to communicate with research participants, record information in the research log, and refer to literature for similar or divergent findings. Ultimately, I aimed to produce a qualitative report that is rich and vivid, complete with quotations from participant interviews and field notes, as well as narrative vignettes that are extracted from observations. 


\section{Chapter Four: Findings}

This present study examines how pre-service teachers encounter, make sense of, and respond to sexual and gender diversity. The results are reported here in two sections: Individual case descriptions and a cross-case synthesis. Section One presents general case descriptions for all eight participants over the course of seven months in the field. Each case is described holistically by highlighting important contextual information and illustrating unique and critical events experienced by each participant. By unique I mean that the encounter is exclusive to a given participant's experience. I use critical to suggest data that had a profound impact on a participant and/or data that emerged multiple times and/or across multiple collection methods (e.g., within an interview and journal entry). Section Two offers a cross-case synthesis, which includes a description of themes and sub-themes that emerged across multiple, if not all, participant experiences.

\section{Section One: Case Descriptions}

Jack. In August 2010, Jack was assigned Willow School for his yearlong student teaching placement. In contrast to a neighborhood school, Willow operates on a lottery system to enroll K-8 students with special interests in math and science. Approximately $42 \%$ of the student population $(\mathrm{n}=360)$ has been identified as talented and gifted (TAG) and there is little racial, ethnic, and linguistic diversity. Jack was one of seven teacher candidates within his cohort placed at Willow.

Mrs. Turner, a veteran teacher at Willow, was assigned to mentor Jack as he engaged in a full range of teaching responsibilities in a first grade classroom. Although the two maintained open communication and professional respect for one another, Jack 
characterized their relationship as rocky, in part, because Mrs. Turner struggled to understand a major aspect of Jack's identity. Jack identifies as a trans male. He was born with female genitalia, but inside his mind and heart, he is a man. Jack self-injects testosterone weekly and is referred to by trusted friends and family as he... His identity expression at Willow is a different story.

Most of Jack's encounters with queer issues in the field are unique, owing to his queer identity. Outing himself in the beginning weeks of the program, Jack told members of his cohort, including his cohort leaders, that he was transgender. He was met with some genuine questions, but overall he felt his cohort understood him and offered their unconditional support. Later he admitted that it was his peers' overwhelming backing that encouraged him to come out to his cooperating teacher, Mrs. Turner.

She was like 'can I ask why your voice is so low?' and I was like sure...it's kind of a big secret here. I said, in the rest of my life, I'm a guy and people refer to me as a he. I said it's going to be really weird being $M s$. [Jack Waters] here. I was hoping to get around that and use my first name, but they don't do that at this school. (Jack, interview, September 26, 2010)

Jack described Mrs. Turner's reaction to his trans identity as "cool" at first, but as the year progressed he found her lack of support and understanding discouraging (interview, January 19, 2011). Although Jack found it difficult to pinpoint a specific 
downturn in their relationship, he described one incident that was particularly disheartening; it involved two cohort colleagues also placed at Willow. Jenny and Townes are so mad at my CT [cooperating teacher] because Jenny was talking to my CT and she was referring to me as...'blah blah blah he' and my CT was just like, 'oh no Jack is she in school'. Jenny was like, 'but no one is here and he's a guy' and she was like not in school. The way they describe it, it was after hours and no one else was around. Jenny was upset and she didn't want to tell me, but Townes was really mad and she was like, 'I just felt like you had to know because this is your teacher and I want you to know what she's thinking about you'...I was glad she told me. (Jack, interview, January 19, 2011)

Although his relationship with Mrs. Turner was "rocky" at best, his connection to his first graders can be characterized as influential, inspiring, deep, and meaningful. After inner debate and a candid conversation with his cohort leaders, Jack decided not to come out to his students or the greater school; he said he "passed" more easily as a female. He also feared parent/community backlash and questioned the stance TPP would take on his behalf. When I asked if he felt like he had support from the teacher preparation program Jack responded:

Um I felt like I had a lot of support from you actually. Actually like the only reason I considered coming out was 
because of like your support and I hadn't even considered it and then you were like we have your back and like we'll totally be there for you whatever you want and everything and that was like really encouraging and exciting to me and I was like yeah I can do this. And then I just decided not to because like you weren't my supervisor at the school and I didn't get that support from anywhere else. (Interview, January 19, 2011)

Perhaps most troubling is the cognitive dissonance Jack experienced and transmitted on a daily basis when his students branded him Ms. Waters. "I feel like the kids see me and I really want to be honest with them...like they know something is a little different about me" (Jack, interview, January 19, 2011). One can surmise the courage it takes to acknowledge one's assigned sex at birth contradicts one's core gender identity and then explain and defend this to members of a heteronormative and transphobic society over and over again. He knew this program would be difficult regardless of his decision to come out or stay closeted. Although Jack was as prepared as he could possibly be, he confessed that at this stage of his journey, the year has been particularly discouraging.

I really have to psych myself up every night before I go in there...like it's okay, I'm gonna do this and it's going to be great! It's about the kids um but it's really hard and so I like go in there and I feel like I would have so much more 
energy to bring if I could just be myself. (Interview, January 11, 2011)

In addition to his queer identity, Jack encountered issues around gender stereotypes and heteronormativity that directly involved his students. In fact, school-wide controversy surrounding gender equity surfaced before students' first day of school because, as Jack explained, “A lot of parents were stressed about the kindergarten class being primarily boys; they were concerned that the lottery had been tampered with" (interview, September 28, 2011). A group of parents voiced concern to the principal about the overall school population consisting of $61 \%$ boys and $39 \%$ girls, and then promptly wrote a press release which was sent to the local news and television stations. Media picked up the story and reported their conclusion that Willow was favoring boys over girls in their enrollment selection process (See Appendix L). In an interview (September 26, 2010), Jack reflected on the staff meeting that discussed the issue:

Some teachers started talking about class management and "boy energy"...I hate that shit! It's used to pigeonhole kids! The third grade teacher responded, "It's the girls in my class who are the noisiest!' See! Generalizations don't work!

Jack also debunked stereotypes that he noticed in his classroom on a regular basis. One particular incident included a male-bodied first grader who defied traditional gender preferences for reading material. Mrs. Turner called the student out on his choice to read a book from The Rainbow Fairies series, which visibly embarrassed him in front of his 
peers. Jack noted that Mrs. Turner would not have asked the same question, or with the same tone of voice, if the student had been reading a book about baseball, for example. Jack found it uneventful that a male student would choose to read a fantasy book of this sort, and in a private conference with the student, Jack encouraged him to continue to read any books which he found personally interesting.

Mrs. H. Across from Jack's classroom in the primary wing of Willow School sat Ms. Jones's second grade classroom. Ms. Jones started out the year accompanied by a teacher candidate named Mrs. H. Young and eager with a passion for teaching, Mrs. H immediately stood out among fellow cohort members as a highly thoughtful learner. Her pensive nature and willingness to engage, however, were put to a test by this particular group of learners who were infamously referred to by school staff as the problem class. Indeed, Mrs. H encountered challenges, some of which related to gender and sexual diversity. During the first four months of the study, Mrs. H discussed in vivid detail several incidences she observed involving a second grader named Jessica.

[Her] father writes graphic novels and her mother screen writes for graphic novel films so they take her to a lot of premieres that are not developmentally appropriate. She talked about how a few weeks ago she went to see the premiere of Scott Pilgrim Versus the World. She said there was a scene in the movie with a naked boy and girl that made her feel funny...she said she enjoyed watching it. That really blew me away. I had really not fathomed these 
issues would come up this early, at age seven. (Mrs. H, interview, September 30, 2010)

As defined previously, sexual diversity encompasses a range of emotional, erotic, and/or physical attractions toward others. In this case, Mrs. H encountered, and attempted to make sense of, Jessica's sexualized behaviors towards others, including both male and female peers. Mrs. H observed the student trying to kiss and rub her chest against classmates numerous times. In a journal entry marked September 22, 2010, Mrs. H wrote, "One student came up to the teacher and told her that Jessica kissed her repeatedly and wouldn't stop after she asked her to." Within the same entry she also recorded, "I heard her say 'Do you know about sex and kissing?' to another boy in the class as we walked to lunch. I told her these things were not appropriate to talk about at school!"

During an afternoon visit I observed Jessica's behavior firsthand. Students were playing a board game called Upwords, which like Scrabble, challenges them to create words from a collection of letter tiles. Jessica noticed that she could spell the word sex given the seven letters she possessed. After sharing giggles with friends, she marched up to Ms. Jones and asked, "Would it be inappropriate to spell the word sex?" (Direct observation, December 2, 2010). Jessica quickly noted to Ms. Jones that there are multiple meanings of the word. However, given the attention she sought from her friends (and Ms. Jones) it was obvious that she had one particular definition in mind.

As an individual who experienced abuse as a child herself, Mrs. H was keenly aware of, and predictably triggered by, possible antecedents that could explain Jessica's ongoing inappropriate, sexualized behavior. Courageously, she initiated a conversation 
with her CT, which according to Mrs. H, was met with transparent denial and fearfulavoidance. In an interview, Mrs. H revealed:

I've had boys in class come up and tell me that "she's doing this and it makes me uncomfortable" and to me it's like a flashing red light. It's huge and you know the teacher is kind of looking the other way and not really addressing it. She's talked to her but you know she's seven years old, she's not going to address these issues by herself.

(September 30, 2010)

Mrs. H broached the topic of Jessica with her CT over a dozen times and yet nothing was done beyond throwing verbal reprimands at the child. In response, Mrs. H finally spoke with the school counselor who greatly appreciated Mrs. H's communication and promptly called a meeting with Jessica's parents. It was about the same time, after weeks of agonizing about the neglect concerning Jessica's behavior, and after seeking ongoing guidance from her program mentors, that Mrs. H resigned her placement at Willow School. She decided that the classroom environment was too unsafe and emotionally debilitating to continue. In reflecting upon the sequence of events that led to getting Jessica help, and ensuring her own constructive growth in the program through relocation, Mrs. H said:

I embraced this extra challenge with the knowledge that these things do exist and I can't look the other way. These kids need guidance and that's what I'm here for and I'm 
not going to just act like it's an easy road because it's not and I really want to make sense of this and figure out how to mediate these things and how to address these things positively and constructively so we can have teachable moments instead of moments when things go wrong and we look the other way because we're uncomfortable.

(Interview, September 30, 2010)

Mrs. H moved to Spruce Elementary to complete student teaching I and II in January 2011. She was paired with a fourth grade teacher, Mrs. Banksy, an individual Mrs. $\mathrm{H}$ described as caring and highly skilled in effective instruction and classroom management. Although she found the knowledge, skills, and dispositions of her mentor teachers to differ greatly, she noticed one striking resemblance between the two schools: Willow and Spruce presented issues surrounding sexual and gender diversity. At her new placement, she encountered a boy, Joey, "exhibiting signs that he may not be sure of or comfortable with his sexuality...that he might be gay" (Mrs. H, interview, January 13, 2011). Mrs. H's intuitive assessment was based on non-verbal cues (i.e. flamboyant mannerisms) and his rejection of traditional gender roles (e.g., he reads princess books, and wears flashy clothing and stereotypically feminine accessories). A person's sexual orientation is distinct from a person's gender identity and expression and Mrs. H. couldn't pinpoint whether Joey was perhaps experiencing gender dysphoria and/or developing same-sex attractions. She consulted Mrs. Banksy in an effort to make further sense of Joey's experience. In her journal (January 15, 2011), Mrs. H wrote: 
He's still just figuring things out and to me that signals that he's just in a fragile place and we want to make sure we're supporting him. I see other kids picking up on it and I just wonder if that's going to become a problem...I'm afraid he might be susceptible to bullying. (p. 46)

This time Mrs. H's cooperating teacher was likeminded and the two began talking about ways they could support the student's positive identity development in the classroom. Mrs. H recalled one particular conversation they shared:

It was very supportive and we were both on the same page. You know, like that's great, he should be whoever he wants to be, and we just want to make sure that it's a safe environment for him. [Mrs. Banksy] even used "safe environment" like as a term, it was just great. Maybe he's not even necessarily aware of what he's feeling or what kind of confusion is going on and maybe even aware that there's that support there from her and I but I think he knows that with whatever he wants to do that he would know that we want what's best for him and I think that's what makes all the difference. (Interview, January 13, 2011)

At the conclusion of the study Mrs. H was asked to reflect upon her findings of gender and sexual diversity in both placement settings. She made sense of the question by 
comparing the two prominent learning experiences offered first through her encounter with Jessica, followed by that of Joey. She said:

Again and again I asked myself, how can I best help these students? Especially with regard to that first student where I was really concerned there was some things that shouldn't have been happening going on um I really just looked at it and reflected on the situation on how can I work with my cooperating teacher who maybe wasn't having the same focus or trying to really support the student in that way. I mean they are very different scenarios but in terms of the greater the issues or the greater focus of discussion in terms of gender and sexual issues I think that [Jessica] really was crying out for help and doing things to get attention almost being ignored and to be kind of the only one, I felt, on the forefront for her I felt was really hard for me especially in my first experience in student teaching and being thrown into all of this and I was really you know really taken back by that. (Interview, March 16, 2011)

Although Mrs. H discontinued her interactions with students from Willow School for the duration of the program, she occasionally checked in with a cohort colleague placed there. In a journal entry marked January 28, 2011, Mrs. H wrote: 
There are a few students in particular who I still check up on and am worried about. When I asked about a female student who I had observed acting out sexually last term, this colleague said that she was "turning into a little lezbo" and was "kissing all the girls." Although I didn't let this person know at that time, I found their choice of words personally offensive, particularly because I had opened the conversation expressing concern for this student. In reflecting upon this, I wonder if these covert messages of unacceptance are being conveyed to her and whether she will grow to feel ashamed of who she is attracted to. (pp. $51-52)$

Quercus. In addition to housing Mrs. H for the latter part of the school year, Spruce Elementary also served as Quercus's field placement. He worked among a triad in a fourth grade classroom; Mrs. North served as his cooperating teacher and Heidi was his cohort colleague and co-teacher candidate. The three engaged in collaborative planning, and shared instruction and management responsibilities in the classroom. The composition of his triad model affected Quercus in ways that he hadn't anticipated, and that also directly relate to the research study. Early in the program, he pointed out that he was the only male teacher candidate paired with a female cooperating teacher (please note Jack's exclusion here because Jack presented as female in his field placement). The additional four male teacher candidates in the cohort were unintentionally matched with 
male cooperating teachers. Although Quercus valued members in his triad, he attributed an initial inefficient negotiation of his "teacher voice" and authority to the gender imbalance. Mirroring his immediate colleagues, Quercus discussed the conflict he experienced in his stereotypically feminine approach to classroom management:

I see people instinctually as equal...we're all very different, but I try to approach people as much as I can as equals. I try to treat them as how I would like to be treated. I did this last term...and it didn't work. And I attribute some of that to me being male and me behaving with some reservations. I didn't want to take over...I didn't want to so I was kind of doing the traditional feminine approach. It's really interesting [students] voice their confusion when you don't match their gender role associations. (Quercus, interview, January 12, 2011)

Throughout the study, Quercus maintained a high level of awareness of his selfand perceived identities, as well his influence over students' development of identity. He systematically reflected on his own gender expression and recalled moments when students questioned his hair length or style of dress, which he felt attacked his masculinity. His connections to identity transcended self and encouraged him to understand how structures in education and school discourse can affect student identity. Written journal entries, as well as transcripts from both group conversations and 
individual interviews, illustrate his desire to make sense of his experience. In an entry dated September 27, 2010, Quercus wrote:

We separate students by boy/girl to serve various purposes.

A tool. This may simplify the grouping process for teachers

but it does reinforce the notion of gender, sex, and their

various stereotypical inequalities. So the question is: Does

this harm? And if so, how much and in what ways? (p. 8)

Employing the use of metaphor assisted Quercus in answering his question. In the same

September entry he recorded, "Consider a person as a mason. They are the self-

determining factor in the construction of their identity. The supplies they use to build this identity are the outside influence..." (p. 9).

Figure 1. Quercus' Understanding of Teachers' Responsibility to Deconstruct the Gender Binary System

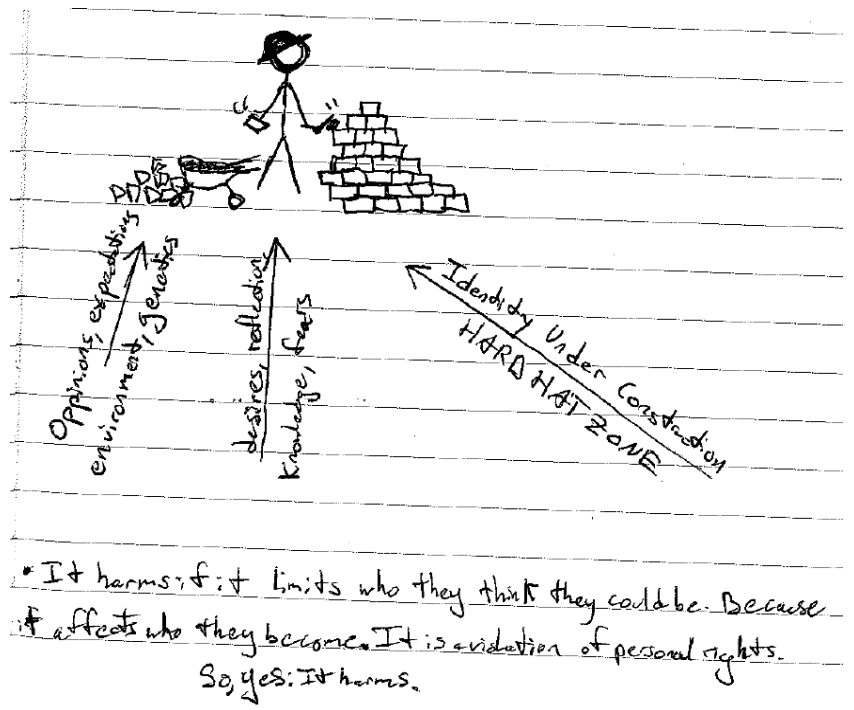

Figure 1. Image and writing representative of a teacher's role in developing healthy student identities given the threat of a gender dichotomy that separates girls and boys in schools across the nation. Taken from Quercus' journal (September 27, 2010, p. 9). 
As shown in Figure 1, Quercus concluded that teachers potentially harm students when they utilize tools to separate individuals into gender binaries. According to him, harm ensues because binary systems and dichotomies limit notions of who students think they can be, and who they may ultimately become.

Moses. Like Quercus, Moses encountered a sensitive negotiation of his gender and overarching assumptions surrounding gender expression within his triad at Spruce Elementary. Moses shared teaching responsibilities with a male mentor teacher and female co-teacher candidate named Nel. His cooperating teacher, Mr. Swimmy, provided solid leadership, guiding the three in effective collaboration that directly led to student learning. Despite this triad's ability to orchestrate a healthy working relationship over the course of the year, Moses remembered a couple of instances that could have potentially caused tension.

I have noticed that [Mr. Swimmy] seems to give [Nel] more of the clerical tasks and me more one-on-one or group instruction opportunities. But, I think that's because he knows I've worked with low behavior kids, but it also seems like we're going to give the girl the secretarial tasks and the guy the real tasks. (Moses, interview, September $23,2010)$

Moses acknowledged his male privilege within the triad many times and juxtaposed this against an incident that exposed what can happen if the opposite were true. In an interview on January 7, 2011, Moses described an event (overseen by another 
cooperating teacher, Mrs. Henning), concerning a first grader with a habit of missing her mother and who often cried in an effort to be sent home. According to Moses, when Mrs. Henning told him and Nel about this girl she said, "If we help her out throughout the day then [Nel] will probably want to work with her more because she's a woman." To make sense of this he later said:

I didn't know if it was accurate you know cause... I don't know how she'd respond to a man maybe she'd think there would be stricter rules and know that she couldn't just break down and cry and uhhh I know that's like gender charged or whatever, but I didn't think it was necessarily true that $[\mathrm{Nel}]$ would be the better person to work with her. I wanted to help out and join in but seeing as how I was a man I was blocked off from it. (Moses, interview, January 7, 2011)

In another encounter, Moses (and Quercus) described a school staff meeting where the principal mentioned a plethora of toys donated to the school and dispersed among classrooms. After donations were distributed it was discovered that a kindergarten classroom received all pink toys. The principal shared that one boy in particular would be really excited about the shades of pink color palette. Quercus, who was also at the staff meeting, recorded that the principal said, "He is probably so excited about playing with the pink princess clothes" (journal, September 9, 2010, p. 4). Moses remembered, "Everybody laughed at the meeting because it was ridiculous that a boy wanted to play 
with pink things" (interview, September 23, 2010). Moses suggested the boisterous laughter among staff was a response to their discomfort around homosexuality. He said teachers assumed this boy was gay, which disrupted their equilibrium and caused their laughter of distraction. Perhaps what made Moses keenly aware of this coping mechanism was his own uneasiness about homosexuality. Before participating in the study, he voiced anxiety about the topic. In preparation for our first interview, I recorded the following in my research log (September 23, 2010):

Moses is thoughtful and articulate. He likes to ask tough questions that challenge people's thinking. With regard to the content of the study, I know that Moses is somewhat uncomfortable. He communicated his discomfort with issues of sexuality during the multicultural class this summer. He explored reasons for his discomfort in a thoughtful and honest way. In a very open forum, he processed his many encounters with aggressive gay men, and the homophobic beliefs he held, all while living as a homeless man in San Francisco in the '90s.

Although the critical encounters that Moses experienced in San Francisco during the late 1990s precede the present study, it informed his recognition of staff laughter as a psychological coping strategy, which is significant for two reasons. First, deducing the root cause of staff tongue-in-cheek rhetoric and corresponding laughter allowed Moses to reflect upon, and make sense of, his prior discomfort surrounding the topic. Second, 
through dialogue embedded within the structure of the study, Moses came to see his criticism of staff members as a measure of his own growth toward queer acceptance and understanding.

Christine. Another teacher candidate, Christine, was immersed in student diversity at her placement site. Juniper is an urban elementary school with significant cultural and linguistic diversity. Although most student families are from similar working class backgrounds, they exhibit a wide range of social and cultural capital. Christine grew up in generational poverty and attended only two years of formal public schooling before entering an alternative high school completion program. Her own unconventional education helped her relate to Juniper students.

It is noteworthy that a member of Juniper's administration is an "out" lesbian who often brought her partner and their child to school events. Despite overwhelming acceptance for this staff member, Christine said heteronormative discourse ran rampant among staff and students. She documented specific instances in her on-site journal. On September 13, 2010 she recorded a conversation in which a group of third graders were talking about Justin Bieber, a pop culture icon. Christine wrote:

A boy said that the girl next to him couldn't like the music because he [Justin Bieber] was gay. The little girl said she could still like his songs even if he was. This just egged the little boy on. He taunted her saying, 'you can't he's gay, he's gay, he's gay.' (Journal, p. 6) 
Christine realized the student interaction, while saturated in misunderstanding, did not itself present gayness in a pejorative way. Still, she felt a need to interrupt or guide the dialogue. Turning again to her own words, Christine (September 13, 2010) recorded:

I wanted to intervene but at the same time the teacher was in ear shot and I observed her do nothing. I never know if it's okay to say something or not. It was wrong, but it's her classroom. Reflecting now, I should have said something but in the moment I looked to the teacher not knowing what to do. (Journal, p. 6)

Three days later Christine visited a kindergarten classroom down the hall. She noted, "It was interesting to me how much gender was being literally taught" (journal, September 17, 2010, p. 8). She went on to describe how her cooperating teacher excused students to their cubbies according to gender, saying, "boys first! Let's see who knows they are a boy!" (p. 8). Christine then observed some girls put their papers away in their cubbies upon which they were told to sit down because they were not boys. Later that day, during an academic activity, kindergartners were again surveyed according to gender. Christine noted, "I was only there an hour and gender was brought up soooo much" (p. 8).

While there are many noteworthy examples of Christine's encounters with heteronormativity, one final instance discussed here occurred in an after-school staff meeting. On October 4, 2010 Christine described a conversation in her journal which was 
brought up by a fellow teacher candidate named Ramona (also a research participant). Christine wrote:

A student had come up to her and said a guy had given another guy a lap dance and that meant he was gay. It seemed to make our [cooperating] teachers uncomfortable so we didn't really get any advice on what to do. (p. 12)

In addition to typifying her encounters, Christine continually sought meaning from her experiences and reflected on actual (and possible) responses. On November 25, 2010 she emailed:

Students start forming biases very early in life. Imagine how different our world could be if we never created this stereotype of heterosexuality being 'normal' and anything else being “abnormal." If we can teach students very young that neither is wrong, neither is better, and somehow perhaps take away the either or issue all together, then our job of promoting social justice would become a lot easier. The preceding examples are only three of the many ways in which Christine stumbled upon sexual and gender diversity at Juniper Elementary. She also connected the research study to her encounters on campus as a graduate student. On November 11, 2010 she sent this email:

I think that [TPP] faculty needs to be very aware of what they say about gender. You are very conscious of the things 
you say but other faculty members aren't so careful. Often I have seen stereotypical gender roles being taught and added to stereotypes. I think that they should be more aware of how they talk.

Beatrice. Juniper Elementary opened its doors to another teacher candidate, Beatrice. In fact, she and Christine worked as two legs of a triad in their third grade classroom. Led by their mentor teacher, Miss Chops, the three engaged in collaborative planning. Over the course of the seven month study, Beatrice maintained diligent notes in her journal, responded to nearly every email prompt, and engaged in every interview and group conversation. A recurring theme that emerged from all sources of her data set was the notion of gender as a social construct that can be driven by, and also lead into, stereotyped assumptions. Beatrice examined instructional language, curriculum, student discourse, and her own assumptions around gender and sexual orientation, to arrive at telling conclusions about the journey of negotiating gender and sexuality in a third grade classroom.

Beatrice's reflections began on the first day of school. Students were charged with a task to decorate personal nametags. As a preamble to the artistic endeavor, the class engaged in a short discussion about what is, and what is not, an appropriate school illustration. Beatrice recalled boys dominating the conversation with requests to draw weapons, such as army jets and machine guns. Her cooperating teacher silenced the dialogue with a no weapons policy. Viewing the end products, Beatrice (journal, September 8, 2010) noticed, “There were as many boys as girls who'd drawn little 
geometric designs or put a flower on their nametags" (p. 5). The exercise challenged some core assumptions Beatrice held about masculinity as she questioned the authenticity of male's desire to depict violence. In actuality, the boys seemed very content to abandon their war crafts, which caused her to consider the peer-pressure to preserve a stereotypical tough image that male students experience. In a journal entry dated September 8, 2010, Beatrice wrote:

[It] makes me wonder if some of the conversation was happening not because they actually intended to draw anything dangerous but because of the need to seem tough in front of their peers by acting like weapons were interesting to them. (p. 5)

According to Beatrice, her third graders conformed to gender stereotypes because "The desire to be liked by classmates is the focus for most students all day" (journal, September 8, 2010, p. 27). Schools intentionally divide students by gender for instructional and management purposes. Based on observation, Beatrice felt this gender segregation encouraged students to conform to high levels of stereotypically masculine and feminine norms in order to be liked by their peers and live up to expectations of school culture and global media images.

An email prompt (December 26, 2010) delivered to research participants asked them to comment on the following quotation (Levin \& Kilbourne, 2008):

Children growing up today are bombarded from a very early age with graphic messages about sex and sexiness in 
the media and popular culture...Children are paying an enormous price for the sexualization of their childhood. Girls and boys constantly encounter sexual messages and images that they cannot understand and that can confuse and even frighten them. Gender roles modeled for children have become increasingly polarized and rigid. (pp. 4-5)

Beatrice connected the quotation to her male students' obsession with the gaming world and associated propaganda. She agreed with the quotation that children today are being surrounded by violent and sexual images/ideas that they will most likely not understand. Day after day she overheard her male students talking about one particular video game, Call of Duty: Black Ops, which she viewed as highly violent and inappropriate for her students. Beatrice wrote:

When I got online to see what the game was about the website wouldn't open until I entered my age. Reading about the game and the violence that it involves makes me wish that the students in my class were not so excited about it. I do think that the boys in this class who I have talked to are really attracted to the violence of the game and they would consider it pretty weak if one of them wasn't interested in that violence. I think they identify the violence as a male interest. None of them expected me to be interested and they assumed that I would know nothing 
about the game (which I didn't) and I am assuming that is because I am female. (Email, December 26, 2010)

Beatrice thinks the classroom should be a place to talk about these ideas, but her cooperating teacher never discussed violence and sexuality in the classroom. In an interview on January 12, 2011, Beatrice said, "We could have a productive class conversation. I think that more opportunities for discussion would give students time to reflect on the images and ideas that they see." In fact, after her encounters this year she believed that teachers have an obligation to address such violence with students.

You know you can feed the kids two to three meals a day, they get their vision and hearing checked...we just had a dental screening. I mean there are all these things now that are a part of what's happening at the school and so it really feels, at least in this instance, I feel like if we're taking these extra steps for their physical wellness then we do have a moral obligation to their mental, behavioral, and emotional wellbeing. (Interview, January 12, 2011)

Direct observation of student concerns and behavior reinforced Beatrice to turn inward and consider her own pre-conceived notions of gender. She confronted her assumptions in a journal entry dated September 13, 2010.

Within the classroom I am working hard not to start stereotyping the students. I am getting to know them just well enough to where it is hard not to just categorize them. 
There are a group of cis-girls who are quiet and well behaved. I found myself surprised today when one of them was not in a higher reading group. Her quietness and organized behavior led me to assume something about her current reading level. (pp. 6-7)

Another encounter that was unique to Beatrice's experience included specific instructional language used by a substitute teacher. Upon thoughtful reflection, Beatrice noted the repercussions of using exclusive, heteronormative discourse such as "mom and dad" when referring to students' families. This exclusivity, she noted, is avoidable and can ostracize students for various reasons. The substitute teacher also perpetuated traditional gender roles when introducing vocabulary words associated with a read aloud. She defined laundry as something a mom does at home. This struck Beatrice as misogynistic and classist. She thought the narrow definition could alienate students with same-sex parents as well as those not having an at-home mother or access to laundry. Sexist, heterosexist, and transphobic language also penetrate the curriculum. Beatrice recalled her students watching a School House Rock video that featured, "Three is a Magic Number". Although she had listened to, and sang, the lyrics as a child, Beatrice was surprised by what she heard, "A man and a woman had a little baby, yes, they did. They had three in the family, and that's a magic number." She wondered how many of her students had families that fit this description. She wrote, "The heterosexualcouple assumption didn't surprise me, but it did bother me" (journal, p. 25). 
Townes. Requiring a mid-level placement, Townes landed at Willow School where she instructed seventh and eighth graders in mathematics. Like many research participants, Townes was a member of a triad. She worked alongside her co-teacher candidate, Travis, and cooperating teacher, Mr. Kubasak. Interestingly, and unintentionally, the cooperating teacher in her guest placement classroom (also within the building) was also male. One recurring theme in her data was negotiating her identity and gender expression among a group of white, middle-class, male counterparts.

Townes is Asian-American. She was adopted by a Caucasian, American family when she was a baby and grew up with brothers and sisters of varying racial and ethnic identities. I came to know Townes as a hard-working student. She was passionate about mathematics and possessed sophisticated knowledge in the subject. In her first individual interview, Townes voiced frustration with living this stereotype (i.e. an Asian-American girl who excelled at math). As a student she resented people who assumed mathematics came easy for her and spent most of her childhood masking her interest in mathematics in an effort to be popular. Townes admitted:

Females are supposed to be cute and little and passive compared to male peers. I see girls in my class now and it reminds me of the way people treated me when I was that age. I did hide that I was good at math. I relate to that pressure to be attractive...you don't want to be too much of a nerd or too smart...you don't want to fall into that 
stereotype because for some reason it's not attractive.

(Interview, January 9, 2011)

Townes realized that her own gender construction was strongly influenced by societal norms. This thought was in mind as she reflected upon the ways her seventh and eighth grade girls interacted with peers. Over the course of the year she came to many generalizations based on observable behavior. One particular student, Brittany, exemplified Townes's assertion that girls tend to dilute their intelligence and focus more on social rather than academic aspects in order to impress friends, increase popularity, and attract crushes. One day Townes overheard Brittany voice concern about riding the bus home because, according to Brittany, every time she took public transportation the police got involved somehow. As she began to recall details, a male student spoke up and said, "Stop acting so stupid" (Townes, interview, January 19, 2011). The girls at the table laughed and she engaged in conversation with the boy as she now had his full attention. Townes' point was that Brittany often masked her intelligence (she is incredibly bright) behind a veil of make-up and sparse clothing as well as mannerisms that perpetuate the image of a mature socialite. In fact, her projection of this socially constructed and highly reinforced identity was so revealing that Townes' cooperating teacher expressed visible shock when Brittany won a prestigious school-wide math award.

Narrow assumptions about gender surfaced in Townes's work sample as well. She wrote and illustrated a multi-step mathematical word problem that featured two skateboarders. Her co-teacher candidate, Travis, specifically wanted two boys skating because there were two skater boys in the class. Townes interjected, "Oh, well I skate and 
I'm like really good at it so let's name one of them a more generally feminine name" (interview, March 31, 2011). Examination of completed assessments containing the word he revealed that many students assumed both skaters were male, despite having named one Cheyenne.

Finally, a broader issue Townes encountered was an unequal distribution of attention provided to males. Townes often tried to make sense of this and although she never determined whether it was intentional or unintentional, she noted the imbalance persisted throughout the study. She also became aware of her cooperating teacher's habit of interrupting females in mid-sentence to request they speak louder. Townes offered that Mr. Kubasak probably doesn't understand that girls are socialized to speak quietly and that many educational settings encourage girls to appear introverted. When asked how she would serve as a role model to counteract this, Townes (interview, March 31, 2011) said:

Regarding gender and sexuality, I hope to push the envelope of what is socially accepted. I'm going to be standing in front of students as a real-life female who is good at math and who is opinionated. Essentially I really want to be a subtle example of something students, girls in particular, can return to later and be like...I remember her, she was licensed to be articulate and opinionated, and lead the class as a good mentor. 
Townes, who has known Jack for over three years, found it difficult to interact with him in and out of Willow school. She admitted that she often confused his pronouns and felt terrible when she made a mistake. They knew each other so well that I heard from Townes before Jack ever told me, about the reason for his trepidation in not coming out. Townes (interview, September 26, 2010) confessed:

If I can be really honest, I don't want to speak for Jack, but I do know that if she, I mean if he, felt like he had back up from his site supervisor, which is our other cohort leader, I'm sorry, but ummm if he had, then he would have been out, is what sh-...he told me.

Townes, who has had relationships with women in the past, empathized with Jack's need to feel supported. She admitted:

It's like having that person who has your back...that's like, if teachers or parents are questioning it, they have authority and connections in schools to say 'no, it isn't a problem'. I think it is disappointing that this didn't happen. (Interview, September 26, 2010)

On another occasion, Townes said:

It's been really difficult to accept him as a male when for the majority of the time I see him at [Willow] school and have to say she...and I see him dressing in a way that hides the fact that he's a he. I see him wear a lot of skirts and I'm 
always like what a cute outfit and it reinforces that confusion for me. I just think it's insane that we're still at this point where he can't be who he truly is. God, it's taking forever for these kinds of inventions to die out. So...what would it look like if he was able to be out? It would be so positive. It would be so rad and I think it would be such a great experience for his students. (Interview, January 9, 2011)

Townes was not alone when it came to making sense of trans identity. Over the course of the seven-month study, she engaged in dialogue with teachers and teacher candidates at Willow who didn't know which pronoun to use for a colleague or student that appeared gender non-conforming. Although Townes confessed to experiencing discomfort at the time, she was pleased to have these conversations within her building. Still, she thinks the school as a whole has a long way to go before taking gender and sexual diversity issues seriously. At the beginning of the year, staff staged a school-wide assembly to communicate behavior expectations and dress code. Townes and Travis were asked to adorn human-size paper doll clothing for staff to carry out a skit. When it was over, Townes described the transphobic and sexist nature of the presentation.

The teachers were joking around about having people cross-dress...like Mr. Kubasak wearing a really short skirt. I said I didn't want to do that, that I thought it was disrespectful, but I noticed during the assembly that 
teachers did switch their paper doll clothing and pranced around in a way that mocked all kinds of people I know and love. Everyone laughed. (Interview, September 26, 2010) During recess duty later the same day, Townes observed a teacher and a small handful of students passing around a ballerina tutu, placing it over their clothing, and flamboyantly moving across the soccer field. She was really offended by this mockery of crossdressing and found the entire scene all too common and constraining. The episode was so familiar, in fact, that it triggered a similar incident she experienced on campus:

It happened during one of our classes...he [Quercus] was playing a female role for some skit and everyone was laughing because of how outlandish it was... his feminine mannerisms. Jack ended up writing the instructor an email to voice that it was not okay. (Townes, interview, September 26, 2010)

Ramona. Ramona joined Christine and Beatrice at Juniper Elementary in a third grade classroom located down the hallway from her cohort colleagues. Like many other participants, Ramona started the year writing diligently in her journal. She noted many observations during the initial weeks of school, such as gender segregation and heteronormative language, both of which will be explored in a cross-case analysis presented in Part Two of this section.

Unique to Ramona's experience, however, are two separate incidents that involve students confusing gender in an attempt to negotiate and express their identities. The first 
was when Ramona made her lunchtime rounds in the cafeteria when she came upon one of her students, Alfred, who looked quite sad. When probed, he said he was upset because a student from Beatrice and Christine's class called him a "girly sissy" (Ramona, group conversation, October 27, 2010). Ramona glanced down and immediately understood. She saw a pink lunchbox adorned with a myriad of Disney princesses. She asked him if he liked his lunchbox and when he replied yes, Ramona engaged the girls surrounding Alfred in a conversation that affirmed the boy and perhaps broadened everyone's conceptualization of binary preferences. The conversation uncovered that a girl liked Star Wars and Alfred could hardly believe his ears or contain his excitement. Scooby Doo and SpongeBob Square Pants then entered the discussion, and again, students were amazed that both boys and girls adored these media.

Ramona talked about her encounter with Alfred in a group conversation with study participants. Christine, who teaches the boy that teased Alfred, admitted, "What upset me was that our teacher didn't ask us to address it and this made me mad because I just think it was something we could address as a class" (group conversation, October 27, 2011). When the group asked how their cooperating teacher responded, Beatrice nodded in agreement, as Christine explained:

She just really shut down. I was like...it doesn't matter who teased him...it would be a good lesson for the whole class and she was like 'no I'll just talk to him' and so she pulled [Joey] out of class. I mean she doesn't even know if it was him. (Group conversation, October 27, 2011) 
Following this incident, Ramona requested to borrow a book from me called The Sissy Duckling (Fierstein, 2002) but never read it to her students, as she intended, because she and her cooperating teacher feared parent reaction.

Another incident that caught Ramona's attention, and which is unique to her experience, was her class's creation of I am poems. "They're really neat," Ramona (interview, September 28, 2010) said, “They start off with 'I see' and students fill it out, then they write in 'I hear' followed by 'I am'. When they are finished, they read like, 'I hope, I cry, I...I feel, I am'.”

Figure 2. Jane's I Am Poem

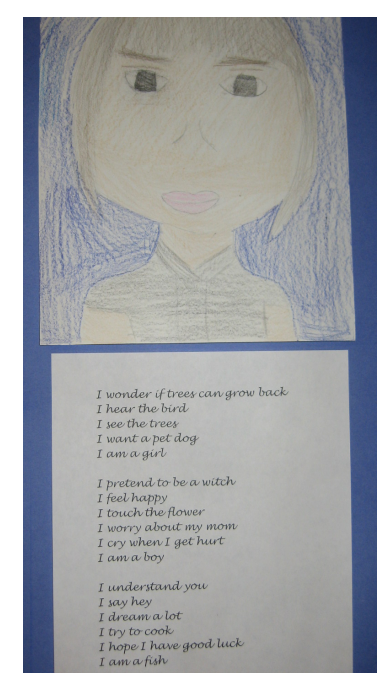

Figure 2. Image of Jane's I am poem, which hung outside of her third grade classroom, featured the words: I am a girl, I am a boy, I am a fish. Artifact obtained by researcher on September 28, 2010).

What made this experience memorable for Ramona was one student, Jane, whose poem, as shown in Figure 2, included the phrases, I am a girl, I am a boy, I am a fish. Ramona noticed that all of the other students identified as boy or girl, brother or sister, 
and she appreciated Jane's level of comfort to write what she did. Ramona did not know quite how, and to what extent, to interpret this as significant. Further, she did not feel safe asking the student to elaborate on her writing, so it was not examined beyond what was written on paper.

As evidenced above, each participant experienced one or more critical encounters related to sexual and/or gender diversity. In addition to their unique familiarity and inner sense-making, several overarching patterns were identified to describe participant experience. The following section describes such themes and sub-themes that emerged across the data, and which respond directly to the research question by naming ways in which participants encountered, made sense of, and responded to sexual and gender diversity.

\section{Section Two: Cross-Case Synthesis}

The preceding data, organized into individual cases, highlight unique encounters, sense-making, and outcomes experienced by participants with regard to sexual and gender diversity. Zooming out, this section offers a cross-case synthesis to reveal themes and sub-themes across multiple sets of data. As outlined in Figure 3, participants' knowledge and realities are examined by first considering patterns in how they encountered sexual and gender diversity. The sub-themes described under the umbrella of participant encounters are (a) gender dichotomy, (b) classroom students perceived to be queer, and (c) participant identity construction. I then describe five categories that emerged from the data to characterize how participants made sense of their experiences. These include: (a) identity and visibility; (b) language in discourse and media; (c) fear; 
(d) the impact of the study on participant experience; and (e) ways in which participants made sense of issues as they relate to components of teacher preparation. Finally, this section illuminates patterns of response (by both teacher candidates and cooperating teachers) to sexual and gender diversity in the field.

Figure 3. Cross-Case Synthesis Themes and Sub-Themes

1. Encounters with gender and sexual diversity

a. Gender dichotomy

b. Classroom students perceived to be queer

c. Participant identity construction

2. Sense-making of encounters with gender and sexual diversity

a. Identity and visibility

b. Language in discourse and media

c. Fear

d. The impact of the study on participant experience

e. Participant sense-making related to components of teacher preparation

3. Responses to encounters with gender and sexual diversity

Figure 3. Outline of Section Two: Cross-Case Synthesis, which presents study findings using broad themes (directly related to the research question), as well as sub-themes which emerged from data analysis.

Encounters with gender and sexual diversity. As noted in the individual case descriptions, participants encountered gender and sexual diversity on a consistent basis. The three types of encounters that emerged across the data most frequently included: Gender dichotomy; classroom students perceived to be queer; and participant identity construction.

Gender dichotomy. "I think what has resonated with me most is how often teachers use gender to separate children, to sort and manage them" (Christine, email 
prompt, October 1, 2010). Similar observations were made as participants encountered what they came to understand as a gender dichotomy. All participants noticed a dualistic relation of gender within the first two days of school. Gender dichotomy, which is the perception of the two main genders (female and male) as mutually exclusive (even diametrically opposed), surfaced in numerous ways. Constructed and transmitted socially, gender dichotomies define gender identity as entailing specific traits, roles, rights and responsibilities (Butler, 1990). As Beatrice describes below, using this binary system to inform instructional practice reinforces dominating patterns of gender and power and can harm students who reside outside socially constructed categories.

The moment that spoke the clearest to me about social constructions of gender identity in the classroom was when my cooperating teacher talked about the class on the first in-service day. Though she had not yet taught any of the students, she was clearly preparing herself for a certain type of class. From her language I understood that she was concerned about having so many boys. She didn't elaborate on specific male students or behavior issues she had heard from second grade teachers. Her preparation for having a more difficult class was purely based on the number of boys on the class list. This means she assumed that she knew the gender of each student before they even entered her room. Since she is most likely the adult that these 
students spend most of their waking hours with, her perception of their gender and their behavior will likely affect them. As these students continue to build and change their identities they are in a situation where certain qualities socially assigned to their gender were assumed based on their school paperwork. (Beatrice, email, October 1, 2010)

Jack's cooperating teacher initiated a similar conversation with him at the beginning of the year. He remembered, "It started right off the bat. She made stereotypes like, of course it will be chattier and more gossipy, but this is going to be a great class because it's mostly girls" (Jack, interview, September 26, 2010). Mrs. Turner went on to talk about how tidy the room would be because female students love to clean. Jack noted:

I don't want to negate her observations because she's been teaching for 25 years so I just nod my head and try to debunk her generalizations every once in awhile. I'm like oh yeah, the girls do seem really clean and you know Stephen is a super clean freak too! (interview)

Although Jack didn’t make any concessions for Mrs. Turner's tendency to categorize students and make assumptions based on gender, many participants made minor allowances for their cooperating teachers' use of a gender dichotomy as a pattern of practice. Mrs. H, Townes, Quercus, Moses, and Ramona perceived their cooperating teachers' language and actions, which created a divide between students based on gender, as unintentional. In his book, Language and Power, Fairclough (1988) explains 
normalizing discourses as the ways of thinking, doing, and being that become so

ingrained in our way of life that we think of them as commonsense.

Over the course of the study, participants named many systems, practices,

management techniques, and isolated events that reinforced gender separation. Table 1

re-presents data that typify encounters participants experienced with gender dichotomy.

Table 1

Participant Observations of Gender Dichotomy as Perceived in the Field

\begin{tabular}{|c|c|c|}
\hline $\begin{array}{c}\text { Gender } \\
\text { Dichotomy }\end{array}$ & Encountered by & Specific Examples \\
\hline $\begin{array}{l}\text { Bathroom } \\
\text { passes }\end{array}$ & $\begin{array}{l}\text { Beatrice, Christine } \\
\text { Jack, Moses, Mrs. H } \\
\text { Ramona, Quercus }\end{array}$ & Separate bathroom passes for girls and boys \\
\hline $\begin{array}{l}\text { Instructional } \\
\text { activities/ } \\
\text { choice times }\end{array}$ & $\begin{array}{l}\text { Beatrice, Christine } \\
\text { Jack, Mrs. H } \\
\text { Ramona, Townes }\end{array}$ & $\begin{array}{l}\text { Boy v. girl teams for academic games; Survey/graph gender; } \\
\text { directing girls want to play with dolls, color/paint, and play } \\
\text { board games; boys encouraged to play with blocks, read- } \\
\text { aloud v. read-to-self, and move about the room }\end{array}$ \\
\hline Seating charts & $\begin{array}{l}\text { Beatrice, Christine } \\
\text { Jack, Moses } \\
\text { Mrs. H, Quercus }\end{array}$ & $\begin{array}{l}\text { Seating segregated by gender. Like-gender placements to } \\
\text { encourage partner participation and collaboration; boy/girl } \\
\text { seating to discourage social discourse and off-task behavior; } \\
\text { new students get placed with like-gender student }\end{array}$ \\
\hline Transitions & $\begin{array}{l}\text { Beatrice, Christine } \\
\text { Mrs. H, Quercus }\end{array}$ & $\begin{array}{l}\text { Boys go first, then girls; “you're not a boy, you can't go } \\
\text { yet”; separate boy/girl lines for hallway walking; } \\
\text { competitions for which gender group can be quieter, faster, } \\
\text { etc. }\end{array}$ \\
\hline $\begin{array}{l}\text { Academic and } \\
\text { behavioral } \\
\text { expectations }\end{array}$ & $\begin{array}{l}\text { Beatrice, Christine } \\
\text { Jack, Moses, } \\
\text { Townes }\end{array}$ & $\begin{array}{l}\text { Generalizations about boys as loud, rowdy, and physically } \\
\text { active...girls as quiet, passive, and gossipy (e.g., "boys give } \\
\text { me the most problems", "oh, girls will be girls", "boys aren't } \\
\text { supposed to whine, Mikey"; calling on boys more than girls } \\
\text { when hands are raised }\end{array}$ \\
\hline Color-coding & $\begin{array}{l}\text { Beatrice, Christine } \\
\text { Jack, Mrs. H }\end{array}$ & Blue v. pink nametags, bulletin boards \\
\hline $\begin{array}{l}\text { Division of } \\
\text { materials }\end{array}$ & Mrs. H, Quercus & $\begin{array}{l}\text { Separate bins for boy-preferred v. Girl-preferred books, } \\
\text { board games, activities }\end{array}$ \\
\hline $\begin{array}{l}\text { Recess } \\
\text { activities }\end{array}$ & $\begin{array}{l}\text { Beatrice, Christine } \\
\text { Jack, Moses, Mrs. H } \\
\text { Ramona, Quercus }\end{array}$ & $\begin{array}{l}\text { Gender-segregated activities/playground areas (e.g., girls } \\
\text { jump rope and boys play basketball, tag) }\end{array}$ \\
\hline $\begin{array}{l}\text { Attention } \\
\text { signals }\end{array}$ & $\begin{array}{l}\text { Beatrice, Christine } \\
\text { Jack, Moses, Mrs. H } \\
\text { Ramona, Quercus }\end{array}$ & $\begin{array}{l}\text { Teachers signaling student attention with words, such as } \\
\text { "Okay, boys and girls..."; order for picking students to } \\
\text { provide answers, elicit information (e.g., a girl chooses a boy } \\
\text { and then a boy chooses a girl) }\end{array}$ \\
\hline
\end{tabular}


Clearly, categorical blinders restrict what is known and can be imagined about gender. Once sorted, anticipated gender norms highly affect students who reside outside, or outright defy, the gender binary. The way in which one individual perceives another individual's gender expression, which again, in mainstream society is filtered through a male/female dichotomy, often leads to assumptions about that individual's sexual orientation.

Classroom students perceived to be queer. Assumptions about stereotypical gender preferences fuel teachers' tendency to separate boys and girls. Discourses of masculinity and femininity are fundamental to social life and inform instructional and management decisions in the classroom. Once in awhile (and research suggests with growing frequency), teachers will come across students who defy stereotypical gender preferences. Six of the eight participants encountered such students in their classrooms. As mentioned in their case descriptions above, Jack, Mrs. H, and Ramona all worked with students that exhibited stereotypically gender non-conforming behaviors. In a group conversation, Moses added himself to this list. He said:

I have a student like [Mrs. H] was talking about that's kind of in-between having the gender or sexuality...in-between what he thinks he should be or his family has modeled, and what he might actually be when he finds himself. (February $1,2011)$ 
Beatrice and Christine, who shared the same classroom placement, also encountered a student that challenged stereotypical gender norms. When asked what she took away from the initial group conversation, Beatrice responded:

Since having the group meeting and hearing everyone else's experiences, I decided to have a conversation with my CT about one of the students in our classroom. He is by far the tallest student in the class. He prefers to play with the girls in the classroom and I rarely see him interact with boys. His behavior is more feminine and [Christine] and I are both concerned about this becoming a problem for him with some of the boys in the class. My CT expressed that she was glad he was so much larger than any of the other boys. She felt that this was going to keep him from being teased. I have had this same thought but I have also wondered if, though he is not teased, he is excluded from the groups of boys who play together. I need to spend more time watching my kids at recess to see how he is treated outside the classroom. I want to make sure that he is being supported and not bullied by others in the class. (Email, January 26, 2011)

Participant identity construction. In addition to considering student identity, all participants came to see aspects of their own individual identity through this 
research process. Negotiating identity as it related to sexual orientation, gender, power, race, ethnicity, and the role of a classroom teacher, as well as a teacher candidate, all emerged as patterns across the data.

The notion of identity dominated the initial group conversation when Quercus declared:

To identify something, you have certain ownership in that identity. So for example, I spent a lot of time around Baptists growing up, I mean I was in that community. Although I never identified as one, I identify as someone who had an experience with them so when people speak poorly of them, I often get offended...not because I don't agree, but because the people talking about them don't have that full experience. So to stereotype genders and orientations, especially ones you don't identify as or seek to understand, is a bit destructive. How do you really know if you're not that way? Coming to see gender and sexuality on a spectrum more and more it's harder for me to know. I went with [Mrs. H] to her school and I noticed the only classroom that doesn't have the student teacher's name on the door is mine back at [Spruce], but then I saw [Jack's] nametag on the door and I was like, maybe I'd rather not have my name on the door if it doesn't actually respect who 
I am or fully identify me because it said "Ms. Waters,"

which is maybe a minor thing, but what if it's not because

it's the little things often matter most. (Group conversation,

October 27, 2011)

When asked if it was "a minor thing" Jack confessed that indeed the nametag on his classroom's front door greeted him as a daily reminder of his closeted identity. I walked through this (closet) door on February 28, 2011. A guest instructor was teaching a Spanish lesson, a language in which all words have gender. Although the division of nouns into masculine and feminine genders is somewhat arbitrary, students learn subliminal messages about classification. When I walked into the classroom Mrs. Turner pointed to Jack and said, "She's over there" (direct observation, February 28, 2011). After my brief visit, I too, reflected on Jack's identity expression in the classroom. There were no students - those she is aiming to "protect" in earshot and yet [Mrs. Turner] felt it necessary to invalidate Jack's identity. This made me very angry because I feel like it was a conscious and purposeful action to underscore Jack. This is disheartening to me personally and professionally as an educator who has spent all year trying to inspire and encourage teacher candidates to teach who they are. This is not based on touchy feely philosophy or any other subjective quality...it is a simple and researched fact. When we teach who we are, we sustain our 
selves in this vulnerable profession. (Direct observation, February 28, 2011)

Moses and Townes talked about their closeted identities as well. When asked if he felt comfortable embracing his true self in the field, Moses, who is a practicing Buddhist, wrote:

$$
\begin{aligned}
& \text { Alternative ways of being are made to hide and feel } \\
& \text { ashamed. I feel ashamed. I don't belong, and I don't dare } \\
& \text { tell the school I'm in about my beliefs. I wouldn't even tell } \\
& \text { our cohort about them. If I feel this way, I assume that } \\
& \text { those who are more readily stigmatized feel even worse. }
\end{aligned}
$$$$
\text { (Email, March 3, 2011) }
$$

Townes also remained hesitant to reveal aspects of her identity that she predicted were unwelcomed by Willow staff and community members. However, over the course of the year she befriended a teacher (who did not host a teacher candidate), and in a group conversation, Townes explained how she initiated dialogue to reveal a significant aspect of her identity.

She was giving me a ride to school and she outted herself because I told her that I had had a girlfriend before my boyfriend. We wouldn't have had that conversation on [Willow] campus, like I mean none of that would have happened. It's uncomfortable to have to edit myself in that way and to be like if I talk about my partner...[waving hand 
in front of face to dry tears] It's just like it's really frustrating...[crying]...because it makes you afraid that you're going to say something wrong. It's just frustrating that you have to edit yourself. (Group conversation, October 27, 2011)

Offering a counter narrative, Beatrice outwardly reflected on her heterosexual identity, which admittedly grants her numerous invisible privileges. She articulated her heterosexual identity development, a process that is likely to be ignored or relegated to unconsciousness in a heterosexist society as a result of "normative" assumptions about heterosexuality (Fassinger, 2000). Putting words to her experience, Beatrice used the study, in part, to deepen her understanding of majority and minority group identity development. In an email (November 25, 2011), she wrote:

When I look back at my evolving views on homosexuality I see that, while I accepted the homosexual relationships some of my friends began in high school, it was not until a few years ago that I really started to question the view of heterosexuality as normal. I was very comfortable with homosexuality, but my experience with it had not ever caused me to really think about my own decision to identify as heterosexual. I think there is a big difference between understanding homosexuality as normal/good for a specific person who has identified themselves as such, and seeing 
homosexuality and heterosexuality as equally normal/good options for everyone.

Beginning to recognize her heterosexual privilege may have started years ago, but the group conversation prompted Beatrice to begin to make sense of it in a way unlike she had before. Likewise, all participants, when given an audience, not only came to name their encounters in the field, but engaged in a retrospective process that enabled them to rationalize words and images to explain phenomena.

\section{Sense-making of encounters with gender and sexual diversity. Numerous}

patterns emerged from the data to characterize how participants made sense of their encounters with gender and sexual diversity. The most frequently coded themes were: Identity and visibility; fear; language in discourse and media; the impact of the study on participant experience; and participant sense-making related to components of teacher preparation.

Identity and visibility. As evidenced by their encounters, participants spent a lot of time and energy challenged by the notion of identity. Whether the focus was self-, student-, privileged-, and/or closeted identity; or teacher's voice and authority as related to gender and socialization; or the negotiation of their role as teacher candidates, all participants grappled with identity construction on some level. By analyzing the data I came to see the notion of identity as intimately interwoven with the concept of visibility. Among participants, it was my perception that one was not able to fully recognize others (i.e. students), nor themselves, unless aspects of identity became visually apparent, transparent. In other words, the study showed that, conceptually, 
claiming one's identity or perceiving an aspect of another person's identity is, in some way, a rite of passage toward becoming a teacher, a fuller human being. I choose here to pair identity and visibility because when considering queer issues, to "identify" often means to "become visible"...to stand out as the other in a heterosexist and transphobic society.

At some point during the study, each participant came to consider his or her identity as a teacher candidate. In the initial group conversation, Townes responded angrily to a comment Quercus made about his co-teacher candidate, Heidi. Quercus said that Heidi had yet to find her "teacher voice" (group conversation, October 27, 2011) and Quercus asserted himself to be the authoritarian in their classroom. Later, in an individual interview, Townes recalled the encounter:

When [Quercus] said that [Heidi] needed to work on her teacher voice it really upset me because I just felt like the trend is for girls to be more submissive, more passive, and like more polite so when I heard him saying that so lightly it really upset me. I was like no...you don't understand, we're like breaking conditions that we've been taught for so long...that in some way we've accepted from way back in elementary school...and from interaction through interaction through interaction. (January 9, 2011)

Townes admitted that at the time of the group conversation she struggled with the same issues Quercus accused Heidi of experiencing. Her university supervisor recently 
observed her and Travis in the field. According to Townes - and supported by her evaluative documentation - the supervisor praised Travis for asserting himself as a poised and strict presence, but suggested that Townes strengthen her management skills and work on commanding more control over student attention. She specifically remembered her supervisor challenging what he termed her nurturing nature. Drawing from her own experience, this request conflicted with the ways in which Townes had been socialized. All participants agreed that it was unfortunate and unfair for Jack to closet his identity. In group conversations it was unanimously decided that presenting as a woman brought harm to Jack and presented a missed opportunity for his students, school, and the greater community to learn and grow. A related lesson learned as a result of making sense of Jack's experience, was a collective criticism of the educational system as a whole. Whether their own identities were suppressed, or the queer students they cared for in the field were targeted, participants came to acknowledge schools as heterosexist and transphobic institutions. A critical examination of school discourse and contemporary media provided ample means for their defense.

Language in discourse and the media. Participants made sense of their encounters with gender and sexual diversity, in part, by characterizing the language they heard within educational discourse and related social media. Many acknowledged that the implicit, exclusive language used by their cooperating teachers cultivated a culture of silence and fear around non-normative gendered and sexual identities. However, although every participant admitted hearing pejorative language about homosexuality and gay and 
lesbian epithets on the university campus, only one participant heard "that's so gay" at her school site. Beatrice (interview, March16, 2011) described the encounter:

Kids were lining up to get fluoride before they came into the classroom when I heard one student say, “That's so gay." I called the boy back and told him what he said was unacceptable and offensive. I didn't know how much to talk to him about it. I didn't know if he knew what it meant. Jack also commented on language, "I have friends working in elementary schools around here. They hear 'that's so gay' and 'faggot' on a regular basis from the students... fortunately, I haven't experienced this yet" (email, December 9, 2010). On college campus, however, Jack said homophobic and transphobic language runs rampant. Moses (email, December 9, 2010) also observed this phenomenon and in trying to make sense of it, he wrote:

Phrases like "That's so gay" are commonplace on campus. The words have lost all meaning, sort of like "lame" and “crazy”. When I call someone “crazy" or "insane”, I don't mean to offend the mentally ill. These words have entered into our language as multiple definition words. To decrease their frequency, I don't know what method should be used, other than fear. When I am told about how these words are offensive, I am challenged to change my language or face social excommunication from those who tell me of this. 
This causes fear, not enlightenment. "Don't say that word, it offends me." This is a powerful statement trying to mold the ingrained habits of the listener. It is an "I statement" of force. It is saying: "I am better than you; you are inconsiderate." The problem is these words are elements of our culture. Adherents to culture are victims of proximity. A Mormon doesn't know that being a Mormon is bunk, as a bigot thinks his offensive actions are honorable and virtuous. We can see their actions as inconsiderate or their conviction to be respectable. Culture creates perspective and virtues are subordinate to a given cultural perspective.

Cultural values and social pressures were identified by a majority of participants as influencing factors in a highly sexualized contemporary childhood experience. Jack explained, "Skinny jeans are all the rage and outfits marketed to girls are more and more scandalous. This would be fine if girls wore what they wanted and weren't objectified for it, but that's not the case" (email, December 26, 2010). Townes attempted to make sense of similar styles of dress in an eighth grade classroom. "I've actually heard other teacher candidates - not members of this study - call a specific female student 'slutty', which is so bad. But, I mean, it does kind of speak to the way students dress...low-cut shirts and tight pants or skirts" (interview, January 9, 2011). Christine also encountered her third graders striving to obtain a mature, sexualized image. She attributed this to strategic advertisers and mass media: 
Our marketing tells children what sex or being sexy should look like. Girls see women portrayed as objects, as submissive, and as something for men to enjoy. Boys see men who are portrayed as very tough and authoritative. We thereby push our children into these very untrue (and in my opinion unhealthy) gender roles. I can't count how many times I turn on the TV to see half-naked, submissive or seductive women and can't even figure out what the commercial is trying to sell! But they are definitely selling a powerful image to young girls. (Email, December 26, 2010)

Other participants blamed Disney for perpetuating stereotypes, Hasbro for their My Little Pony figures that have evolved over time to be skinnier and more made-up. Still, others pointed fingers at video games, which tend to target boys with realistic graphics and hardcore violence. Beatrice tried to make sense of her third graders' obsession with one particular online game (mentioned earlier in her case description), Call of Duty: Black Ops:

Reading about the game and the violence that it involves makes me wish that the students in my class were not so excited about it. I do think that the boys in this class who I have talked to are really attracted to the violence of the game and they would consider it pretty weak if one of them 
wasn't interested in that violence. I do think that they identify the violence as a male interest. None of them expected me to be interested and they assumed that I would know nothing about the game (which I didn't) and I am assuming that is because I am female. (Beatrice, email, December 26, 2010)

Christine observed the same group of learners' interest in music. "Take a popular song like 'Get Low' and just look at the lyrics," she said (email, December 26, 2010). Following her own advice, Christine dissected the popular song that describes degrading sex. She noted the following:

Songs like "Get Low" are everywhere and I hear my third graders singing them so I know that they are exposed to them, even perpetuating them. I have heard seven and eight year-olds singing this particular song. Whether or not they understand the terms used is irrelevant because they are still getting a very clear message about gender roles and sexuality. What a horrible message to give anyone! (Email, December 26, 2010)

As participants found, language can indeed transmit powerful messages. Or, in the presence of fear, which was manifested throughout the data, language (and dialogue) can often become dangerously silenced. 
Fear. Fear is a complex human reaction. According to Blanchard, Blanchard, Griebel, and Nutt (2011), fear is "the motivation associated with a number of behaviors that normally occur on exposure to clearly threatening stimuli" (p. 3). A high frequency of the following words were coded in the data: Fear, afraid, scared, apprehension, worry, and concern. In analyzing the content that surrounded these terms I came to define these occurrences as an experience of fear. One hundred percent of participants experienced fear as the major emotion responsible for impeding their willingness and future likelihood to stand against heteronormativity and transphobia in education. Each participant was induced by a perceived threat in addressing queer issues in the classroom, regardless of their own sexual and/or gender identity. Moses, who identifies as a heterosexual male, responded to an email prompt that asked him to predict how his colleagues would react if he were to "come out" as a gay man at school. He wrote, “Open minds aren't always the majority here [at Spruce]. I'd lie in fear if it was my choice. Better to be the shy guy than the gay guy" (October 14, 2010). Moses went on to characterize the fear that motivated his response. Job security topped the list, but a desire to be liked and accepted among others was also recognized as an attributing factor to his resolution.

Jack, on the other hand, didn't live in the hypothetical. He experienced fear in a myriad of ways on a daily basis. He felt apprehension and concern toward presenting himself as a lie to his students. He was worried about accidently going into the boy's bathroom out of habit. He was panicked when students' parents looked at him questioningly. Indeed Jack lived in fear every day - fear his secret would always come 
out, fear it would never come out. Part of Jack's fear was rooted in the vulnerability of his role as a teacher candidate. In fact, all participants were afraid to elicit unwanted controversy in taking a stance against heteronormativity given the infancy of their professional careers.

Ramona identified fear as the reason she and her cooperating teacher opted not to read The Sissy Duckling (Fierstein, 2001) in response to Michael's lunchbox incident. She said, "I think the kids could handle a conversation about homosexuality or racism or whatever. It's the parents and administrators that freak out. I guess in that way, we're kind of teaching in fear" (group conversation, January 26, 2011).

Townes spoke candidly about an incident she experienced among a group of teachers at her placement site, and in doing so, named her own fear. "They were talking about getting a substitute teacher and I said, 'Get a cute one.' Then they said, "Do you want a boy or a girl?” and I was like, “oh I don't care” (Townes, interview, March 31, 2011). Townes admitted that she regretted saying the words as soon as they left her mouth. "They were definitely put off by my comment, but then they had asked me. Should I have lied? In that second I felt like, I wonder if it is okay for me to say that." Participating in the study raised the issue of censorship for Quercus as well. According to him, queer content/issues can serve as a relevant and educational resource for interdisciplinary teaching in school. While reviewing queer youth risk statistics, Quercus said:

You know I look at these numbers and I'm seeing fractions! This would be so great to include in a math class, 
but we teach with our hands tied behind our backs. And if you openly address an issue like this without really building that support then we're at risk of losing our jobs. I mean think about if we taught these things, if we used these real-life statistics in our reading and writing and part of our social studies, think about how empowering that could be.

(Group conversation, January 26, 2011)

According to the data, all participants shared similar trepidation when faced with an issue related to gender and/or sexual diversity. Most followed in the footsteps of their cooperating teachers and decided not to address the matter in an explicit way for fear of upsetting or defying their cooperating teachers, or "outing" themselves in some way. Others made subtle attempts to deal with the issue, but were still acting out behaviors that were by and large motivated by fear. However, one thing is for certain: All participants fully engaged in the research study, and in doing so, found a forum to critically reflect upon their knowledge, skills, and dispositions around issues of sexual and gender diversity as it related to education and their role as educators. In this way, the study served as an intervention, altering what participants came to experience in their teacher preparation program.

The impact of the study on participant experience. When designing the methods for this study, prior to implementation, I anticipated that the participant group would likely become somewhat of an intervention. Indeed, by engaging in continuous critical, and at times collective, dialogue, as well as undergoing the process of negotiating 
meaning, participants came to identify, make sense of, and respond to queer issues in alternative ways. The impact of the study on participant experience, and their ability to make sense of their experience, came up early (and often, over time) in individual and group conversations, as well as email prompts and journal entries.

In the third and final interview I asked participants, what if anything (positive or negative) did you take away from participating in this study? Although answers varied, all responses reflected positive outcomes for having participated in the study. Jack and Christine specifically spoke to the necessity of talking about gender and sexuality in order to desensitize such rhetoric in educational discourse. Jack shared the following in our concluding interview, "It's good to talk about this stuff with other teachers because the more we talk about it the less scary it gets for everyone" (March 17, 2011). This was certainly the case for Christine, who upon completion of the study articulated her desire to support queer youth as a means of promoting social change.

It is a scary thing as a pre-service teacher to start considering all the things we do not know. Things we are afraid to talk about. We are about to be thrown into the world of teaching and there is no way a year-long program can prepare us for everything we need to know and be able to do. We do have something on our side though...we have a crazy passion to teach and to fight for social justice in our world. Participating in this study has helped me find this passion and redefine its meaning for me. Because of this I 
am an asset to gender non-conforming and queer youth that would perhaps not otherwise find a teacher they could trust. (Christine, email, March 11, 2011)

Others, such as Beatrice and Ramona, commented on building awareness around students as complete individuals with distinct gender and sexual identities. This realization challenged their prior assumptions about child development and student awareness of societal gender norms and sexual identity. Beatrice admitted that her participation in the study helped her identify, and then adequately support, a student in her class whom she believed questioned his sexual orientation. She said:

The way he talks, the way he compliments my clothes or my earrings when nobody else is in the classroom...I think that wondering about his sexual identity based certain clues like that would have just slid by me before [the study]. (Interview, March 16, 2011)

For others, participating in the study helped shape ideas about education and the role of the teacher. It provoked constructive dialogue with cooperating teachers, students, university instructors, and cohort colleagues - both within and outside of the study. Arguably, the most invigorating conversations included the two planned meetings referred to in the research design as group conversations. On such occasions, all participants and I gathered to talk about issues of relevance with regard to sexual and gender diversity. Shortly after the second conversation, Christine wrote: 
I think the group meeting went really well actually. It seems we all had a lot of thought-provoking ideas to share, more so than at our first group meeting. We sure are developing our critical minds! What I think I took away more than anything was how much of a role we, as future teachers, play in issues around gender and sexual diversity in the schools we teach. (Email, February 3, 2011)

Reflecting on the process, Mrs. H contributed:

It provides a forum where it's like...here is some information and a loose framework for how we can look at these issues with others. On my own I wouldn't know what to do or how to do it. I needed the guidance to engage in important discussions and to self-reflect in a critical way. (Interview, March 16, 2011)

Critical reflection was identified by a handful of participants as a major component of the study. It was also viewed as an effective tool for aiding the process of sense-making of ideas about education and the role of the teacher in relation to gender and sexual diversity. In fact, the space and intentionality set aside for reflection was what first attracted Quercus to participate. In our initial interview he explained, "I jumped at the opportunity...inside I was like, I definitely want to do this for the opportunity to reflect...the opportunity to pay attention to those sensitivities are so important" (September 26, 2010). 
Quercus found his journal particularly helpful in getting to deeper levels of selfunderstanding. Turning again to his commentary in the initial interview, Quercus said, "I take notes in my journal of things that stand out, like quotes, observations. I constantly find myself naming, reflecting, acting...that whole process" (September 26, 2010). This notion of praxis typifies Mrs. H's experience as well. When asked if and how the study impacted her student teaching experience, Mrs. H said:

I've reflected a lot. Given all the journal entries and the different meetings we have had, it's really helped me to focus in on things with a different lens and I do see things differently. The study has really helped me learn a lot of different ways that I can incorporate inclusivity into my practice...ways I can support students and that's really the heart of it for me, to learn how to be a better teacher. (Interview, March 16, 2011)

Participants viewed the study as a means to learn, analyze, and reflect upon inclusive practices and critical pedagogy. Data described in this sub-section, which focuses on how the study impacted participants, relates to the ways in which participants made sense of queer issues positioned within teacher preparation programs.

Participant sense-making related to components of teacher preparation. Preservice teachers attended numerous graduate-level courses while completing their teaching and learning responsibilities in the field. Their experiences on campus, as consumers of university coursework and instructional methods, comprised a substantial 
amount of coded research. Presented here is a synthesis of the ways in which participants made sense of queer issues related to components of teacher preparation programs.

As participants made sense of their encounters with queer issues they looked to bridge practice in the field with the theory they acquired on campus. Perhaps it was the magnified lens used to examine sexual and gender diversity, or the notion that the study served as an intervention, but at any rate, all participants voiced a need to explicitly cover queer issues in greater detail on campus. Jack believed that increased attention to these issues could help prepare teachers to see their role as influential and acknowledge that bringing up the issues does not have to be as controversial as one may think. He wrote:

I think it is really important for straight and cis-gendered people to tackle homophobia and transphobia in their classrooms and at large because there is the threat for queer and/or trans teachers of losing their jobs for bringing up these issues and being told they are pushing their own agenda onto others. Having conversations with students about gender dynamics is really important and can often come up organically by reading a story or on the playground or students' comments such as, "I don't want to sit next to all these girls!” (Email, November 11, 2010)

In addition to voicing an overall need to address queer issues in teacher education, participants noted the importance of approach in introducing the topic. Expressing her needs as a social learner, Beatrice clarified, "Talking about these issues and knowing I 
have a support system are more important to me then having certain strategies worked out" (email, November 11, 2010). Still, other participants, such as Mrs. H, requested concrete strategies.

I really want to make sense of these issues and figure out how to mediate and address them positively and constructively so we can have teachable moments instead of moments when things go wrong and we look the other way because we're uncomfortable. (Mrs. H, interview, September 30, 2010)

Educating pre-service teachers on basic laws, such as anti-discrimination legislation, is another suggestion that emerged from the data. Other recommendations included helping pre-service teachers break down and map their own gender and sexuality on a spectrum, incorporating more readings on critical theory in courses, and engaging in more dialogue about children and social development. Another suggestion was for the program to offer courses on conflict and resolution in education and/or classes on developing communication skills.

In a group conversation Moses argued that the university must take ownership by requiring a field assignment that develops the practice of such strategies, the implementation of what Mrs. H described as a teachable moment. Figure 4 illustrates the dialogue that unfolded. 
Figure 4. Transcript from Second (and Final) Group Conversation (January 26, 2011)

Moses: I think there should be some sort of lesson plan assignment presented to us that we have to teach. Or if we had an opportunity to micro-teach, with cohort members as our students, just to get a feel for what it would be like. To get a feel for the awkward things that would come up so when we go to do it in front of a class and it doesn't blow up in our faces. I'm sure that if I were to do it in front of us I'd make several mistakes and say the wrong thing because I do that, but it would be a lot easier to do it a second time.

Christine: That's a really good idea.

Townes: Yeah, that would be so cool if we had [GU] backing us and that was one of our assignments out in the field.

Beatrice: That would be really cool!

Ramona: Yeah. We could be like, sorry, we have to!

Moses: (Laughing) it's a field requirement. Yeah, that would make sense. It would change something. (Looking at the researcher) Make it required!!

Townes: But [GU] has partnerships that they build with these schools-

Mrs. H: Well, if that's what you're teaching then we don't want to support your interests-

Moses: Can you make it a requirement, like can we make it happen?

Olivia: For you?

Moses: Sure.

Olivia: I mean I'm hoping that this research informs future practice here, so you know, who knows what the future will hold-

Moses: I want to go over to [Spruce Elementary] and say I have to do this!

Figure 4. The transcript except highlights participants' collective desire for their teacher preparation program to approach queer issues in an intentional and explicit way, such as designing field-based assignments that require teacher candidates to create and implement a lesson focused on issues of gender and/or sexual diversity. 
After reflecting on the group dialogue, Moses reiterated his point in an individual interview. He said:

At the very least it should be mandated for student teachers to develop and execute a lesson in the field because if we don't get used to doing it now while we are building our repertoire of lessons and our feelings of how we are in the classroom, then our efforts to address gender and sexual diversity will be weak when we go out into a school and teach on our own. (March 16, 2011)

In addition to making sense of specific assignments, participants agreed that issues of social justice should transcend a five-week course preceding active field engagement. According to Beatrice, the timing of the course presented itself as a missed opportunity. "It was more like an academic/social interest than a this-is-how-it-directlyrelates-to-my-students interest" (March 16, 2011). Mrs. H observed, "Multicultural and urban education was an amazing class, but one class is not enough, especially given the importance and prevalence of these issues" (email, March 16, 2011).

Another theme shared by participants focused on GU faculty language and word choice. Representative of similar data offered by her co-participants, Christine wrote:

I think the faculty needs to be very aware of what they say about gender and assumptions they make around relationships and families. You [the researcher] are very conscious of the things you say, but other faculty members 
aren't so careful. Often I have seen stereotypical gender roles being taught and added to stereotypes. I think that they should be more aware of how they talk and remember that members of their audience come from all walks of life.

(Email, November 11, 2010)

A final element of sense making coded within teacher preparation was the need for intentional, transparent, and inclusive field placement assignments. Mrs. $\mathrm{H}$ felt that her harmful experience with Mrs. Jones could have been prevented had the program conducted more informed school visits and acquired a sense of how the teacher would respond to issues related to gender and sexuality in her classroom. As it was, because the teacher failed to respond, Mrs. $\mathrm{H}$ became increasing discouraged and eventually transferred schools.

In addition to determining where individual cooperating teachers stand with regard to social justice and equity, including a need to address queer issues, Moses recommended that the program also examine schools more closely as it continues developing meaningful partnerships. The following quotation also implies his suggestion for the university to consider school demographics and seek placements that reflect the diversity found in schools across the nation.

Unfortunately, a quasi-democratic, two-party, pseudocapitalistic environment makes it difficult to find truly democratic institutions that are open-minded. Teachers from these close-minded mental places need more 
preparation, but the best prep would be, in my opinion, an immersion. The person(s) would need to be around diversity. They need to socialize or work with queer students or dyad-moms/dyad-dads and understand their humanity. (Moses, email, November 11, 2010)

Moses also added, from his experience working with a male cooperating teacher, that the program should intentionally pair male teacher candidates with same-sex mentors. He explained:

I know this sounds kind of...segregating, but I think it might be wise to match student teachers with a cooperating teacher of a like gender. As a male in elementary education I'm a minority, which I know this is like the first time I'll ever be the minority, but I think it might be hard for a female teacher to relate to a male teacher. (Moses, email, November 11, 2010)

Again, numerous patterns emerged from the data to characterize how participants made sense of their encounters with gender and sexual diversity. Participants' ability to make sense of their experience was, in part, informed by the ways in which individuals responded.

Responses. Certainly the recommendations above constitute a response to participants' encounters with sexual and gender diversity in the field. Calling attention to inadequate preparation within a teacher preparation program is one response to high- 
frequency encounters. The descriptions of encounters and sense-making up to this point have already divulged many acts of response. It is hard to separate the response to a situation from the story itself. Still, it is important to explicitly address common responses coded across the data in order to identify patterns and themes. In other words, what did the participant, cooperating teacher, and/or student(s) say or do in return to a particular encounter.

According to the data, students who possessed gender-defying preferences and mannerisms in the classroom were met with one of two responses. Cooperating teachers and teacher candidates either quietly, but tangibly, supported the particular student or the cooperating teacher ignored/denied the issue altogether. In both cases, the teacher candidate acknowledged the student and tried to make sense of his or her identity in order to provide support. A co-supportive example is referenced in Mrs. H's case description. She and her cooperating teacher, Mrs. Banksy, maintained open communication to support a student in their classroom, a boy who appeared to be queer. Moses, Ramona, Christine, and Beatrice engaged in similar co-supportive responses.

However, before Mrs. H transitioned to Spruce Elementary, she met the counter response to that mentioned above. Despite explicit pleas to help Jessica, a second grader who acted out sexually, her cooperating teacher at the time, Mrs. Jones, ignored the issue. Jack experienced a similar mismatch of support between himself and his cooperating teacher. In response to a first grade boy who consistently exhibited stereotypical gender non-conforming preferences, Jack felt it was vital to affirm his choices whereas, according to Jack, his cooperating teacher often drew negative attention to the young boy. 
Findings were reported here in two sections: Individual case descriptions and a cross-case synthesis. In the next, and final, chapter I summarize findings and present subsequent assertions as well as a framework for envisioning the inclusion of queer issues in teacher education. 


\section{Chapter Five: Discussion}

This chapter begins with a summary of the findings from the study and conclusions that grow out of those findings. Findings are summarized by recalling the themes and sub-themes that emerged from the data and which were described in the cross-case synthesis. A list of ten logical and concise assertions based solely on a close examination of the data follows. In a way these assertions summarize the data, but they also provide a unique and critical response to the overarching research question by unequivocally recognizing that indeed pre-service teachers encounter, make sense of, and respond to issues surrounding sexual and gender diversity. Thereafter, in concordance with previous research and driven by principles of critical social theory, these findings and subsequent conclusions are reassembled into a proposed framework, as well as viable options, for including queer issues in pre-service teacher preparation programs.

Following a description of the framework I suggest some implications that the study may hold for a variety of groups, including the stakeholders mentioned in Chapter One. Next I reflect on my own positionality and how it may have affected the study. Two final sections leading to my conclusions will acknowledge limitations of the study and offer suggestions for future research.

Summary of findings. The purpose of the study was to identify and understand the ways in which pre-service teachers encounter, make sense of, and respond to, sexual and gender diversity in the field. By thinking about, and talking through, issues of sexual and gender diversity as they occurred, participants came to see this study as an additional 
opportunity to examine the process and outcomes of providing prospective teachers with instruction and space to process queer issues as they relate to education.

A multiple case study approach was used to collect data on eight pre-service teachers over the course of seven months in the field. Data was organized for analysis using ATLAS.ti software and findings were presented in two ways. First, I zoomed in to showcase one or more unique incidents experienced by each participant. Then I zoomed out to examine themes and sub-themes that emerged across the data. A summary of the cross-case data analysis brought forth the following themes and subthemes:

- Encounters: Gender dichotomy, classroom students perceived to be queer, and participant identity construction;

- $\quad$ sense-making of encounters with gender and sexual diversity: Identity and visibility, language in discourse and media, fear, the impact of the study on participant experience, and the ways in which participants made sense of issues as they relate to components of teacher preparation; and

- responses to encounters with gender and sexual diversity: Cooperating teachers and teacher candidates either quietly, but tangibly, supported queer students, or the cooperating teacher ignored/denied the issue altogether.

Subsequent conclusions. In many ways the findings presented in Chapter Four constitute conclusions from the data analysis. The experiences felt and managed by participants, told and re-told in forums provided by the methods of the study, explain how queer issues were encountered, processed, and responded to. A personal interest that informed my research was the investigation into the extent to which education is 
inclusive of queer issues. The findings presented in this paper demonstrate that education is inclusive of queer issues in the sense that they exist. Participants identified them. Critical reflection and collective agency provided a means for examining, or making sense of, encounters by tracing their roots, postulating their consequences, and judging their merit. A cycle of praxis (Freire, 1970) formed, which was on-going and transparent, and which led to the following assertions. The language and composition of each assertion is carefully chosen to form accurate affirmations that can be traced back to the data. The intention here is not to generalize across the field, although the following assertions do align with current literature, but rather the purpose of representing the data in a succinct and declarative fashion is to highlight the scope and depth of the study and also to position it within a critical theory perspective. To further support my assertions from a research perspective Nolen and Talbert (2011) offer:

Qualitative research is not conclusion oriented as it is directed at capturing life as it is lived. With the passing of time and changes within or among the informants themselves, there is no assumption that a study's findings would not change as well. Qualitative researchers embrace the temporal nature of a "truth" that is context dependent and therefore do not claim that findings can close an argument; findings simply begin a new conversation. Reflecting the situational nature of findings, researchers make assertions rather than conclusions. (pg. 69) 
Assertions. Findings from the present study informed these subsequent conclusions:

1. Whether intentional or not, teachers separate students into a gender dichotomy;

2. Gender dichotomies potentially harm all students by endorsing narrow definitions of identity, and are particularly restricting for gender nonconforming students;

3. Queer students (and/or students perceived to be queer) exist; and can often be detected by teachers, especially when given an opportunity to discuss and process queer issues;

4. As early as first grade, queer students can begin to feel alienated and/or closeted by school structures (e.g., social dynamics, peers, teacher discourse);

5. For teacher candidates, personal identity is constantly being informed by, and shaped through, the learning to teach process;

6. Legitimate fear and heteronormativity force queer pre-service teachers (including straight allies) into closeted classrooms;

7. Language is a powerful tool often used to bring about liberation through dialogue and sense-making, but with queer issues related to education, language is often silenced and what messages people do transmit and receive are often heteronormative and transphobic; 
8. Pre-service teachers who are encouraged (and given some tools) to identify and make sense of queer issues in the field begin to voice a professional responsibility to address, if not outright counter-teach, issues that arise in schools which are homophobic and/or transphobic;

9. Requiring explicit and intentional pre-service teacher education on queer issues, as well as opportunities to engage in ongoing dialogue with others relating this discourse the field, can begin to effectively dismantle heteronormativity in education; and

10. Pre-service teachers want to explore how gender and sexual diversity manifest in schools and seek ways to support queer students.

To highlight my process in framing these assertions I will focus on three, namely numbers three, four and seven, and support them with direct findings presented in Chapter Four. Thereafter I describe the significance of the assertions.

The third assertion states that queer students (and/or students perceived to be queer) exist; and can often be detected by teachers, especially when given an opportunity to discuss and process queer issues. This assertion was informed by Jack's encounter with a male-bodied first grader who defied traditional gender preferences for reading material. His cooperating teacher, who visibly embarrassed the boy in front of his peers, also supports the fourth assertion, which states that as early as first grade, queer students can begin to feel alienated and/or closeted by school structures (e.g., social dynamics, peers, teacher discourse). In this particular incident, Mrs. Turner brought attention to the first 
grader by challenging his choice to read a book from The Rainbow Fairies series, and as Jack observed and verbally confirmed, caused the boy public shame.

Other findings support these assertions as well. As noted in Chapter Four, six of the eight participants identified at least one student in their field placement that they perceived to be queer. In many of these cases, their cooperating teachers upheld participants' instinct. In Beatrice's instance, it was not until she returned to the field after the study's initial group conversation that she realized one of her students might be questioning his sexual and/or gender identity. Beatrice immediately spoke with her cooperating teacher who had not yet made the connection, perhaps in part, because she lacked the forum to process queer issues. Beatrice's experience is reflected in assertion three, which again states, "Queer students (and/or students perceived to be queer) exist; and can often be detected by teachers, especially when given an opportunity to discuss and process queer issues" (p. 139).

Findings related to Beatrice also support the fourth assertion - that queer students can feel alienated and/or closeted by school structures (e.g., social dynamics, peers, teacher discourse). Beatrice encountered specific instructional language used by a substitute teacher that she interpreted as exclusive and heteronormative. Findings represent her claim that such language, as well as sexist, heterosexist, and transphobic language within the classroom curriculum, observably ostracized some of her students. Assertion seven states, "Language is a powerful tool often used to bring about liberation through dialogue and sense-making, but with queer issues related to education, language is often silenced and what messages people do transmit and receive are often 
heteronormative and transphobic" (p. 139). Findings for this assertion were by and large presented in the cross-case synthesis. Based in part by the data surrounding gender dichotomies (see Table 1), it was asserted that language (e.g., attention signals, communicated academic and behavioral expectations, transition markers, instructional discourse, etc.) often sends heteronormative, categorical, and transphobic messages. Language as a tool for sustaining normative discourse can also be located in the silence evoked from Mrs. Jones when Mrs. H presented concerns about Jessica. According to the data, Mrs. Jones put forth great effort to silence the dialogue surrounding Jessica's highly sexualized behavior in class.

Language was also a vivid and powerful tool in Jack's experience. It was the medium first used to communicate my unconditional support to Jack, offering a window into a reality where he could (student) teach as a man. Language, or rather the silenced words from others, also played a factor in his choice to remain closeted. Jack felt he had no other allies and thus identified as a woman in his placement, which permitted daily spoken reminders of his identity: Mrs. Waters.

Cross-case findings described under the heading "Language in discourse and the media" (p. 116), further support assertion seven. Pejorative language like "that's so gay" and the societal value of highly sexualized media were identified as ways language transmits powerful messages. Another section of the cross-case synthesis entitled "The impact of the study on participant experience" (p. 123) revealed that all participants cited positive outcomes for having participated in the study. Many specifically stated the need for talking about gender and sexuality in order to desensitize such rhetoric in educational 
discourse and to bring about greater awareness and understanding. In other words, participants built consensus around the importance of using language to bring about ideas that led to sense-making and ultimately socially-just action.

The assertions listed above are important for many reasons. First, they provide insight into the way things are. They reflect a current reality for school stakeholders; a truth which participants came to recognize as institutional heterosexism and cissexism in their field placements. Locating and naming the system of attitudes, bias, and discrimination that further disenfranchises queer people contributes to congruent literature cited in Chapter Two (e.g., hooks, 1994; McLaren, 2003; Sears \& Williams, 1997; Sedgwick, 1990).

Second, the assertions are significant because they focus on outcomes for K-12 learners. Core themes focused on the presence or lack of support and empowerment which participants believed influenced youth's sense of human agency in school. Negative attention themes were indicative of the vulnerability that youth felt at school whereas positive support gave rise to students' sense of belonging and self-pride.

Participants of the study also developed an increased awareness of self. Assertions that speak to the identification and sustainability of the person within the profession are important because teaching stems from one's inwardness and knowing oneself is as important as employing sound instructional strategies and knowing your students well (Palmer, 1997). The acknowledgement of queerness in the classroom, as well as within the study, triggered each participant to consider his or her own sexual orientation and gender identity which established a deeper sense of self-identity. 
A fifth reason the assertions are important is because they acknowledge that concentrated efforts toward deconstructing heteronormative and cisnormative institutions require resources, such as time. This recognition can move the field toward identifying which resources are needed and how these resources might be utilized.

Finally, the assertions authenticate successful outcomes for putting forth such efforts. By developing agency within group conversations and on-going sense-making and support, participants were able to contribute a group impact. Acquiring this influence was likely unique to those who participated in the study, however, if presented with a theoretical framework for queer inclusion, teacher educators could begin to imagine and produce a far greater collective impact.

Proposed Framework. It has always been my intent to interpret how prospective teachers experience the phenomenon of sexual diversity and non-conforming gender identification and expression in the field. Gathering this information is an important step toward improving teacher preparation programs to better meet the needs of queer youth and to dismantle heteronormativity within education. The findings of the present study prompted the assertions above and also guided me to construct a framework that situates and justifies queer inclusion in pre-service teacher preparation programs. As illustrated in Figure 5, (pre-service) teacher education is highly influenced by politics, ideology, and culture. 
Figure 5. Framework for Queer Inclusion in Pre-Service Teacher Education

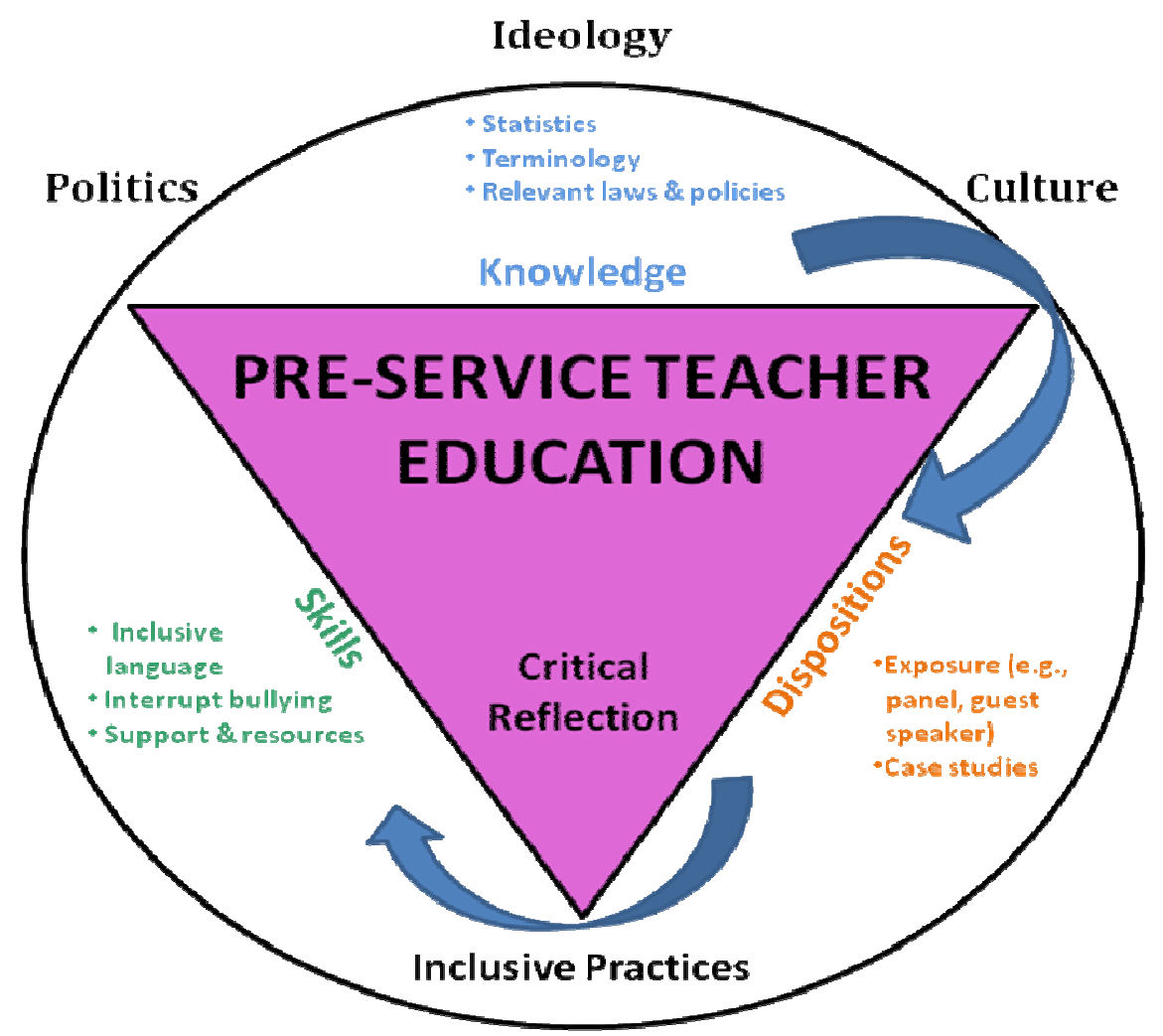

Figure 5. The framework proposes intentional and explicit inclusion of queer issues in pre-service teacher preparation by equipping students with the knowledge, skills, and dispositions necessary for implementing inclusive practices. By acknowledging overarching politics, ideology, and culture, and through critical reflection, pre-service teachers can be prepared to support queer youth and work to dismantle heteronormativity in education as a matter of social justice.

Participants in the study, as well as me as researcher, constantly negotiated and reflected upon the politics (e.g., norms, operations, inter-relations) of the university, as well as the K-12 schools where participants were placed. Our roles within the Teacher Preparation Program (and the study itself) were also impacted by personal and societal ideology and culture. An example of this is when Jack and Townes expressed fear in 
embracing their true identities within their field placement due to their perception of a homophobic school culture. Likewise, ideology, a set of ideas that constitutes one's goals, expectations, and actions came into play when participants asked for a field-based assignment that would require pre-service teachers to explicitly address gender and sexual diversity in K-12 schools. A collective desire to carry out this task was met with trepidation when participants remembered the university's commitment to building and fostering university-school partnerships.

It is important to acknowledge the presence and influence of the overarching political, ideological, and cultural landscape, which affects pre-service teacher education. The proposed framework suggests that recognition, however, is not enough. Critical social theorists would argue a need to penetrate the outer ring of influence to consider what individual programs could, and should, do to equip pre-service teachers with the knowledge, dispositions, and skills necessary to implement queer inclusive practices. The present study finds that elementary students indeed experience sexual and gender diversity (and at times, oppression) that is seldom addressed. Thus, it is logical to propose a course, or several courses within a professional teacher preparation program, that intentionally provides opportunities for pre-service teachers to gain accurate knowledge of queer statistics, terms, and laws and policies. As illustrated in the framework, and confirmed by previously cited literature, knowledge alone is not enough (Bennett, 2003; Brown, 2004; Gay, 2000; Pang 2001). Because the topic of sexual and gender diversity can be contentious in education, particularly elementary education (DePalma \& Atkinson, 2009; Sears, 1999), it is important for teachers to develop in teachers professional 
dispositions toward queerness. A self-awareness of dispositions can help pre-service teachers confront queer issues in school. Teacher educators need to provide opportunities for exposure to queerness, such as in-class panel discussions and guest speakers, employing the method of case study, and/or utilizing media that features queer youth. As was evidenced by study findings, I believe that increased knowledge and deeply developed dispositions will cause pre-service teachers to yearn for practical skills so that they may implement a queer-inclusive pedagogy (including the skill of interrupting antigay bullying and adopting inclusive language) and interact with queer faculty, students, and families in an authentic way. Proposed methods for skill development include, but are not limited to, course readings, open dialogue, and role play.

Finally, the proposed framework implies that pre-service teachers must be taught how to engage in on-going critical reflection as they develop knowledge, skills, and dispositions centered on queerness. Consequently, teacher educators need to facilitate the process of learning to analyze, reconsider and question knowledge and experiences with heterosexism, homophobia, and transphobia. As the present findings suggest, pre-service teachers who critically reflected on knowledge, skills, and personal dispositions related to queerness were prompted toward social action to liberate knowledge and validate diverse ways of being. The participants engaged in this form of praxis (Freire, 1970) and articulated a sense of preparedness, willingness, and desire to disrupt heteronormativity as K-8 educators and to provide increased support for queer youth.

In order to explore the implementation of this framework I elicited the help from a university colleague, and together, we developed a Spectrum of Visibility (see Appendix 
M). This spectrum offers a menu of inclusive opportunities that range from maintaining heteronormative status quo to more progressive practices, such as altering dichotomous language on admissions applications, nominating (and making known) queer faculty mentors, and offering electives and coursework that grapple with queer issues. Informed by the framework for queer inclusion in pre-service teacher education, the spectrum can be used by faculty in teacher education to examine personal and professional knowledge, skills, and dispositions on the topic, as well as implement and assess progress toward developing a more inclusive approach to sexual and gender diversity.

Implications for stakeholders. In Chapter One I suggested that increased awareness of how pre-service teachers encounter and make sense of queer issues in their field placements could produce advantages for multiple groups. The results from this study support that claim. Research participants and K-8 students benefited from a concentrated effort to track sexual and gender diversity in the field. As noted in Chapter Four, every single participant expressed positive outcomes as a result of their participation in the study. A number of individuals spoke of their need to identify and process their encounters in order to decipher how to respond. Findings embedded within these responses indicated how the study also benefited K-8 students. Jack, Mrs. H, Ramona, Moses, Beatrice, and Christine all encountered students they perceived to be queer and therefore vulnerable to challenges at present or later in life (D' Augelli, et al., 2008; Grossman et al., 2009; Kimmel \& Mahler, 2003; Kosciw et al., 2010; Strauss \& Corbin, 1990; Wells, 2000). A synthesis of literature reviewed in Chapter Two pertaining to teacher influence concluded that when teachers acknowledge alternative ways of being 
and reach out to students perceived to be queer, it has a direct and positive influence on students (Bochenek et al., 2001; Kosciw et al., 2008; Owens, 1998). The participants overwhelmingly attributed their positive influence on students to a personal acknowledgment of sexual and gender diversity as well as talking through possible support.

An additional example of classroom students benefiting from an increased attention toward queer issues within teacher education can be found in young Jessica. Without Mrs. H's intervention, which she attributed to her participation in the study, it can be assumed that Jessica would not have received support from the school counselor for (at the very least) one year. Thus Jessica's sexually explicit behavior could have continued to negatively affect her as well as her classmates.

Finally, to recognize queerness as a central component of the study, indeed poised within higher education, supported and validated queer participants. Jack and Townes both voiced a growing sense of pride and affirmation for identifying as queer. I, too, experienced a newfound sense of belonging that had been void in my previous work as a university instructor, and which is explored further in the following sub-section.

Reflections on my positionality. Undoubtedly the multiple roles I performed over the course of the year affected the present study. I served as participants' cohort leader and advisor, instructor of multiple courses, research facilitator, and in some cases, university supervisor. On the one hand it can be accurately assumed that my position as an evaluator of pre-service teachers' knowledge, skills, and dispositions, influenced not only which participants volunteered to come forward, but also impacted study findings. It 
would not serve students' best interests, for example, to volunteer for the study if they knowingly fostered homophobic beliefs given that I had identified as a lesbian. On the other hand, however, I do not believe my positionality influenced findings on a significant level. My intimate participation throughout the process, throughout participants' processing, in some unexplainable way, allowed me to fade into the background of normalcy. In one research log entry I wrote:

They don't need me anymore. Today in the group conversation, participants posed problems, critically reflected on their field experiences, and talked about their roles as agents of change. I'm still learning a lot in interviews and on the receiving end of email prompts, but even in those, I don't seem to be the intended audience. It's as if I've disappeared (January 26, 2011).

My positionality carried implications for the validation of my research. Throughout the study I acknowledged to the participants the power relations involved and was transparent in differentiating my role as their leader from my role as a researcher. I constantly made it explicit that participant knowledge, experience, and dispositions toward gender and sexual orientation would have no bearing on academic performance or individual standing within the program.

I also attempted to increase research validation and reliability by maintaining a written log. In addition to serving as a "chain of evidence" (Yin, 2009, p. 122), this log provided a means for me to bracket my own bias and record important observations as 
they emerged from the data. I used the log, for example, to process bias judgments I formed after an interview in which I interpreted a participant's comments as homophobic and misogynistic. I have strong personal beliefs about the treatment of women and queer individuals, but didn't want my initial reactions to cloud sense-making and prevent me from interpreting what this individual understood to be true. Instantly recording my bias allowed me to later return to the participant's words and process meaning in a way that reestablished my focus on the research question. Overtime, this strategy has helped me confront worldviews that are totally opposite to my own.

I must also attribute my confidence of valid findings to the maturity among participants and to the respective community cultivated within group conversations. Early on it was quite clear that participants within the group felt comfortable affirming and challenging each other's beliefs. It was also established within group conversations that participants would agree to disagree (group conversation, October 27, 2010).

Despite efforts to carry out a highly valid and reliable study, as with all research, the present held limitations that impact the overall findings. The two final sections will acknowledge these limitations and offer suggestions for future research.

\section{Limitations of the Study}

There are two overarching limitations that need to be acknowledged and addressed regarding the present study. The first limitation concerns the participant sample and the second includes measures, which are the items in a research study to which the participant responds. 
Restricted sample. As mentioned, knowledge of my lesbian identity preceded cohort members' invitation to participate in the study. Thus, it could be argued, given my authoritative position, that disclosing my sexual orientation attracted participants who were predisposed to think of, and talk about, queerness in a positive light. Nothing within the study findings indicated participants' thoughts or feelings were inhibited as a result of my identity and/or presence, however, I cannot rule out the possibility that my sexual orientation, combined with my positionality, may have restricted the sample.

The eight pre-service teachers who participated in the study were in many ways a heterogeneous group. Among them was a myriad of races, ethnicities, social and economic classes, perceived genders, gender identities, gender expressions, and sexual orientations. However, some common characteristics were found among all participants, including American citizenship, age range 22-32 years old; and all were academically successful. The restricted age range, in particular, presents a limitation. One could surmise that the relatively young sample population was predisposed to identify and be more accepting (than their older counterparts) of non-normative identities, such as queer. This is based on research that illustrates American society becoming more tolerant and accepting of diversity, which includes gays and lesbians (Hicks \& Lee, 2006).

Self-report measures. Another limitation of the study is that it relied heavily on self-report measures. The study asked participants to share answers to personal and sensitive questions, which were likely influenced by social context and self evaluation. Spector (1994) describes social desirability bias as the tendency of participants to reply in a way that will be viewed favorably by others. Within group conversations, for 
example, participants may have overstated the extent to which they encountered or experienced sexual and/or gender diversity because it was the topic of interest that connected us. To account for social desirability bias I provided opportunities for participants to share information in a myriad of ways. This triangulation allowed me to cross-reference participants' responses from multiple sources to see if they produced similar findings. I also led all individual interviews and group conversations with lessintimidating questions to make the participants feel more comfortable before asking anything that might be more difficult to answer honestly.

Among self-report measures, self-evaluation bias (Robins \& John, 1997) presented another limitation. Participants may have self-regulated their responses on selfreport measures (e.g., journal entries, electronic prompts) to better reflect how they "think they should be" rather than what they actually were. To counter this bias I made several efforts to reiterate my neutrality by normalizing participants' thoughts and feelings and by encouraging honesty.

Although self-report measures posed potential threats to the validity of findings, they should not be completely discredited. Self-report measures generally reflect participants' affective reactions to the topic under investigation (Sector, 1994). In this way, the methodology allowed me to obtain participants' sense-making, which by and large, reflected personal attitudes, assumptions, values, and beliefs. More research is needed in this area as well as the ways in which pre-service teachers encounter and respond to queer issues. 


\section{Suggestions for Future Research}

Issues relating to queer students have long plagued school efforts for creating and maintaining academic cultures of equity, inclusivity, and safety. From bullying and harassment in the K-12 schools to the topic's unquestioned exile from teacher education programs, preparing teacher candidates to effectively deal with questions and conflicts about sexual orientation and gender identity is an effort that is long overdue. However, how prepared are teacher-educators when it comes to supporting, serving, and mentoring teacher-candidates who identify as members of sexual or gender minorities, as well as teacher-candidate allies who identify as queer? This study served as a precurser to these troubling questions directly by describing how pre-service teachers encountered, made sense of, and responded to queer issues in the field.

Many implications for future research can be derived from what the present study found, as well as what the study did not find. Findings clearly demonstrate that preservice teachers encountered queer issues within their K-8 field placements. The field would benefit from similar research, possibly with participants that reflect an older age range. The additional knowledge gleamed from older teacher candidates could contribute to the larger body of literature on evolving attitudes and beliefs about queer issues, as well as extend the present study's findings to include a more heterogeneous sampling.

Another important area that warrants further investigation is long-term outcomes for K-12 students. The present study reveals that over half the participants encountered students they believed to be queer. Interviewing these students about what, if any, impact the teacher candidates had on their individual identity growth could contribute important 
data. Determining the influence of teacher candidates, as perceived by queer students, can justify the importance of (and begin to typify) preparing pre-service teachers to develop knowledge, skills, and dispositions toward queerness.

Findings from the cross-case synthesis also suggest that teacher candidates desired to implement a field-based assignment required within TPP that specifically attended to sexual and gender diversity. Thus, another logical avenue for future research is to examine the process and outcomes of this proposed task. Results could determine what, if any, assignments are perceived as valuable and also measure the impact of the assignment on pre-service teacher learning, as well as those affected in the field (i.e. classroom students, cooperating teachers, and administration).

Finally, implications for future research include field testing the proposed framework for queer inclusion in pre-service teacher education (see Figure 5), as well as the spectrum of visibility (see Appendix M). Examining if and how these tools help facilitate the learning and teaching of queer issues among teacher educators could challenge, and perhaps lead to altering, heteronormative practices in pre-service teacher preparation.

\section{Conclusion}

The population of the United States is growing increasingly diverse (Banks, 2006; Irvine, 2003). This reality creates both challenges and opportunities for the educational system (Vescio, Bondy, \& Poekert, 2009). Presently most literature on sexual and gender diversity in education focuses on the challenges of overcoming violence and tiptoeing around controversial issues. Alternatively, the present study has argued a need to see 
beyond the victimization of queer youth and the political and ideological challenges to embrace the opportunity of queer inclusion in K-12 schools. As a matter of social justice and human decency, schools must identify suitable and relevant ways to include topics of sexual and gender diversity in order to support queer youth and provide an accurate portrayal of the world in which we live.

The purpose of this study was to identify and understand the ways in which preservice teachers encountered, made sense of, and responded to, sexual and gender diversity in the field. Through open dialogue and ongoing critical reflection, participates grappled with issues of sexual and gender diversity as they occurred. In doing so, they came to view these opportunities as a means of gaining better understanding about queer students and also negotiating personal sexual and gender identity as it related to the role of the teacher, and indeed life itself. A thorough interpretation of participants' individual and collective processes and outcomes led me to articulate ten assertions that justify, and perhaps may guide, the task of providing prospective teachers with instruction and space for making sense of queer issues as they relate to education.

There are more than 4 million queer youth living in the United States (Bochenek et al., 2001). As previously stated, and supported by the present study, these youth are becoming aware of, identifying, and disclosing their sexual and gender identities at younger ages (Grossman et al., 2009). The inclusion of queer family members produces a statistic far more telling: As many as nine out of 30 students are significantly affected by sexual orientation (Fontaine, 1998). When teacher education follows the standard set by public schools and avoids topics related to sexual and gender diversity, then a cycle of 
ignorance persists. Likewise, when pre-service teachers are not encouraged to identify and challenge heterosexist ideologies and heteronormative assumptions, then homophobia is likely to ensue (Lipkin, 2002). However, if pre-service teacher education facilitates an understanding of sexual and gender diversity, then perhaps we would witness people self-identified or perceived as heterosexual and/or cisgender working with queer individuals to create a school climate imbued with social justice. The present study is a logical and necessary step toward achieving this goal. 


\section{References}

Abdal-Haqq, I. (1998). Constructivism in teacher education: Considerations for those who would link practice to theory. Washington, DC: Office of Educational Research and Improvement. (ERIC Document Reproduction Service No. ED426986)

Ahlquist, R. (1992). Manifestations for inequity: Overcoming resistance in a multicultural foundations course. In C.A. Grant (Ed.), Research \& multicultural education: From the margins to the mainstream (pp. 89-105). Bristol, PA: Taylor \& Francis.

Allman, P. (1999). Revolutionary social transformation: Democratic hopes, political possibilities and critical education. Westport, CN: Bergin and Garvey.

Applefield, J. M., Huber, R., \& Moallem, M. (2000). Constructivism in theory and practice: Toward a better understanding. High School Journal, 84(2), 35-53.

Ashiabi, G. (2000). Promoting the emotional development of preschoolers. Early Childhood Education Journal, 28(2), 79-84.

Ashton, P., \& Crocker, L. (1986). Does teacher certification make a difference? Florida Journal of Teacher Education, 3, 73-83.

Athanases, S. Z., \& Larrabee, T. G. (2003). Toward a consistent stance in teaching for equity: Learning to advocate for lesbian- and gay-identified youth. Teaching and Teacher Education, 19, 237-261. 
Baldwin, E. S. (2002). Lesbian, gay, bisexual, and transgender equity issues: A study of preservice teachers' perceptions of current practices in teacher education (Doctoral dissertation). Retrieved from ProQuest. (Document No. 765001401)

Banks, J. (1995). Multicultural education: Historical development, dimensions, and practice. In J.A. Banks \& C.A. McGee Banks (Eds.), Handbook of research on multicultural education (pp. 3-24). New York: Simon and Schuster Macmillan.

Banks, J. (1997). Teaching strategies for ethnic studies ( $6^{\text {th }}$ ed.). Boston, MA: Allyn \& Bacon.

Banks, J. (2006). Cultural diversity and education: Foundations, curriculum, and teaching $\left(5^{\text {th }}\right.$ ed.). Boston and New York: Pearson Education.

Barry, N. H., \& Lechner J. V. (1995). Preserves teachers' attitudes about and awareness of multicultural teaching and learning. Teaching \& Teacher Education, 11(2), $149-161$.

Battistich, V., Solomon, D., Kim, D., Watson, M., \& Schaps, E. (1995). Schools as communities, poverty levels of student populations, and students' attitudes, motives, and performance: A multilevel analysis. American Educational Research Journal, 32, 627-658.

Bedford, T. (2002). Queer developments in teacher education: Addressing sexual diversity, homophobia, and heterosexism. In R. M. Kissen (Ed.), Getting ready for Benjamin: Preparing teachers for sexual diversity in the classroom (pp. 1331142). Lanham, MD: Rowman \& Littlefield Publishers. 
Bennett, C. (2003). Comprehensive multicultural education: Theory and practice $\left(5^{\text {th }}\right.$ ed.). Needham Heights, MA: Allyn \& Bacon.

Beyer, L. E. (1984). Field experience, ideology, and the development of critical reflectivity. Journal of Teacher Education, 35(3), 36-41.

Blanchard, R. J., Blanchard, C. D., Griebel, G., \& Nutt, D. (2011). Introduction to the handbook on fear and anxiety. In R.J. Blanchard, C.D. Blanchard, G. Griebel, \& D. Nutt (Eds.), Handbook of anxiety and fear (p. 3). London: Elsevier.

Bochenek, M., Brown, A. W., \& Human Rights Watch. (2001). Hatred in the hallways: Violence and discrimination against lesbian, gay, bisexual, and transgender students in U.S. schools. New York: Human Rights Watch.

Bridge 13 Program. (2006). Bridging our differences. Retrieved April 15, 2010, from http://www.prideproject.org/bridge_13

Brookfield, S. (1988). Developing critically reflective practitioners: A rationale for training educators of adults. In S. Brookfield (Ed.), Training educators of adults: The theory and practice of graduate adult education. New York: Routledge.

Brown, E. L. (2004). Relationship of self-concepts to changes in cultural diversity awareness: Implications for teacher educators. Urban Review, 36(2), 119-145.

Butler, J. (1990). Gender trouble. NY: Routledge.

Butler, K. L. (1994). Prospective teachers' knowledge, attitudes, and behavior regarding gay men and lesbians. (ERIC Document Reproduction Service No. ED379251)

Butler, K. L. (1999). Preservice teachers' knowledge and attitudes regarding gay men and lesbians. Journal of Health Education, 30(2), 125-29. 
Cahill, B., \& Adams, E. (1997). An exploratory study of early childhood teachers' attitudes toward gender roles. Sex Roles, 36(7/8), 517-529.

Campos, D. (2005). Understanding gay and lesbian youth: Lessons for straight school teachers, counselors, and administrators. Lanham, MD: Rowman and Littlefield Education.

Charlesworth, R., Hart, C. H., Burts, D. C., \& Hernandez, S. (1990, April). Kindergarten teachers' beliefs and practices. Paper presented at the annual meeting of the American Educational Research Association (AERA), Boston.

Chasoff, D. (Producer/Director). (1995). It's elementary: Talking about gay issues in school [videotape]. (Available from Women's Educational Media, New York).

Clark, C. M. (1988). Asking the right questions about teacher preparation: Contributions of research on teaching thinking. Educational Researcher, 17(2), 5-12.

Clift, S. M. (1988). Lesbian and gay issues in education: A study of the attitudes of firstyear students in a college of higher education. British Educational Research Journal, 14(1), 31-50.

Cochran-Smith, M. (1995). Color blindness and basket making are not the answers: Confronting the dilemmas of race, culture, and language diversity in teacher education. American Educational Research Journal, 32(3), 493-522.

Cole, A. L. (1989, April). Making explicit implicit theories of teaching: Starting points in preservice programs. Paper presented at the Annual Meeting of the American Educational Research Association (AERA), San Francisco. 
D’Augelli, A. R. (1992). Lesbian and gay male undergraduates' experiences of harassment and fear on campus. Journal of Interpersonal Violence, 7, 383-395.

D’Augelli, A. R., Grossman, A. H., \& Starks, M. T. (2008). Gender atypicality and sexual orientation development among lesbian, gay, and bisexual youth: Prevalence, sex differences, and parental responses. Journal of Gay \& Lesbian Mental Health, 12(1/2), 121-143.

Danielewicz, J. (2001). Teaching selves: Identity, pedagogy, and teacher education. Albany, NY: State University of New York Press.

Darling-Hammond, L. (2006). Powerful teacher education. San Francisco, CA: JosseyBass.

Delamont, S. (1990). Sex roles and the school. NY: Routledge.

Delpit, L. D. (1995). Other people's children: Cultural conflict in the classroom. New York: New Press: Distributed by W.W. Norton.

DePalma, R., \& Atkinson, E. (Eds.). (2009). Interrogating heteronormativity in primary schools: The no outsiders project. Oakhill, VA: Trentham.

Dewey, J. (1933). How we think. Lexington, MA: D.C. Health and Company. Dewey, J. (1938). Logic: The theory of inquiry. New York: Holt, Rinehart and Winston. Dolan, J. (1998). Gay and lesbian professors out on campus. Academe, 84(5), 40-45.

Eddy, W., \& Forney, D. S. (2000). Assessing campus environments for the lesbian, gay and bisexual population. In V. A. Wall, \& N. J. Evans (Eds.), Toward acceptance: Sexual orientation issues on campus (pp. 131-154). Lanham, MD: University Press of America. 
Emmons, C. L., Comer, J. P., \& Haynes, N. M. (1996). Translating theory into practice: Comer's theory of school reform. In J. P. Comer, N. M. Haynes, E. Joyner, \& M. Ben-Avie (Eds.), Rallying the whole village (pp. 27-41). New York: Teachers College Press.

Epstein, D. (Ed.). (1994). Challenging lesbian and gay inequalities in education. Buckingham, UK: Open University Press.

Euben, D. (1999). Domestic partnerships benefits for faculty. Academe, 85(2), 111. Evertson, C., Hawley, W., \& Zlotnik, M. (1985). Making a difference in educational quality through teacher education. Journal of Teacher Education, 36(3), 2-12.

Fairclough, N. (1988). Language and power. London: Longman

Fassinger, R. E. (2000). Gender and sexuality in human development: Implications for prevention and advocacy in counseling psychology. In S. D. Brown \& R.W. Lent (Eds.), Handbook of counseling psychology (pp. 346-378). New York: John Wiley.

Fierstein, H. (2002). The Sissy Duckling. New York: Simon \& Schuster Books for Young Readers.

Fieser, J., \& Dowden, B. (2004). The internet encyclopedia of philosophy. Retrieved August 1, 2009 from http://www.utm.edu/research/iep/e/ethics.htm

Fish, L. S., \& Harvey, R. G. (2005). Nurturing queer youth: Family therapy transformed ( $1^{\text {st }}$ ed.). New York: Norton.

Fontaine, J. H. (1998). Evidencing a need: School counselors' experiences with gay and lesbian students. Professional School Counseling, 1(3), 8-14. 
Freire, P. (1970). Pedagogy of the oppressed. New York: Continuum.

Fricke, A. (1981). Reflections of a Rock Lobster: A story about growing up gay. Boston, MA: Alyson.

Friend, R. A. (1993). Choices, not closets: Heterosexism and homophobia in schools. In L. Weis, \& M. Fine (Eds.), Beyond silenced voices: Class, race, and gender in United States schools (pp. 209-235). Albany, NY: State University of New York Press.

Gay, G. (2000). Culturally responsive teaching: Theory, research and practice. New York: Teachers College Press.

Giroux, H., \& McLaren, P. (1986). Teacher education and politics of engagement: The case for democratic schooling. Harvard Educational Review, 56(3), 213-238.

Glenn, N. D., \& Weaver, C. N. (1979). Attitudes toward premarital, extramarital and homosexual relations in the U.S. in the 1970s. The Journal of Sex Research, 15, 108-118.

Grace, A. (2005). Critical social theory. In J. Sears (Ed.), Youth, education, and sexualities: An international encyclopedia (pp. 218-222). Westport, CT: Greenwood Press.

Grant, C. (1994). Best practices in teacher preparation for urban schools: Lessons from the multicultural teacher education literature. Action in Teacher Education, 16(3), $1-18$. 
Grant, C. A., \& Sleeter, C. (1989). Turning on learning: Five approaches for multicultural teaching plans for race, class, gender, and disability. New York: Macmillan.

Grant, C. A., \& Sleeter, C. E. (1993). Race, class, gender, exceptionality, and educational reform. In G. A. Banks and C. M. Banks (Eds.), Multicultural education: Issues and perspectives ( $2^{\text {nd }}$ ed.) (pp. 48-68). Boston, MA: Allyn \& Bacon.

Griffith, J. (1999). School climate as "social order" and "social action": A multi-level analysis of public elementary school student perceptions. School Psychology of Education, 2, 339-369.

Grimmett, P. P., Erickson, G. L., Mackinnon, A. M., \& Riecken, T. J. (1990). Reflective practice in teacher education. In R. T. Clift, W. R. Houston, \& M. C. Pugach (Eds.), Encouraging reflective practice in education: An analysis of issues and programs (pp. 20-38). New York: Teachers College Press.

Grossman, A. H., Haney, A. P., Edwards, P., Alessi, E. J., Ardon, M., \& Howell, T. J. (2009). Lesbian, gay, bisexual and transgender youth talk about experiencing and coping with school violence: A qualitative study. Journal of LGBT Youth, 6, 2446.

Guba, E. G., \& Lincoln, Y. S. (2005). Paradigmatic controversies, contradictions, and emerging confluences. In N.K. Denzin \& Y.S. Lincoln (Eds.), The Sage handbook of qualitative research ( $3^{\text {rd }}$ ed.) (pp. 191-216). Thousand Oaks, CA: Sage Publications. 
Haggerty, G. E. (2000). Gay histories and cultures: An encyclopedia. New York: Taylor \& Francis Publishing.

Hammerness, K., Darling-Hammond, L., Bransford, J. with Berliner, D., Cochran-Smith, M., McDonald, M., \& Zeichner, K. (2005). How teachers learn and develop. In Darling-Hammond, L., \& Bransford, J. (Eds.), Preparing teachers for a changing world: What teachers should learn and be able to do (pp. 358-389). San Francisco: Jossey-Bass.

Hansley, M., \& Pratt, D. (2005). Tools for teaching social skills in school. Boys Town, NJ: Boys Town Press.

Harbeck, K. M. (1992). Coming out of the classroom closet: Gay and lesbian students, teachers and curricula. New York: Harrington Park Press.

Herek, G. M. (1984). Beyond "homophobia": A social psychological perspective on attitudes toward lesbians and gay men. Journal of Homosexuality, 10(1/2), 1-21.

Herek, G. M. (1988). Heterosexuals' attitudes toward lesbians and gay men: Correlates and gender differences. The Journal of Sex Research, 25(4), 451-477.

Herek, G. M. (1994). Assessing heterosexuals' attitudes toward lesbians and gay men: A review of empirical research with the ATLG scale. In B. Greene, \& G.M. Herek (Eds.) Lesbian and gay psychology: Theory, research, and clinical applications (pp. 206-228). Thousand Oaks, CA: Sage Publications.

Hicks, G., \& Lee, T. (2006). Public attitudes toward gays and lesbians. Journal of Homosexuality, 51(2), pp. 57-77. 
Holmes, S. E., \& Cahill, S. (2005). School experiences of gay, lesbian, bisexual and transgender youth. In J.T. Sears, (Ed.), Gay, lesbian, and transgender issues in education: Programs, policies and practices (pp. 63-76). New York: Harrington Park Press.

hooks, b. (1994) Teaching to transgress. Education as the practice of freedom, London: Routledge.

hooks, b. (2000). Feminist theory: From margin to center. Cambridge, MA: South End Press.

Howard, J. (2002). Technology-enhanced project-based learning in teacher education: Addressing the goals of transfer. Journal of Technology and Teacher Education, $10(3), 343-364$.

Hudson, W. W., \& Ricketts, W. A. (1980). A strategy for the measurement of homophobia. Journal of Homosexuality, 5, 357-371.

Hunsicker, J., \& Freedley, J. (2000). Significant labor and employment law issues in higher education during the past decade and what to look for now. Journal of Law and Education, 29(3), 343-351.

Hunter, J. (1990). Violence against lesbian and gay male youths. Journal of Interpersonal Violence, 5, 95-300.

Irvine, J. J. (2003). Educating teacher for diversity: Seeing with a cultural eye. New York: Teachers College Press. 
Jennings, K. (1994). Becoming visible: A reader in gay and lesbian history for high school and college students. Los Angeles, CA: Alyson Publications.

Kemple, K. M., \& Hartle, L. (1997). Getting along: How teachers can support children's peer relationships. Early Childhood Education Journal, 24(3), 139-146.

Kimmel, M. S., \& Mahler, M. (2003). Adolescent Masculinity, Homophobia, and Violence: Random School Shootings, 1982-2001. American Behavioral Scientist, 46(10), 1439-1458.

King, J. E., Hollins, E. R., \& Hayman, W. C. (Eds). (1997). Preparing teachers for cultural diversity. NY: Teachers College Press.

Kissen, R. (1993). Listening to gay and lesbian teenagers. Teaching Education, 5(2), 5767.

Kochheiser, C. (1975). What happened when a speaker for gay liberation addressed high school students? Social Education, 39(4), 219-21.

Kosciw, J. G., Diaz, E. M., \& Greytak, E. A. (2008). 2007 national school climate survey: The experiences of lesbian, gay, bisexual and transgender youth in our nation's schools. New York: GLSEN.

Kosciw, J. G., Greytak, E. A., Diaz, E. M., \& Bartkiewicz, M. J. (2010). 2009 National School Climate Survey: The experiences of lesbian, gay, bisexual and transgender youth in our nation's schools. New York: GLSEN.

Ladson-Billings, G. (1995). Multicultural teacher education: research, practice, and policy. In J. Banks, \& C. Banks (Eds.), Handbook of research on multicultural education (pp. 747-759). New York: Macmillan. 
Larrabee, T. G. \& Morehead, P. (2010). Broadening views of social justice and teacher leadership: Addressing LGB issues in teacher education. Issues in Teacher Education 19(2), 37-53.

Leitner. L. M., \& Cado. S. (1982). Personal constructs and homosexual stress. Journal of Personality and Social Psychology, 43, 869-872.

Letts, W. J. (2002). Revisioning multiculturalism in teacher education: It's it queer? In R. M. Kissen (Ed.), Getting ready for Benjamin: Preparing teachers for sexual diversity in the classroom (pp. 119-131). Lanham, MD: Rowman \& Littlefield Publishers.

Letts, W. J., \& Sears, J. T. (Eds.). (1999). Queering elementary education: Advancing the dialogue about sexualities and schooling. Lanham, MD: Rowman \& Littlefield Publishers.

Levin, D. E., \& Kilbourne, J. (2008). So sexy so soon: The new sexualized childhood and what parents can do to protect their kids. New York: Ballantine.

Liebert, R. (1971). The “Gay” Student: A psychopolitical view. Change, 3(6), 38-44.

Lipkin, A. (2002). The challenges of gay topics in teacher education: Politics, content, and pedagogy. In R. M. Kissen (Ed.), Getting ready for Benjamin: Preparing teachers for sexual diversity in the classroom (pp. 13-27). Lanham, MD: Rowman \& Littlefield Publishers.

Massachusetts Department of Education. (2006). 2005 Massachusetts Youth Risk Behavior Survey Results. Malden, MA: Author. 
Mathison, C. (1998). The invisible minority: Preparing teachers to meet the needs of gay and lesbian youth. Journal of Teacher Education, 49(2), 151-155.

Maxwell, J. A. (2005). Qualitative research design: An interactive approach ( $\left.{ }^{\text {nd }} \mathrm{ed}.\right)$. Thousand Oaks, CA: Sage Publications.

McIntyre, A. (1997). Making meaning of whiteness: Exploring racial identity with white teachers. New York: State University of New York Press.

Merrell, K. W., \& Gimpel, G. A. (1998). Social skills of children and adolescents: Conceptualization, assessment, treatment. Mahwah, NJ: Lawrence Erlbaum Associates.

Merriam, S. (2009). Case study Qualitative research: A guide to design and implementation. San Francisco, CA: Jossey-Bass.

Meyer, I. H. (1995). Minority stress and mental health in gay men. Journal of Health and Social Behavior, 36, 38-56.

Mezirow, J. (1998). On critical reflection. Adult Education, 48(3), 185-198.

Mezirow, J. (2000). Learning as transformation: Critical perspectives on a theory in progress. San Francisco, CA: Jossey Bass.

Miles, M. B., \& Huberman, M. (1994). Qualitative data analysis: An expanded sourcebook $\left(6^{\text {th }}\right.$ ed.). Thousand Oaks, CA: Sage Publications.

Mishler, E. G. (1986). Research interviewing: Context and narrative. Cambridge, MA: Harvard University Press.

Mission, R. (2005). Sexual identity. In J. Sears (Ed.), Youth, education, and sexualities: An international encyclopedia (pp. 778-781). Westport, CT: Greenwood Press. 
Moos, R. H. (1979). Evaluating educational environments: Procedures, measures, findings, and policy implications. San Francisco, CA: Jossey-Bass.

Mussen, P., \& Eisenberg, N. (1977). Roots of caring, sharing, and helping: The development of prosocial behavior in children. San Francisco, CA: Freeman.

NCATE (National Council for Accreditation of Teacher Education). (2008). Professional standards accreditation of teacher preparation institutions. Retrieved on January 3, 2010 from http://www.ncate.org/public/standards.asp

Nespor, J. (1987). The role of beliefs in the practice of teaching. Journal of Curriculum Studies, 19, 317-328.

Nieto, S. (2000). Affirming diversity: The sociopolitical context of multicultural education ( $3^{\text {rd }}$ ed.). New York: Longman.

Nieto, S. (2003). What keeps teachers going? New York: Teachers College Press.

Nolen, A., \& Talbert, T. (2011). Qualitative assertions as prescriptive statements. Educational Psychology Review, 23(2), 263-271.

Nyberg, K. L., \& Alston, J. P. (1976). Analysis of public attitudes toward homosexual behavior. Journal of Homosexuality, 2, 99-107.

Olsen, D. G. (1985). The quality of prospective teachers: Education vs. noneducation graduates. Journal of Teacher Education, 36(5), 56-59.

Orenstein, A. (2001). Substance use among gay and lesbian adolescents. Journal of Homosexuality, 41(2), 1-15.

Owens, R. E. (1998). Queer kids: The challenges and promise for lesbian, gay, and bisexual youth. New York: Haworth Press. 
Pai, Y. (1990). Cultural foundations of education. New York: Merrill.

Palmer, P.J. (1997). The heart of a teacher. Change Magazine, 29(6), 14-21.

Pang, V. O. (2001). Multicultural education: A caring-centered, reflective approach. New York: McGraw-Hill.

Payne, E., \& Smith, M. (2010). Reduction of stigma in schools: An evaluation of the first three years. Issues in Teacher Education 19(2), 11-36.

Petrovic, J. E., \& Rosiek, J. (2003). Disrupting the heteronormative subjectivities of Christian pre-service teachers: A deweyan prolegomenon. Equity \& Excellence in Education, 36, 161-169.

Piker, R. A., \& Rex, L. A. (2008). Influences of teacher-child social interactions on English language development in a head start classroom. Early Childhood Education Journal, 36, 187-193.

Pilkington, N. W., \& D’Augelli, A. R. (1995). Victimization of lesbian, gay, and bisexual youth in community settings. Journal of Community Psychology, 23, 33-56.

Pinar, W. F. (1998). Queer theory in education. Mahwah, NJ: Lawrence Erlbaum.

Reis, B. (1999). They don't even know me! Understanding anti-gay harassment and violence in schools. Seattle, WA: Safe Schools Coalition.

Robins, R. W., \& John, O. P. (1997). The quest for self-insight: Theory and research on the accuracy of self-perceptions. In R. Hogan, J. Johnson, \& S. R. Briggs (Eds.), Handbook of personality psychology (pp. 649-679). New York: Academic Press.

Rofes, E. (1985). Socrates, Plato and guys like me: Confessions for a gay schoolteacher. Boston, MA: Alyson Publications. 
Rosenbloom, S. R., \& Way, N. (2004). Experiences of discrimination among African American, Asian American, and Latino adolescents in an urban high school. Youth and Society, 35, 420-451.

Russell, S. T., Seif, H., \& Truong, N. L. (2001). School outcomes of sexual minority youth in the United States: Evidence from a national study. Journal of Adolescence, 24, 111-127.

Sammon, P. (2011, August 5). McInerney trial. Ventura County Star. Retrieved from http://www.vcstar.com/news/2011/aug/05/mcinerney-trial

Savage, D. (2010). It gets better project. Retrieved from http://www.itgetsbetter.org Savin-Williams, R. C., \& Berndt, T. J. (1990). Friendships and peer relations. In S. S. Feldman, \& G. R. Elliott (Eds.), At the threshold: The developing adolescent (pp. 277-307). Cambridge, MA: Harvard University Press.

Schön, D. (1983). The Reflective Practitioner. New York: Basic Books.

Sears, J. T. (1989). Personal feelings and professional attitudes of prospective teachers toward homosexuality and homosexual students: Research findings and curriculum recommendations. Paper presented at American Educational Research Association, San Francisco. (ERIC Document Reproduction Service No. ED 312222)

Sears, J. T. (1992). Educators, homosexuality, and homosexual students: Are personal feelings related to professional beliefs? In S. Woods, \& K. Harbeck (Eds.), Coming out of the classroom closet (pp. 29-79). New York: Haworth. 
Sears, J. T. (1999). Teaching queerly: Some elementary propositions. In W. J. Letts and J. T. Sears (Eds.), Queering Elementary Education: Advancing the dialogue about sexualities and schooling (pp. 3-14). Lanham, Maryland: Rowman \& Littlefield.

Sears, J. T. (2002). The institutional climate for lesbian, gay and bisexual education faculty: What is the pivotal frame of reference? Journal of Homosexuality, 43(1), $11-37$

Sears, J. T. (2005). Youth, education, and sexualities: An international encyclopedia. Westport, CT: Greenwood Press.

Sears, J. T., \& Williams, W. L. (1997). Overcoming heterosexism and homophobia. New York: Columbia University Press.

Sadowski, M. (2010). Core values and the identity-supportive classroom: Setting LGBTQ issues within wider frameworks for preservice teachers. Issues in Teacher Education, 19(2), 53-63.

Silin, J. (1995). Sex, death, and the education of children: Our passion for ignorance in the age of AIDS. New York: Teachers College Press.

Sleeter, C. E. (2001). Preparing teacher for culturally diverse schools: Research and the overwhelming presence of whiteness. Journal of Teacher Education, 52(2), 94106.

Sleeter, C. E., \& Grant, C. A. (1988). Making choices for multicultural education: Five approaches to race, class, and gender. Columbus, $\mathrm{OH}$ : Merrill Publishing Company. 
Sleeter, C. E., \& Grant, C. A. (1999). Making choices for multicultural education: Five approaches to race, class, and gender ( $3^{\text {rd }}$ ed.). Upper Saddle River, NJ: Merrill.

Smith, A. D., Resick, P. A., \& Kilpatrick, D. G. (1980). Relationships among gender, sex-role attitudes, sexual attitudes, thoughts and behavior. Psychological Reports, 46, 359-367.

Smith, K. (1971). Homophobia: A tentative personality profile. Psychological Reports, 29, 1091-1094.

Smith, R., Moallem, M., \& Sherrill, D. (1997) How preservice teachers think about cultural diversity: A closer look at factors which influence their beliefs towards equality. Educational Foundations, 11(2), 41-61.

Spector, P. E. (1994). Using self-report questionnaires in organizational behavior research: A comment on the use of a controversial method. Journal of Organizational Behavior, 15(5), 385-392.

Stiggins, R. (2001). Student-involved classroom assessment ( $3^{\text {rd }}$ ed.). Upper Saddle River, NJ: Merrill Prentice-Hall.

Strauss, A., \& Corbin, J. (1990). Basics of qualitative research: Grounded theory procedures and techniques. Newbury Park, CA: Sage.

Swartz, P. C. (2003). It's Elementary in Appalachia: Helping prospective teachers and their students understand sexuality and gender. Journal of Gay \& Lesbian Issues in Education, 1(1), 51-71. 
Tharinger, D., \& Wells, G. (2000). An attachment perspective on the developmental challenges of gay and lesbian adolescents: The need for continuity of caregiving from family and schools. School Psychology Review, 29(2), 158-172.

Temple, J. R. (2005). People who are different from you: Heterosexism in Quebec high school textbooks. Canadian Journal of Education, 28(3), 271-294.

Transactive (2010). Transactive: Supporting children and youth of all genders. Retrieved on May 4, 2010 from http://www.transactiveonline.org/

Trochim, W. M. (2001). The research methods knowledge base ( $2^{\text {nd }}$ ed.). Cincinnati, OH: Atomic Dog Publishing.

Unks, G. (1995). The gay teen: Educational practice and theory for lesbian, gay, and bisexual adolescents. New York: Routledge.

Valli, L. (1990). Moral approaches to reflective practice. In R. T. Clift, W. R. Houston, \& M. C. Pugach (Eds.), Encouraging reflective practice in education: An analysis of issues and programs (pp. 39-56). New York: Teachers College Press.

Valli, L. (1995). The dilemma of race: Learning to be color blind and color conscious. Journal of Teacher Education, 46(1), 120-129.

Vescio, V., Bondy, E., \& Poekert, P. (2009). Preparing multicultural teacher educators: Toward a pedagogy of transformation. Teacher Education Quarterly, 36(2), 5-24. Walkerdine, V. (1990). School girl fictions. London: Verso.

Walling, D. R. (Ed.). (1996). Open lives, safe schools: Addressing gay and lesbian issues in education. Bloomington, Indiana: Phi Kappa Educational Foundation. 
Weick, K. E., Sutcliffe, K. M., \& Obstfeld, D. (2005). Organizing and the process of sensemaking. Organization Science, 16(4), 409-421.

Weinberg, G. (1972). Society and the healthy homosexual. New York: Anchor.

Weisman, E. M., \& Garza, A. (2002). Preservice teacher attitudes toward diversity: Can one class make a difference? Equity \& Excellence in Education, 35(1), 28-34.

Wilson, D. (2004). The interface of school climate and school connectedness and relationships with aggression and victimization. Journal of School Health, 74, 293-299.

Wilson, S. M., Floden, R. E., \& Ferrini-Mundy, J. (2001). Teacher preparation research: Current knowledge, gaps, and recommendations: A research report prepared for the U.S. Department of Education. Seattle, WA: Center for the Study of Teaching and Policy.

Woog, D. (1995). School's out. Boston, MA: Alyson Publications.

Young, N. L., \& Whertvine. J. (1982). Attitudes of heterosexual students toward homosexual behavior. Psychological Reports, 51, 673-674.

Zeichner, K. (1993). Connecting genuine teacher development to the struggle for social justice. Journal of Education for Teaching, 19(1), 5-20.

Zeichner, K. M., \& Liston, D. P. (1996). Reflective teaching: An introduction. Mahwah, NJ: Lawrence Erlbaum Associates. 


\section{Appendix A}

Gender and Sexual Orientation Classifications

\section{GENDER DIVERSITY}

Assigned sex at birth: Biology

Male Intersex $^{1} \quad$ Female

Gender identity: How you feel inside

$\stackrel{\text { Man or Masculine } \quad \text { Androgynous }^{2} \quad \text { Woman or Feminine }}{\longrightarrow}$

Gender expression: Outer appearance and behavior

$\longleftrightarrow$ Stereotypically Masculine $\quad$ Androgynous $\quad$ Stereotypically Feminine

Perceived gender expression: How others read your gender expression

Stereotypically Masculine Androgynous $\quad$ Stereotypically Feminine

\section{SEXUAL DIVERSITY}

Sexual orientation: Gender identity of partner

$\begin{array}{lcc}\text { Man or Butch - Identified } & \text { GenderQueer }^{3} & \text { Woman or Femme - Identified } \\ \text { Sexual orientation: Gender expression of partner } & \\ \stackrel{\text { Stereotypically Masculine }}{\longrightarrow} \text { Androgynous } & \text { Stereotypically Feminine }\end{array}$

\footnotetext{
${ }^{1}$ Intersex people are born with external genitalia, internal reproductive organs, chromosomes, and/or endocrine system that are different from most other people. There is no single "intersex body"; it encompasses a wide variety of conditions that do not have anything in common except that they are deemed "abnormal" by the society.

${ }^{2}$ Androgynous means being neither distinguishably masculine nor feminine, as in dress, appearance, or behavior.

${ }^{3}$ Someone who may think of themselves as being both man and woman, as being neither man nor woman, or as falling completely outside the gender binary.
} 


\section{Appendix B}

\section{Multicultural Education Course Topics and Objectives}

\begin{tabular}{|c|c|c|}
\hline Content/Topics & Objectives & Activities \\
\hline $\begin{array}{l}\text { Introduction to } \\
\text { teaching in a } \\
\text { multicultural society }\end{array}$ & $\begin{array}{l}\text { Establish a sense of community } \\
\text { Begin to understand the philosophy and } \\
\text { methodology of popular education } \\
\text { Be able to identify several components of } \\
\text { multicultural education } \\
\text { Understand the expectations of the course as } \\
\text { outlined in the course syllabus }\end{array}$ & $\begin{array}{l}\text { Dinamicas } \\
\text { Cooperative learning: Course } \\
\text { content/ objectives } \\
\text { Brainstorm }\end{array}$ \\
\hline $\begin{array}{l}\text { Power \& pedagogy } \\
\text { in education } \\
\text { Shades of } \\
\text { oppression }\end{array}$ & $\begin{array}{l}\text { Create a positive learning environment } \\
\text { through developing group agreements for } \\
\text { support and risk taking } \\
\text { Explore the personal experience of learning } \\
\text { about elements of diversity and develop } \\
\text { understanding about how shades of oppression } \\
\text { are communicated and reinforced } \\
\text { Begin exploration of institutional and cultural } \\
\text { forms of oppression }\end{array}$ & $\begin{array}{l}\text { Dinamicas } \\
\text { Cooperative learning: Reflecting } \\
\text { on readings } \\
\text { Discuss readings } \\
\text { Radio play - vocabulary } \\
\text { Social mapping \& discussion }\end{array}$ \\
\hline $\begin{array}{l}\text { Negotiating the role } \\
\text { of self \& educator } \\
\text { Structures and } \\
\text { politics in education }\end{array}$ & $\begin{array}{l}\text { Further develop sense of community } \\
\text { Continue to explore institutional and cultural } \\
\text { forms of oppression } \\
\text { Identify personal gifts and limits } \\
\text { Explore how our goals, assumptions, } \\
\text { experiences, feelings, and values influence } \\
\text { teaching } \\
\text { Engage in a general discussion about the } \\
\text { structures and politics in schools } \\
\text { Discuss teachers as change agents }\end{array}$ & $\begin{array}{l}\text { Dinamicas } \\
\text { Cooperative learning: Problem } \\
\text { posing with personal experience } \\
\text { and case studies } \\
\text { Video clip: Trading Schools } \\
\text { Gifts and limits exercise }\end{array}$ \\
\hline $\begin{array}{l}\text { Culture, pluralism \& } \\
\text { equity } \\
\text { Material } \\
\text { consequences of } \\
\text { racial construction }\end{array}$ & $\begin{array}{l}\text { Further develop sense of community } \\
\text { Identify and analyze the material } \\
\text { consequences of racial construction for people } \\
\text { defined as people of color } \\
\text { Explore the cultural and institutional }\end{array}$ & $\begin{array}{l}\text { Dinamicas } \\
\text { Short video } \\
\text { Read aloud (bell hooks) } \\
\text { Cooperative learning: White }\end{array}$ \\
\hline
\end{tabular}




\begin{tabular}{|c|c|c|}
\hline Urban education & $\begin{array}{l}\text { privileges attached to "whiteness" in the US } \\
\text { Develop a list of methods and instructional } \\
\text { strategies for confronting racism as an } \\
\text { educator }\end{array}$ & $\begin{array}{l}\text { privilege } \\
\text { Brainstorm }\end{array}$ \\
\hline $\begin{array}{l}\text { Examine } \\
\text { heteronormative } \\
\text { values in education } \\
\text { Rethinking gender } \\
\text { and sexual } \\
\text { dichotomies }\end{array}$ & $\begin{array}{l}\text { Further develop sense of community } \\
\text { Understand the significance of queer issues in } \\
\text { education } \\
\text { Identify heteronormative structures in K-12 } \\
\text { schools } \\
\text { Reflect upon personal disposition toward } \\
\text { queerness } \\
\text { Discuss and share recommendations for } \\
\text { supporting queer youth or barriers to } \\
\text { providing this support }\end{array}$ & $\begin{array}{l}\text { Dinamicas } \\
\text { Discussion about readings } \\
\text { It's Elementary video } \\
\text { This American Life audio clip - } \\
\text { written response }\end{array}$ \\
\hline $\begin{array}{l}\text { Investigating } \\
\text { intersections } \\
\text { between classism } \\
\text { and other forms of } \\
\text { oppression } \\
\text { Explore institutional } \\
\text { and cultural ableism }\end{array}$ & $\begin{array}{l}\text { Further develop sense of community } \\
\text { Begin to explore the impact of class on } \\
\text { personal lives, institutions (such as schools), } \\
\text { and culture } \\
\text { Develop basic concepts about class and } \\
\text { classism } \\
\text { Understand intersections between classism } \\
\text { and other forms of oppression } \\
\text { Increase understanding of the experience of } \\
\text { living with disability in an ableist society } \\
\text { Learn strategies for eliminating ableism }\end{array}$ & $\begin{array}{l}\text { Dinamicas } \\
\text { Cooperative learning: Beegle's } \\
\text { exercise } \\
\text { Sociodrama }\end{array}$ \\
\hline $\begin{array}{l}\text { Critical examination } \\
\text { of school curricula } \\
\text { Multicultural } \\
\text { resources and } \\
\text { learning activities } \\
\text { Multicultural } \\
\text { curriculum } \\
\text { development }\end{array}$ & $\begin{array}{l}\text { Further develop sense of community } \\
\text { Examine school realia and curricula and } \\
\text { analyze content/messages } \\
\text { Continue to develop an on-going list of } \\
\text { effective resources for teaching } \\
\text { Develop multicultural curriculum }\end{array}$ & $\begin{array}{l}\text { Dinamicas } \\
\text { Participatory research - rotating } \\
\text { stations } \\
\text { Cooperative learning: } \\
\text { Multicultural curriculum } \\
\text { development }\end{array}$ \\
\hline $\begin{array}{l}\text { Culture, pluralism \& } \\
\text { equity }\end{array}$ & $\begin{array}{l}\text { Tying up loose ends: TBD } \\
\text { Possible topics: } \\
\text { 1. Identify the roles and functions of religion } \\
\text { in relationship to educational institutions; } \\
\text { Understand interconnections and interactions } \\
\text { between religious oppression and other forms }\end{array}$ & $\begin{array}{l}\text { Dinamicas } \\
\text { Cooperative learning: Reflect on } \\
\text { readings } \\
\text { Problem posing }\end{array}$ \\
\hline
\end{tabular}




\begin{tabular}{|c|c|c|}
\hline & $\begin{array}{l}\text { of social oppression, such as homophobia, } \\
\text { ethnocentrism, and racism } \\
\text { 2. Discuss globalization, environmentalism, } \\
\text { and sustainability } \\
\text { 3. Continue discussion from any other } \\
\text { discussion } \\
\text { 4. Continue multicultural curriculum } \\
\text { development from last session }\end{array}$ & $\begin{array}{l}\text { Brainstorm } \\
\text { Video }\end{array}$ \\
\hline Panel & $\begin{array}{l}\text { Establish a sense of community } \\
\text { Understand context behind gathering } \\
\text { Engage in dialogue with others to come to a } \\
\text { deeper understanding of multicultural } \\
\text { education } \\
\text { Reflect on knowledge, skills, and dispositions } \\
\text { needed to become an effective teacher of } \\
\text { diverse learners }\end{array}$ & $\begin{array}{l}\text { Dinamicas } \\
\text { Socio drama } \\
\text { Question and Answer } \\
\text { Debrief discussion } \\
\text { Eat and Chat }\end{array}$ \\
\hline Presentations & $\begin{array}{l}\text { Continue to develop a sense of community } \\
\text { Increase understanding of lived experience of } \\
\text { peers } \\
\text { Continue to reflect on knowledge, skills, and } \\
\text { dispositions needed to become an effective } \\
\text { teacher of diverse learners }\end{array}$ & $\begin{array}{l}\text { Presentations } \\
\text { Reflection } \\
\text { Research survey }\end{array}$ \\
\hline
\end{tabular}




\section{Appendix C}

\section{Letter of Informed Consent \\ Pre-service Teacher Informed Consent \\ A Case Study of How Pre-Service Teachers Experience Sexual and Gender Diversity in Their Field Placements}

You are invited to participate in a research study conducted by Olivia Murray, in the Graduate School of Education at Greensgo University (GU). The researcher hopes to learn more about the ways in which pre-service teachers encounter, make sense of, and respond to sexual and gender diversity in their student teaching field placements. Also, this project is conducted as partial fulfillment for a doctoral degree from GU. You were selected as a possible participant in this study because of your role as a member of Johnson/Murray cohort.

If you decide to participate, you will be asked to describe your experiences with sexual and gender diversity as they surface within student teaching. This information will be shared in six separate group interviews facilitated by the researcher. The group will be comprised of six to eight case study participants within the Johnson/Murray cohort. Interviews will last about one hour and will be videotaped. Participants will also be provided with a personal journal. You will be encouraged to record any situations, emotions, events, etc. that surface within your student teaching pertaining to the focus of this study. This journal will be collected by the researcher at the completion of the study. Your projected involvement in this case study will be from early September 2010 to midMarch 2011.

While participating in this study, it is possible that negative and/or positive experiences may trigger powerful emotions. You may not receive any direct benefit from taking part in this study, but it is hoped that teacher educators may gain insight into better preparing pre-service teachers to meet the unique and diverse needs of all students. In addition, you will experience an opportunities to reflect on your own practice, furthering your personal and professional development.

Any information that is obtained in connection with this study and that can be linked to you or identify you will be kept confidential. Interview transcripts and video tapes as well as other artifacts will be kept in a locked file cabinet by the researcher until they are destroyed. Personal journals will also be stored in a locked file cabinet by the researcher and may be returned to you upon request after the study is completed. If not returned, the journals will be destroyed along with everything else, approximately three years after the study is completed. 
Your participation is completely voluntary. You do not have to take part in this study, and it will not affect your relationship with GU or your evaluation of your course or field work. You may also withdraw from this study at any time without affecting your relationship with GU, the school district, and the researcher.

If you have questions or concerns about your participation in this study or your rights as a research participant, please contact the Human Subjects Research Review Committee, Office of Research and Sponsored Projects, 200 Lovely Bldg., GU, (012) 345-6789. If you have any questions about the study itself, contact Olivia Murray at (123) 456-7890 or omurray@gu.edu.

Your signature indicates that you have read and understand the above information and agree to take part in this study. Please understand that you may withdraw your consent at any time without penalty, and that, by signing, you are not waiving any legal claims, rights or remedies. The researcher will provide you with a copy of this form for your own records.

Name

Signature

Date 


\section{Appendix D}

Data Collection Timeline and Procedures

\begin{tabular}{|c|c|c|}
\hline Estimated Date & Activity & Data Collected \\
\hline September 13, 2010 & $\begin{array}{l}\text { Confirm participants } \\
\text { Distribute journals }\end{array}$ & Research log \\
\hline September 27-30, 2010 & Round 1: Individual interviews & $\begin{array}{l}\text { Transcript } \\
\text { Research log } \\
\text { Artifacts }\end{array}$ \\
\hline September 30, 2010 & Email prompt & Response \\
\hline October 14, 2010 & Email prompt & Response \\
\hline October 25-29, 2010 & Group conversation (No. 1) & $\begin{array}{l}\text { Transcript } \\
\text { Research log } \\
\text { Artifacts }\end{array}$ \\
\hline October 28, 2010 & Email prompt & Response \\
\hline November 8-19, 2010 & Direct observations & $\begin{array}{l}\text { Transcript } \\
\text { Research log } \\
\text { Artifacts }\end{array}$ \\
\hline November 11, 2010 & Email prompt & Response \\
\hline November 25, 2010 & Email prompt & Response \\
\hline December 9, 2010 & Email prompt & Response \\
\hline January 6, 2011 & Email prompt & Response \\
\hline January 10-14, 2011 & Round 2: Individual interviews & $\begin{array}{l}\text { Transcript } \\
\text { Research log } \\
\text { Artifacts }\end{array}$ \\
\hline January 20, 2011 & Email prompt & Response \\
\hline
\end{tabular}




\begin{tabular}{|c|c|c|}
\hline Estimated Date & Activity & Data Collected \\
\hline January 24-28, 2011 & Group conversation (No. 2) & $\begin{array}{l}\text { Transcript } \\
\text { Research log } \\
\text { Artifacts }\end{array}$ \\
\hline February 3, 2011 & Email prompt & Response \\
\hline February 17, 2011 & Email prompt & Response \\
\hline March 1-4, 2011 & Direct observations & $\begin{array}{l}\text { Research log } \\
\text { Artifacts }\end{array}$ \\
\hline March 3, 2011 & Email prompt & Response \\
\hline March 14-18, 2011 & Round 3: Individual interviews & $\begin{array}{l}\text { Transcript } \\
\text { Research log } \\
\text { Artifacts } \\
\text { Participant journals }\end{array}$ \\
\hline March 17, 2011 & Email prompt & Response \\
\hline
\end{tabular}




\section{Appendix E}

\section{Possible Strategies for Organizing Data}

\section{Chronological}

1. Month (e.g., September)

A. Interview transcript(s)
a. Participant 1
b. Participant 2
c. Participant 3
d. Participant 4
e. Participant 5

B. Group conversation transcript(s)

C. Observations

a. Participant 1

b. Participant 2

c. Participant 3

d. Participant 4

e. Participant 5

D. Research log

E. Artifacts

2. Month (e.g., October)

A. Interview transcript(s)

a. Participant 1

b. Participant 2

c. Participant 3
d. Participant 4
e. Participant 5

B. Group conversation transcript(s)

C. Observations

a. Participant 1

b. Participant 2

c. Participant 3

d. Participant 4

e. Participant 5

D. Research log

E. Artifacts

\section{Categorical}

1. Individual interview transcripts

A. Participant 1
a. Interview 1

b. Interview 2

B. Participant 2

a. Interview 1

b. Interview 2

C. Participant 3

a. Interview 1

b. Interview 2

D. Participant 4

a. Interview 1

b. interview 2

E. Participant 5
a. Interview 1
b. Interview 2

2. Group conversation transcripts
A. Session 1

B. Session 2

3. Observations

A. Participant 1
a. Observation 1
b. Observation 2

B. Participant 2

a. Observation 1

b. Observation 2

C. Participant 3

a. Observation 1

b. Observation 2

D. Participant 4

a. Observation 1

b. Observation 2

E. Participant 5

a. Observation 1

b. Observation 2

4. Research log

5. Artifacts 


\section{Appendix F}

Protocol for Individual Interviews

Interviewee:

Interview \#:

Date \& Time \& Location:

1. Begin by sharing the following: Thank you for your willingness to participate in this project. Before we begin, I would like to reassure you that this interview will be confidential and the tape/transcripts available only to me. Excerpts of this interview may be made part of the final research report, but under no circumstances will your name or identifying characteristics be included in this report. Is it all right for me to turn on the recorder now?

2. Remind participant of the purpose of the study: To Identify and understand the ways in which you encounter, make sense of, and respond to, sexual and gender diversity at your site.

3. Facilitate discourse noting possible probes

- Can you say more about that? What do you see going on? What are the issues?

- Can you give us an example? Describe what you see going on in your classroom.

4. Consult calendars and confirm next group interview.

Possible Focus for Interview Sessions:

\begin{tabular}{|c|c|}
\hline $\begin{array}{l}\text { Interview } 1 \\
9 / 27-30,2010\end{array}$ & $\begin{array}{l}\text { Encountering sexual and gender diversity: What do you see going on } \\
\text { in your school? Classroom? How is sexuality and gender } \\
\text { communicated? How do these issues affect students, teachers, } \\
\text { parents, etc.? }\end{array}$ \\
\hline $\begin{array}{l}\text { Interview } 2 \\
1 / 10-14,2011\end{array}$ & $\begin{array}{l}\text { Making sense of sexual and gender diversity: What do you see going } \\
\text { on in your school? Classroom? Why do you imagine sexuality and } \\
\text { gender are communicated/conveyed the way they are in curriculum, } \\
\text { language, etc.? }\end{array}$ \\
\hline $\begin{array}{l}\text { Interview } 3 \\
3 / 14-18,2011\end{array}$ & $\begin{array}{l}\text { Responding to sexual and gender diversity: What do you see going } \\
\text { on in your school? Classroom? How does your cooperating teacher } \\
\text { respond? How does your co-intern respond? How do you respond? } \\
\text { How do students, parents, community members respond? How does } \\
\text { the school administration respond? What about the role of district } \\
\text { leadership? }\end{array}$ \\
\hline
\end{tabular}




\section{Appendix G}

Group Conversation \# 1 Protocol

Date \& Time \& Location: October 27, 2010, ED 308

Members Present: All

Members Absent: 0

\section{Welcome/Introduction}

"Thank you for your willingness to participate in this project. Before we begin, I would like to reassure you that this conversation will be confidential and the tape/transcripts available only to me. Excerpts of this conversation may be made part of the final research report, but under no circumstances will your name or identifying characteristics be included in this report. Is it all right for me to turn on the video recorder now?"

\section{Remind participants}

- Withdraw at any time without consequences

- Confidentiality

\section{Remind Participants of Purpose}

The purpose of this study is to identify and understand the ways in which you encounter, make sense of, and respond to, sexual and gender diversity at your site.

\section{Distribute questions that will guide group discourse (see attached)}

Remember possible probes:

- Can you say more about that? What do you see going on? What are the issues?

- Can you give us an example? Describe what you see going on in your classroom.

\section{Consult calendars and confirm what's ahead}

- $2^{\text {nd }}$ round of individual interviews

- Email prompts 
Group Conversation \# 2 Protocol

Date \& Time \& Location: January 25, 2011; 11:30-12:30; ED 202

Members Present: All

Members Absent: 0

\section{Welcome/Introduction}

"Thank you for your willingness to participate in this project. Before we begin, I would like to reassure you that this conversation will be confidential and the tapeltranscripts available only to me. Excerpts of this conversation may be made part of the final research report, but under no circumstances will your name or identifying characteristics be included in this report. Is it all right for me to turn on the video recorder now?"

\section{Remind participants}

- Withdraw at any time without consequences

- Confidentiality

- Resources available

- Research question (posted)

\section{DISCUSSION PART 1: INSTITUTIONS (i.e. SCHOOLS) \& PRIVILEGE} Distribute cis- and heterosexual privilege handouts. Ask participants to look over the items and first write about questions. After allowing 5-7 minutes of writing engage in discussion.

$1: 250$ children are transgender or significantly gender non-conforming $1: 10$ children/adolescents are gay, lesbian, bisexual Many more children/adolescents question their gender identity and/or sexual orientation

In what ways have you witnessed cisgender/cissexual privilege and/or heterosexual privilege at your school site?

- How do you know?/What are the issues?

- How do these situations/experiences affect:
○ You?
○ Students?
○ Teachers?
$\circ$ Learning?
○ Teaching? 


\section{PART 2: INSTITUTIONS (i.e. SCHOOLS) \& OPPRESSION Watch "Bullied" You-tube video and DVD excerpt; distribute related discussion questions handout}

- Read over discussion questions

- Discuss

1. Have you observed (or experienced) teasing, bullying, and/or harassment at your field site that you perceive to be related to homophobia, transphobia, sexism?
a. How do you know?
b. What happened?
c. How did people (teachers, students, bystanders, administration, etc.) respond?

2. Do you agree or disagree with the following quotation? Why or why not? Explain.

Students have the right to expect teachers to "do something" about the harassment they face on a daily basis (Goldstein, 1997). Consequently, dealing with gay and lesbian issues in schooling, including the ways in which schools and teachers themselves actively police the boundaries of "compulsory heterosexuality" (Rich, 1980) in their daily practices, is imperative to teacher training courses.

$\sim$ Kerry H. Robinson and Tania Ferfolja (2001)

\section{If there is time then ask:}

Is there anything someone wants to talk about or a question someone would like to pose to the group?

\section{Consult calendars and confirm what's ahead}

- Final round of individual interviews

- Email prompts 


\section{Appendix H}

Observation Protocol

Date \& Time:

Setting:

Individuals Involved:

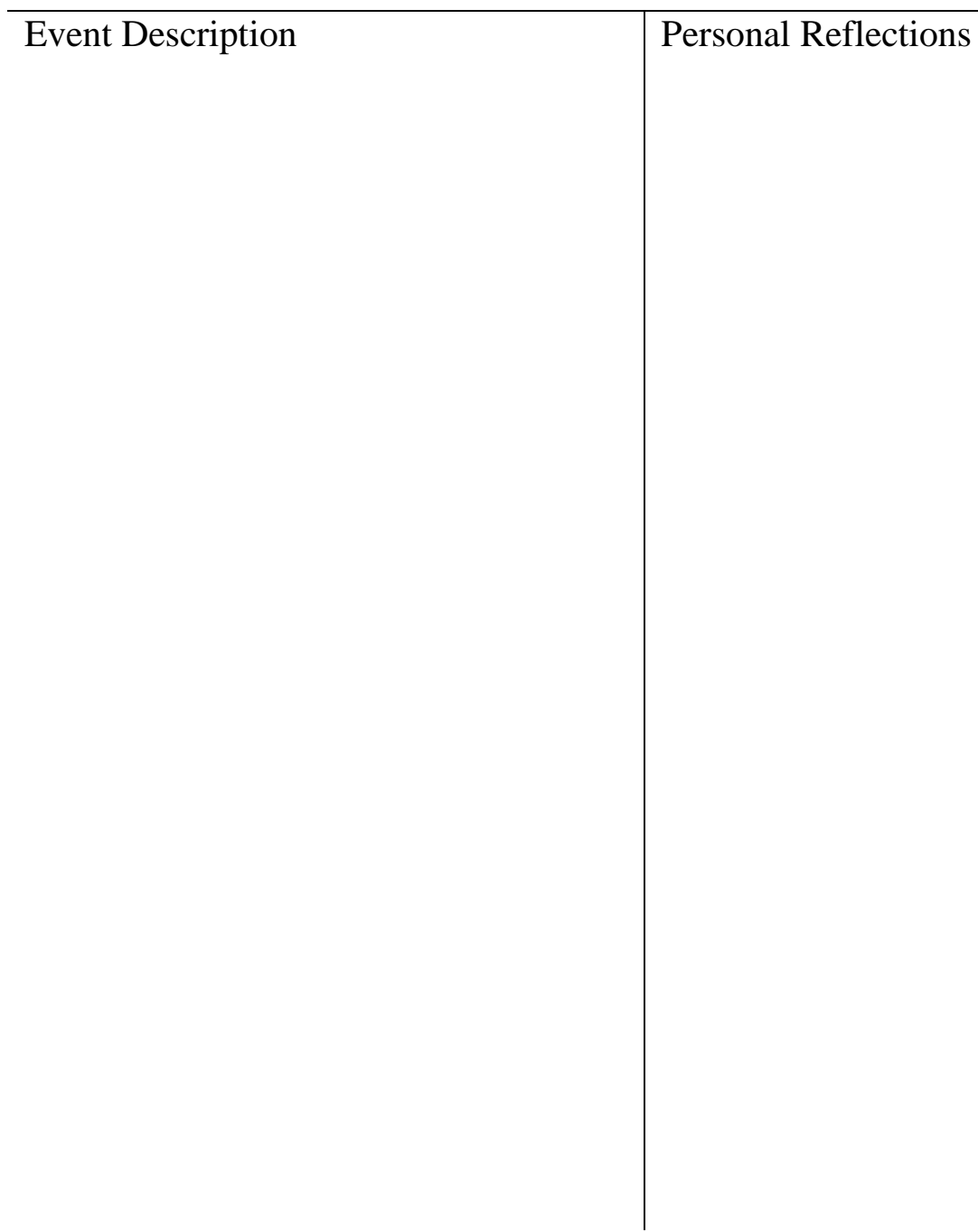




\section{Appendix I}

Journal Guidelines

The following information may be found in the inside front cover of each journal.

\section{PURPOSE OF JOURNALING}

Please use this journal to critically reflect on the ways you encounter, make sense of, and respond to sexual and gender diversity in your field experience.

\begin{tabular}{|l|l|}
\hline QUESTION & ANSWER \\
\hline $\begin{array}{l}\text { How often should I } \\
\text { write? }\end{array}$ & $\begin{array}{l}\text { It would be great if you could set aside 10 minutes each day you } \\
\text { are in the field to write down your observations. I understand this } \\
\text { may be difficult. Perhaps a more realistic goal might be to jot } \\
\text { down your experiences, thoughts, feelings, etc. twice a week for } \\
10 \text { minutes. }\end{array}$ \\
\hline $\begin{array}{l}\text { How should I } \\
\text { "mark" each entry? }\end{array}$ & Please indicate the date and time for each entry. \\
\hline $\begin{array}{l}\text { Should I bring my } \\
\text { journal to our } \\
\text { group interviews? }\end{array}$ & Yes. \\
\hline $\begin{array}{l}\text { Will my journal be } \\
\text { collected? When? }\end{array}$ & $\begin{array}{l}\text { Yes. Journals will be submitted March 2011 for data collection, } \\
\text { but may be returned to you after analysis upon request. }\end{array}$ \\
\hline $\begin{array}{l}\text { What if I write } \\
\text { something I don't } \\
\text { want you to read? }\end{array}$ & $\begin{array}{l}\text { If you write something that you prefer I not read then you may } \\
\text { either black out the section or cover it with a post-it and indicate } \\
\text { that it is "off limits." I will respect your wishes. Journals will be } \\
\text { locked up until returned or destroyed when the study is } \\
\text { completed. }\end{array}$ \\
\hline $\begin{array}{l}\text { Do I only use my } \\
\text { journal to record } \\
\text { stuff about student } \\
\text { teaching? }\end{array}$ & $\begin{array}{l}\text { While the focus of this study is centered on your student teaching, } \\
\text { you can include how relevant issues (i.e. sexuality and gender) } \\
\text { are experienced throughout the program. For example you can } \\
\text { discuss how TPP classes and/or course texts relate to the topic of } \\
\text { the study. }\end{array}$ \\
\hline $\begin{array}{l}\text { Do I only use my } \\
\text { journal to record } \\
\text { stuff about } \\
\text { sexuality and } \\
\text { gender? }\end{array}$ & $\begin{array}{l}\text { For the purposes of this study, yes. But, you are encouraged to } \\
\text { think of these two terms in broad sense. Sexuality, for instance, } \\
\text { includes sexual orientation, perception of orientation and other } \\
\text { people's reactions/attitudes, emotional and/or romantic attraction, } \\
\text { relationships, portrayal of LGBT people, history, events. Gender } \\
\text { includes biological/assigned sex, gender identity (how someone } \\
\text { feels inside), what might be considered stereotypically masculine/ } \\
\text { feminine, androgynous, socialization of gender roles, gender }\end{array}$ \\
\hline
\end{tabular}




\begin{tabular}{|l|l|}
\hline & $\begin{array}{l}\text { expression (outer appearance \& behavior), perceived gender } \\
\text { expression, transgender, stereotypical "sissy"/“tomboy" } \\
\text { behaviors, gender expectations, categorical or dichotomous } \\
\text { (boy/girl) sorting. }\end{array}$ \\
\hline
\end{tabular}

\section{Journal Guidelines}

The following information may be found in the inside end cover of each journal.

\section{Writer's Block? Here Are Some Suggestions \& Ideas to Keep You Going!}

\section{General Suggestions:}

- Make connections with your own experience

- Ask yourself questions (e.g., what am I seeing? What language am I hearing? What's going on? What are the issues? What about the teaching and learning?)

- Write down striking words, images, phrases, or details. Speculate about them. Why did you choose them? What do they add to the experience? Why did you notice them?

- Do not censor yourself

○ Be honest

- Do not worry about spelling, grammar, and/or punctuation

- Feel free to use any style or writing that works best for you

\section{Specific Writing Ideas \& Prompts:}

- Take inventory of the classroom curriculum

- What books are in the classroom library? How are gender and sexuality typified?

- Are there routines and/or procedures set up that separate girls from boys? How are these displayed or communicated?

- Finger through your classrooms adopted textbooks and jot down any words, phrases, concepts, lessons, visuals that you notice. Is the language inclusive?

- Observe students (choice in tasks, classroom jobs, toy selection, recess behavior, clothing, mannerisms, etc.). Do you see decisions being influenced by gender norms?

- Observe your cooperating teacher instruct a lesson looking specifically for any intentional or unintentional lessons about gender or sexuality

○ Is the teacher aware of this content in his or her lesson?

- How do the students react?

$\circ$ What's going on? What are the issues?

- Take a walk in the school hallways. What do you notice about student work on display? What about school posters - what kinds of pictures and language are displayed? 
- Visit the office

- What kinds of documents are sent home to parents

- Is the language inclusive for LGBT families

- Do documents say “...your son/daughter" or is the language more neutral?

- Listen in during student group work time. What do you notice?

- Observe the ways students are grouped. What kinds of configurations and why?

- Informally interview your cooperating teacher

- Think about how you were taught or socialized to conceptualize sexuality? Gender?

- Describe any experiences you had as an elementary, middle, and/or high school student that influenced how you think about your own sexuality and/or gender identity. 


\section{Appendix J}

Artifact Summary Form

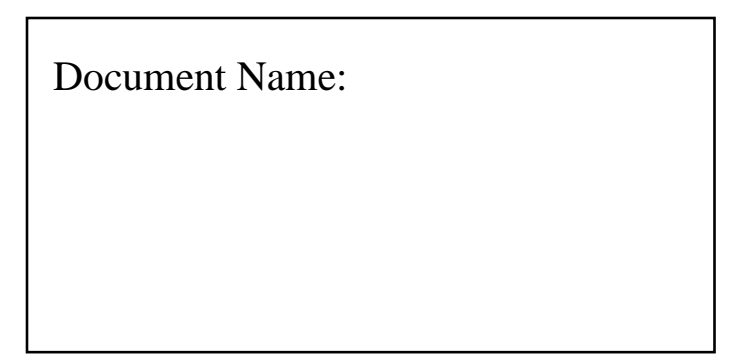

Site:

Document Number:

Date received:

Description of document:

Event and/or Contact associated with document:

Significance of document:

Brief summary of contents: 


\title{
Appendix K
}

\author{
Data Analysis Procedures
}

Presented here in a brief outline are the steps and procedures I completed to analyze and code the data.

1. Transcribed data over the course of the seven month study as it was collected

2. Learned ATLAS.ti data analysis software by reading literature and watching online tutorials

3. Read through electronic email prompts chronologically; coded each response using respondent language sometimes, more often I used codes that I created (from the lit as well). I tried to be consistent in terms of using the same code phrase when I could. For example, if I coded the response language for something related to power of language or experiences/reactions to language. I used "language" again whenever I read an item that referred to language

4. Began to write down words that appeared frequently (e.g., identity, gender binary) as well as ideas/constructs (e.g., research group as intervention)

5. After reading through all of the electronic email prompts I began reading individual interviews in chronological order and by "case". For example, I read Jack's interview 1, then 2, then 3 . As I read and coded these interviews I began writing case descriptions for the corresponding case/individual

6. Re-read group conversations $1 \& 2$ for individual case descriptions

7. Re-read dissertation proposal and re-visited conceptual framework (i.e. critical social theory)

8. Read hand-written journal entries and coded them (i.e. with highlighter and postits) using the same identifiers/labels as electronic documents. I tried to limit redundancy and double-qualifying data through constant cross-reference. I do not believe I double-counted any retold information (e.g., Mrs. H discusses in an interview that she believes one of her students is gay and when reading her journal entry I see this info recorded, I did not count it as her knowing 2 gay students in the classroom)

9. Reviewed and coded all artifacts and supplementary documents kept by the researcher (direct observations, research log, etc.)

10. Formally wrote and edited 8 individual case descriptions while simultaneously reviewing new research and literature (published 2010-2011)

11. Approached cross-case synthesis by sorting through coding and creating themes and sub-themes while revisiting Yin and conceptual framework 


\section{Appendix L}

WW Newspaper Article (Boys v. Girls) Artifact Form

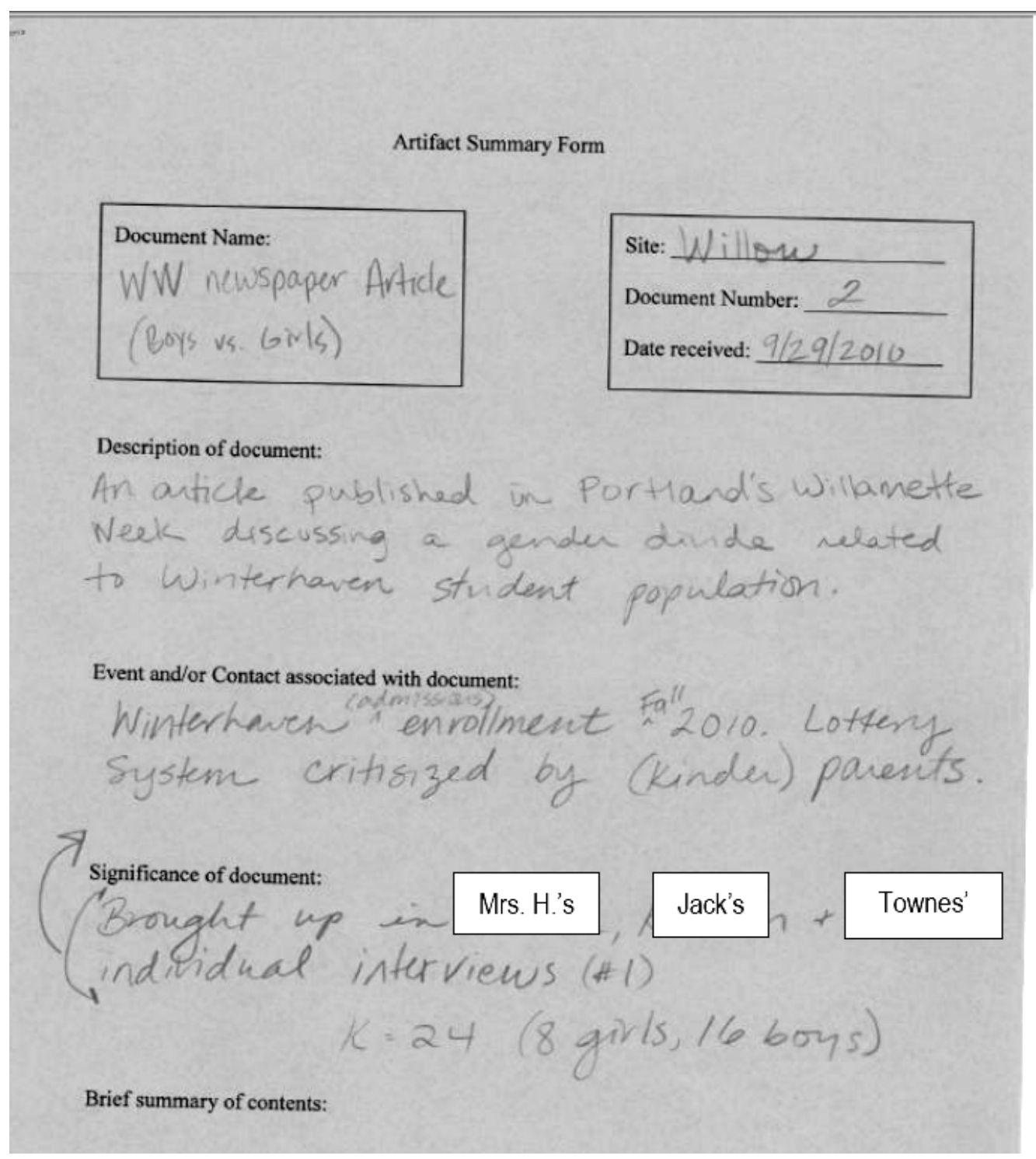




\section{Appendix M}

Spectrum of Visibility

Co-created by Olivia Murray and Audrey Lingley

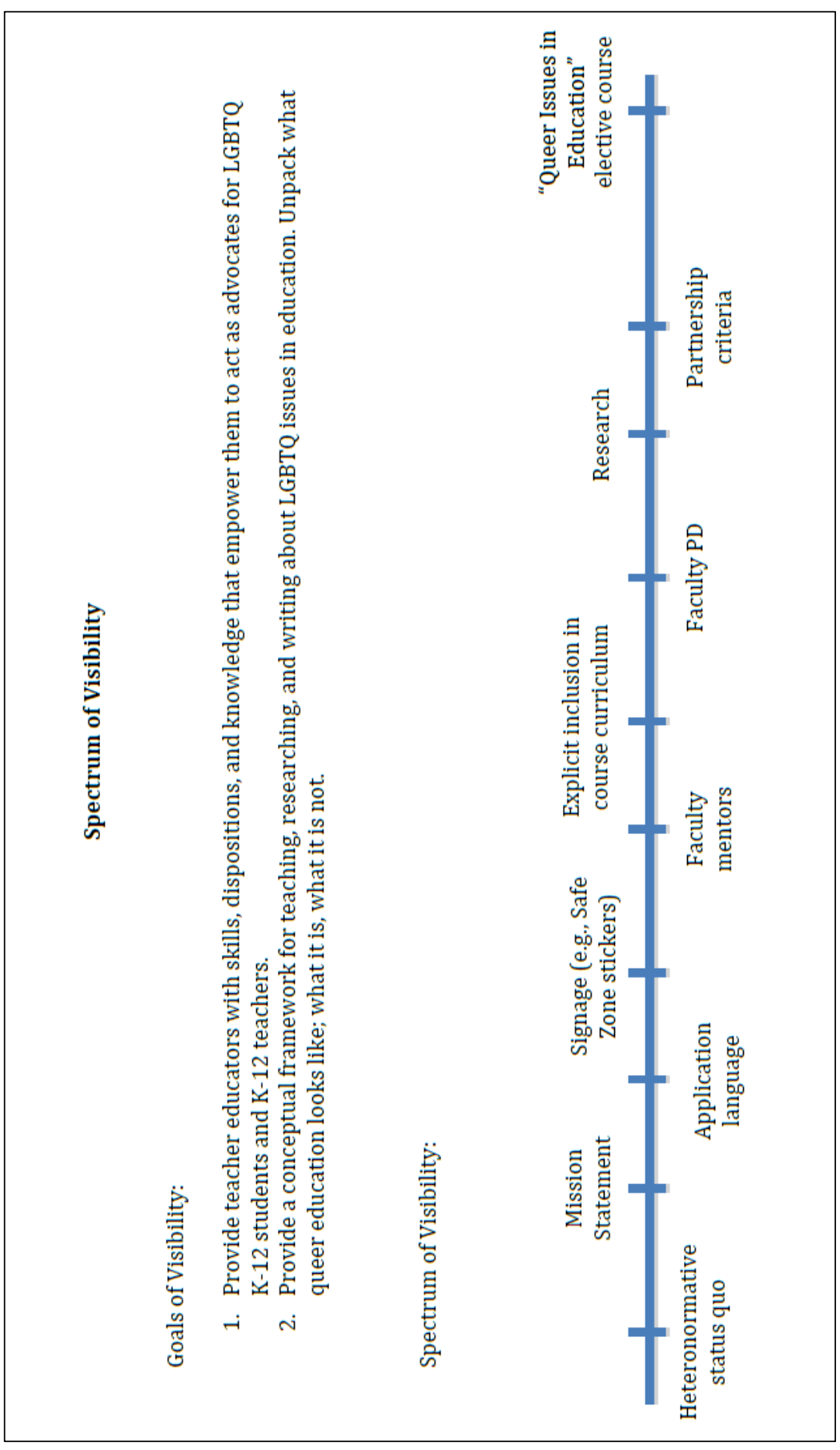

